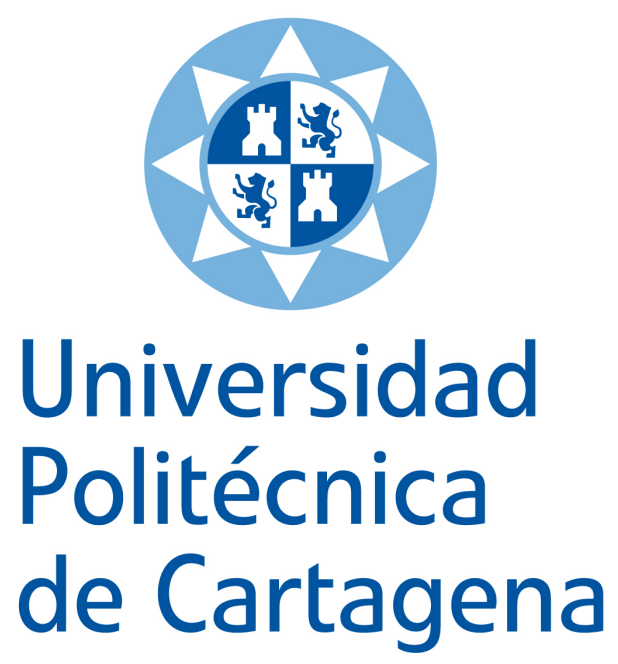

Evaluación experimental de Aprendizaje Máquina Extremo aplicado a los sistemas de Interfaz Cerebro-Ordenador basados en imaginación de movimiento.

Francisco José Martínez Albaladejo

Mayo, 2018 


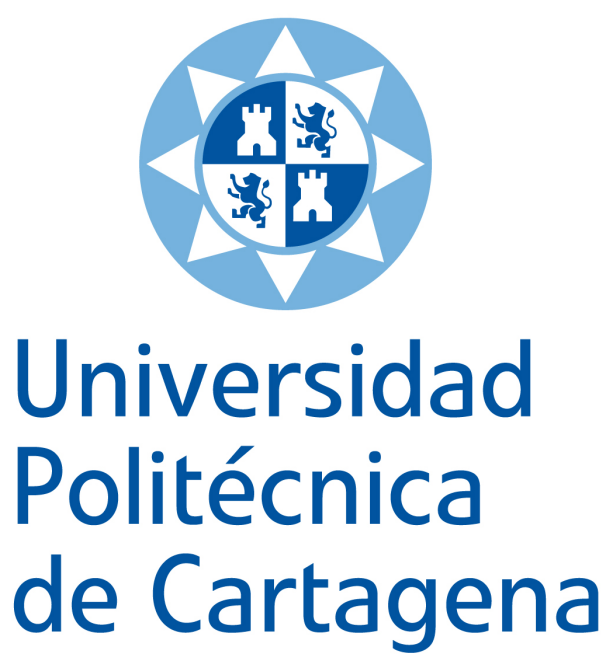

\section{Evaluación experimental de Aprendizaje Máquina Extremo aplicado a los sistemas de Interfaz Cerebro-Ordenador basados en imaginación de movimiento.}

Francisco José Martínez Albaladejo

Director: Juan Luis García Guirao Co-Director: Germán Rodríguez Bermúdez

Mayo, 2018 


\section{Dedicatoria}

Esta Tesis está dedicada al compañero Dr. D. Pedro José García-Laencina, un ejemplo para todos, como persona y como profesional.

A mi hija Marta y a mi familia. 


\section{Agradecimientos}

Agradecer en primera persona a mi amigo y co-Director de esta Tesis, el Dr. D. Germán Rodríguez Bermúdez (CUD) por la dedicación y el esfuerzo tan profundo y constante para la realización exitosa de esta Tesis. Gracias amigo. También al Director de la misma, el Dr. D. Juan Luis García Guirao (UPCT) por sus consejos, seguimiento de la misma y su visión para la publicación de los artículos. 


\section{Resumen}

Un sistema de interfaz cerebro-ordenador o Brain Computer Interface (BCI) permite controlar dispositivos externos sólo con la actividad eléctrica del cerebro. Es decir, permiten enviar comandos al exterior, prescindiendo de todo canal de comunicación muscular. Estos sistemas se desarrollan en varias fases: (i) Adquisición de electroencefalograma (EEG), (ii) Detección de artefactos, (iii) Extracción de características, (iv) Clasificación, (v) Lógica de operación, y (vi) Realimentación. Esta Tesis se centra en dos de estas fases: extracción de características y clasificación.

En la fase de extracción de características, se han implementado las técnicas de Densidad Espectral de Potencia o (PSD, Power Spectrum Density), Parámetros de Hjörth (H), Coeficientes Adaptativos Autorregresivos (AAR, Adaptive Autoregressive Coefficients) y Patrones Espaciales Comunes (CSP, Common Spatial Pattern). Por otra parte, en la fase de Clasificación, se han aplicado las técnicas de Análisis de Discriminante Lineal (LDA, Linear Discriminant Analysis), las Máquinas de Soporte Vectorial (SVM, Support Vector Machine), y los K-Vecinos más cercanos.

A nivel general, los investigadores han propuesto diversas técnicas para cada una de las fases, con el fin de incrementar el rendimiento en Clasificación de estos sistemas, pero, lo más habitual, es probarlas con señales BCI estándar que se obtienen de repositorios disponibles en Internet, o de usuarios expertos que han sido entrenados para trabajar de forma exitosa con BCI. Por otra parte, en la fase de Clasificación, aún no han sido probadas en profundidad las Máquinas de Aprendizaje Extremo (ELM, Extreme Learning Machine).

El objetivo de esta Tesis es evaluar la adecuabilidad del ELM como clasificador para su aplicación a interfaces BCI basadas en la imaginación del movimiento y teniendo en cuenta, tanto sujetos noveles, como expertos. Para ello, se ha utilizado una metodología basada en 2 experimentos.

En el primer experimento se han capturado las señales EEG de 5 usuarios noveles. Se ha realizado una extracción de características mediante (PSD) y se han empleado 3 clasificadores (LDA, SVM y ELM). Los valores obtenidos con los clasificadores LDA y SVM se han utilizado como referencia para evaluar el rendimiento del ELM. Los resultados experimentales indican que sí es un 
método adecuado para clasificar señales de EEG de usuarios noveles, obtenidas bajo experimentos de BCI.

El segundo experimento explora el conjunto de características y la configuración del ELM más adecuadas para este tipo de utilización. Para ello, se emplearon señales estándar, extraídas de conjuntos de datos de referencia, que se obtienen de Internet. Se han implementado tres métodos de extracción de características muy usados en BCI como son: PSD; AAR y Hjörth. Hay que tener en cuenta, que los sistemas BCI deben administrar las variaciones a lo largo del tiempo del EEG, ya que las características extraídas no son estacionarias. Por ello, para tomar en consideración la variabilidad de señal EEG, se definieron tres estrategias de combinación de las mismas.

La clasificación se realizó de dos formas: a) utilizando las características de cada uno de estos métodos combinadas según diferentes estrategias y probando 4 kernels diferentes para el ELM, (lineal, sigmoide, gaussiano y lsg como combinación), y b) utilizando las características de todos los métodos extraídas a la vez y convenientemente combinadas, probando otra vez los 4 kernels para el ELM. Los resultados obtenidos indican que el ELM ofrece bajos valores de adecuabilidad utilizando solo un método de extracción de características, independientemente de las estrategias de combinaciones empleadas y del núcleo implementado. Sin embargo, se observa una mejora de la precisión en la clasificación, mediante el uso de todas las características extraídas al mismo tiempo, adecuadamente combinadas y agrupadas. De esta forma, el ELM se convierte en un método valioso para ser aplicado en sistemas BCI basados en Imaginación de Movimiento. 


\section{Abstract}

A Brain Computer Interface (BCI) system allows to control external devices only by the brain electrical activity. It allows to send commands to the outside world, without any muscular communication channel. These systems are developed in the following phases: (i) EEG acquisition, (ii) Artifact detection, (iii) Extraction of characteristics, (iv) Classification, (v) Logic of operation, and (vi) Feedback. This Thesis focuses on two of these phases: Feature Extraction and Classification.

In the characteristics extraction phase the following techniques were implemented: Power Spectrum Density (PSD), Hjörth Parameters (H), Adaptive Autoregressive Coefficients (AAR) and Common Spatial Patterns (CSP). On the other hand, the techniques of Linear Discriminant Analysis (LDA), the Support Vector Machine (SVM) and the nearest K-Neighbours were used in the Classification stage.

The researchers propose different techniques for each stage in order to increase the classification performance of these systems, but the more usual is to test them with standard BCI signals obtained from repositories available on the Internet, or from expert users trained to work successfully with BCI. On the other hand, Extreme Learning Machines (ELMs) have not been thoroughly tested yet in the Classification phase. The aims of this Thesis was to assess the suitability of the ELM as a classifier to be applied to BCI interfaces based on the imagination of motion, taking into account both novel and expert subjects.

With this aim, a methodology based on 2 experiments have been applied. In the first experiment the EEG signals of 5 new users were gathered. An extraction of characteristic using (PSD) has been performed and 3 classifiers (LDA, SVM and ELM) have been used. The values obtained from the LDA and SVM serve as reference for evaluating the performance of the ELM. Experimental results indicate that ELM is a suitable method to classify EEG signals from new users, obtained under BCI experiments.

The second experiment explores what characteristics set and configuration of the ELM would be suitable for this type of use. Standard signals extracted from Internet reference data sets have 
been used. Three feature extraction methods widely used in BCI have been implemented: PSD, AAR and Hjörth. It should be noted that BCI systems must manage the EEG variations over time, since the characteristics extracted are not stable, therefore, three strategies were defined to take into account the EEG variability and their combination.

The classification was performed in two ways: a) using the characteristics of each of these methods, according to combined different strategies and testing 4 different kernels for the ELM (linear, sigmoid, gaussian and lsg), by using the characteristics of all the methods, extracted at the same time, properly combined and testing again the 4 kernels for the ELM. The results showed low values of reliability of the ELM using only one characteristics extraction method, regardless of the strategies of combination used and the kernel implemented. However, there was an improvement in the accuracy in classification by using all the characteristics, extracted at the same time, appropriately combined and grouped. In this way, the ELM becomes a suitable method to be applied in BCI systems based on Motion Imagery. 


\section{Índice general}

1 Introducción $\quad 3$

1.1 Definición del problema . . . . . . . . . . . . . . 5

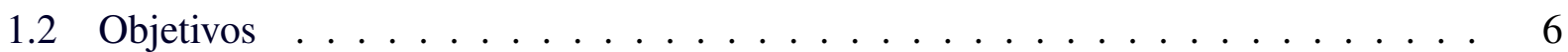

1.3 Estructura de la Tesis. . . . . . . . . . . . . . . . . . 7

2 Bioseñales $\quad 9$

2.1 Marco histórico de las bioseñales . . . . . . . . . . . . . . . . . . 9

2.1.1 Neurona como precursora de la bioseñal. . . . . . . . . . . . . . . . . . 10

2.1.2 Potenciales eléctricos o biopotenciales. . . . . . . . . . . . . 11

2.1.3 Señales o ritmos que intervienen en el sistema BCI. . . . . . . . . . . . . 12

3 Revisión de métodos de Neuroimagen. $\quad 17$

3.1 Técnicas actuales. . . . . . . . . . . . . . . . . . . 17

3.1 .1 Electroencefalografía $(\mathrm{EEG}) \ldots \ldots \ldots \ldots \ldots$

3.1 .2 Magnetoencefalografía (MEG). . . . . . . . . . . . . 21

3.1.3 Electrocorticografía (ECoG.) . . . . . . . . . . . . . . 21

3.1.4 Grabación o registro intracortical. . . . . . . . . . . . . . . 22

3.1.5 Imágenes por resonancia magnética funcional (fMRI) . . . . . . . . . . 23

3.1.6 Espectroscopia Infrarroja Cercana (NIRS). . . . . . . . . . . . . . . . . . . 24

4 Sistemas Cerebro-ordenador (Brain Computer Interface) 25

4.1 Introducción. . . . . . . . . . . . . . . . . . . . . 25

4.2 Descripción de un sistema BCI. . . . . . . . . . . . . . . . . . . 26

4.3 Tipos de señales de control en BCIs. . . . . . . . . . . . . . . . . . . . 28

4.3.1 Potenciales Visuales Evocados (VEPs). . . . . . . . . . . . . . . 29

4.3.2 Potenciales corticales lentos (SCPs) . . . . . . . . . . . . . . 32

4.3.3 P300 Potenciales evocados. . . . . . . . . . . . . . . . . 33

4.3.4 Ritmos Sensorimotores $(\operatorname{ritmos} \mu \mathrm{y} \beta) \ldots \ldots . \ldots . \ldots . \ldots 34$

4.4 Tipos de BCI. . . . . . . . . . . . . . . . . . . . . 35

4.5 Aplicaciones de los sistemas BCI. . . . . . . . . . . . . . . 37 
4.5 .1 Comunicación. . . . . . . . . . . . . . . . . . . 40

4.5.2 Rehabilitación del movimiento. . . . . . . . . . . . . . . . . . 43

4.5 .3 Control de periféricos. . . . . . . . . . . . . . . . . . 44

4.5 .4 Locomoción. . . . . . . . . . . . . . . . . . . . . . . . . . 45

4.5.5 Entretenimiento. . . . . . . . . . . . . . . . . . . 46

4.5.6 Otras aplicaciones de BCI. . . . . . . . . . . . . . . . . . . . 47

4.6 Competiciones en BCI. . . . . . . . . . . . . . . . . . . . . . . . 48

4.7 Estado del arte en plataformas software para el desarrollo de sistemas Brain Computer Interface . . . . . . . . . . . . . . . . . . . . . . . . . . . . 49

4.7 .1 Introducción. . . . . . . . . . . . . . . . . . . . . . . . . . . . 49

4.7.2 Plataformas SW para BCI. . . . . . . . . . . . . . . . . 50

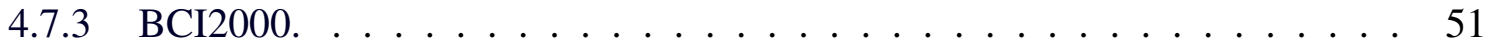

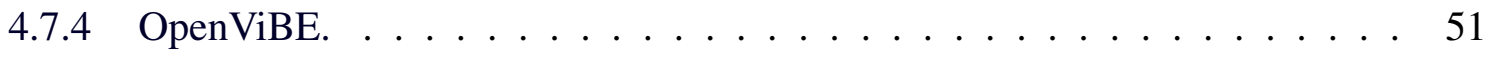

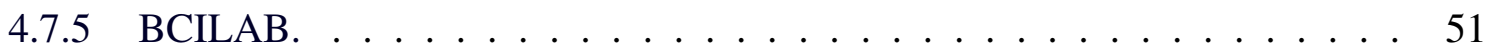

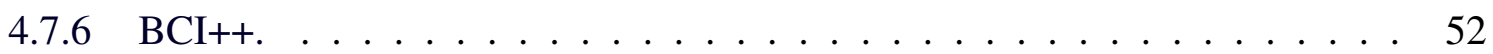

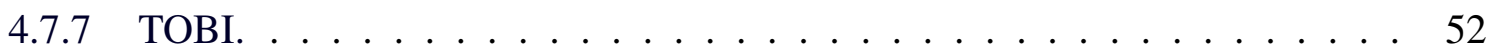

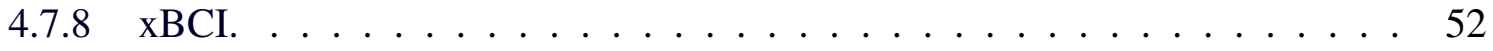

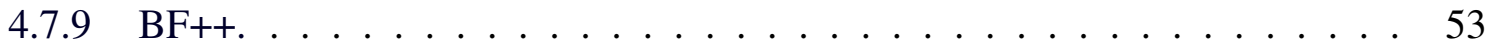

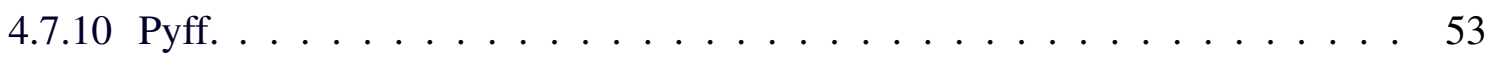

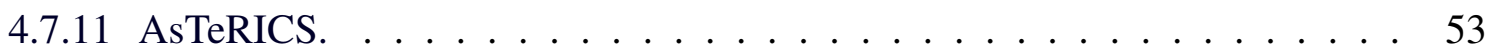

4.8 Sistema BCI utilizado (Hardware) $\ldots \ldots \ldots \ldots \ldots \ldots$

4.8 .1 Hardware g.USBAmp . . . . . . . . . . . . . . . . . . . . 54

4.8 .2 Casco gEEGcap. . . . . . . . . . . . . . . . . . 55

4.8.3 Electrodos $\mathrm{Ag} / \mathrm{AgCl}$ (Plata/Cloruro de Plata). . . . . . . . . . . . . 56

4.8 .4 Paradigma utilizado. . . . . . . . . . . . . . . . . . . 57

5 Extracción y Clasificación de características.

5.1 Extracción de Características. . . . . . . . . . . . . . . . . . . . . . . . . 59

5.1.1 Densidad Espectral de Potencia(PSD). . . . . . . . . . . . . . . 61

5.1 .2 Parámetros de Hjörth. . . . . . . . . . . . . . . . . . . . . 61

5.1 .3 Modelo adaptativo autorregresivo (AAR) . . . . . . . . . . 62

5.1.4 Patrón Espacial Común (CSP). . . . . . . . . . . . . . . . . . . . . 64

5.2 Clasificación de características. . . . . . . . . . . . . . . . . 66

5.2.1 FLD (Discriminante lineal de Fisher). . . . . . . . . . . . . . 66

5.2.2 SVM (Máquina de soporte vectorial). . . . . . . . . . . . . 68

6 Redes Neuronales.

6.1 La Sinapsis. . . . . . . . . . . . . . . . . . . . . . 72 
6.2 Capacidad de clasificación. . . . . . . . . . . . . . . . . . . . . 72

6.3 Redes Neuronales Artificiales (RNA) _ . . . . . . . . . . . . . . . . . 73

6.4 Funciones de Activación de la Neurona. . . . . . . . . . . . . . . . . . . . . . . 74

6.4.1 Modelos básicos de clasificación no formal . . . . . . . . . . . 76

6.5 ELM (Extreme Learning Machine). . . . . . . . . . . . . . . . . . 78

6.5 .1 Algoritmo ELM. . . . . . . . . . . . . . . . . . . . . . . . 79

6.5.2 Métodos de poda para ELM. . . . . . . . . . . . . . . . . . . . . . . 79

6.5.3 Poda Óptima ELM: OP-ELM. . . . . . . . . . . . . . . . . . . . 80

6.5.4 Fase 1. Inicialización aleatoria. . . . . . . . . . . . . . . . . . . . . 81

6.5.5 Fase 2. Ranking de unidades ocultas: Algoritmo MRSR. . . . . . . . . . . 81

6.5.6 Fase 3. Selección de las unidades ocultas. . . . . . . . . . . . . . . 82

6.5.7 Algoritmo de Poda Óptima ELM (OP-ELM) . . . . . . . . . . . . . . . 83

6.5 .8 Optimización para clasificación . . . . . . . . . . . . . . . 84

7 Experimentos y Resultados.

7.1 Experimento 1: Clasificación de señales BCI de usuarios novatos con Máquina de Aprendizaje Extremo (ELM) . . . . . . . . . . . . . . . . . . . 85

7.1.1 Introducción. Experimento 1. . . . . . . . . . . . . . . . . 85

7.1.2 Generación y adquisición de señales EEG. . . . . . . . . . . . . . . 87

7.1 .3 Simulaciones. . . . . . . . . . . . . . . . . . . . . . 89

7.1.4 Resultados y discusión. . . . . . . . . . . . . . . . . . . . . . . 90

7.1.5 Conclusiones y trabajo futuro de este primer trabajo experimental. . . . . . 92

7.2 Experimento 2: Prueba de la Máquina de Aprendizaje Extremo en sistemas de Interfaz Cerebro Ordenador bajo paradigmas de Imaginación de Movimiento. . . . . 94

7.2 .1 Introducción. Experimento 2. . . . . . . . . . . . . . . . . . . . 94

7.2.2 Señales empleadas en el Experimento 2 . . . . . . . . . . . . . . 95

7.2 .3 Simulaciones. . . . . . . . . . . . . . . . . . . . . . 96

7.2 .4 Resultados y discusiones. . . . . . . . . . . . . . . . . . . . . . . . . 98

7.2 .5 Conclusiones. . . . . . . . . . . . . . . . . . . . . . . . . . . . 107

8 Conclusiones y Trabajos Futuros. 109

8.1 Conclusiones . . . . . . . . . . . . . . . . . . . . . . . . 109

8.2 Trabajos Futuros . . . . . . . . . . . . . . . . . . . . . . 110

8.3 Trabajos Publicados . . . . . . . . . . . . . . . . . . . . 111

$\begin{array}{lr}\text { A Tabla de Acrónimos } & 133\end{array}$ 


\section{Índice de tablas}

Tabla 2.1.1 Resumen histórico de los hechos más importantes en la historia de la ence-

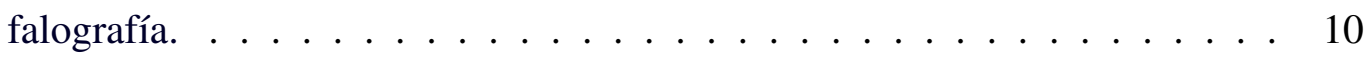

Tabla 2.1.2 Técnicas, siglas y procedencia de los biopotenciales más importantes. . . . 14

Tabla 7.1.1 Resultados de precisión obtenida bajo LOO-CV (en \%) usando PSD como método de extracción de características y ELM, LDA y SVM como clasifi-

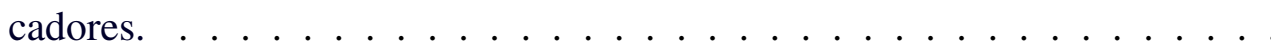

Tabla 7.2.1 Resultados de precisión de clasificación mediante LOO, utilizando PSD, H y AAR como métodos de extracción de características, concatenándolas y aplicando cuatro núcleos diferentes (l, s, g y lsg) para el ELM. . . . . . . 100

Tabla 7.2.2 Resultados de precisión de clasificación mediante LOO, utilizando PSD, H y AAR como métodos de extracción de características, utilizando una ventana central y, aplicando cuatro núcleos diferentes (1, s, g y lsg) para el ELM. . . 101

Tabla 7.2.3 Resultados de precisión de clasificación mediante LOO, utilizando PSD, H y AAR como métodos de extracción de características, promediándolas, y aplicando cuatro núcleos diferentes (l, s, g y lsg) para el ELM. . . . . . . . 103

Tabla 7.2.4 Resultados de precisión de clasificación mediante LOO, utilizando PSD, H y AAR como métodos de extracción de características de forma combinada, aplicando concatenación, ventana central y promedio sobre el conjunto de todas ellas y, aplicando cuatro núcleos diferentes (l, s, g y lsg) para el ELM. 105

\section{Índice de figuras}

Figura 1.0.1 Esquema General de Sistema BCI . . . . . . . . . . . . . . 4

Figura 2.1.1 Representación de las partes de una neurona. . . . . . . . . . . . . . . 11 
Figura 2.1 .2 Esquema célula. . . . . . . . . . . . . . . . . . . . . . . . . . 12

Figura 2.1.3 Esquema del potencial de acción con las diferentes etapas. . . . . . . . . 13

Figura 3.1.1 Métodos de neuroimagen. . . . . . . . . . . . . . . . . . . . 17

Figura 3.1.2 Colocación de electrodos sobre el cuero cabelludo. . . . . . . . . . . 20

Figura 4.2.1 Ejemplo de un sistema BCI completo. . . . . . . . . . . . . . . . . 27

Figura 4.3.1 Tipos de Señales de Control aplicadas a sistemas BCI, Fenómeno Fisiológico, Necesidad de Entrenamiento y Tasa de transferencia de la información. . 29

Figura 4.3.2 Modulaciones VEP y características principales. . . . . . . . . . . . . 31

Figura 4.4.1 Ventajas e inconvenientes de los tipos BCI Exógenos y Endógenos. . . . . . 36

Figura 4.4.2 Principales Ventajas e Inconvenientes de los BCIs síncronos y asíncronos. . 37

Figura 4.5.1 Tasa de transferencia de información BCI en relación con las capacidades del usuario. . . . . . . . . . . . . . . . . . . . 38

Figura 4.5.2 Deletreador original P300. Matriz de símbolos mostrada en un ordenador de pantalla que sirve como teclado o dispositivo protésico (adaptado de [123]).

Figura 4.5.3 Características comparativas de distintos navegadores web controlados mediante señales de EEG. . . . . . . . . . . . . . . . . . . . . 42

Figura 4.5.4 (a) Emotiv EPOC neuroheadset ; (b) Neurosky Mindwave . . . . . . . . . . 46

Figura 4.7.1 Relación de Plataformas SW para el Desarrollo de Sistemas BCI (W, Windows; X, Mac OS X; L, Linux). . . . . . . . . . . . . . . . . 50

Figura 4.8 .1 g.USBAmp. . . . . . . . . . . . . . . . . . . . . 54

Figura 4.8.2 Casco gEEGcap para la inserción de electrodos de la firma Gtec según el sistema estándar $10 / 20 \ldots \ldots$. . . . . . . . . . . . . . 56

Figura 4.8.3 Imagen de electrodo utilizado. . . . . . . . . . . . . . . . . . 56

Figura 4.8.4 Esquema temporal del paradigma que provee el equipo de la firma gTec para la realización de experimentos de BCI basados en Imaginación de Movimiento. . . . . . . . . . . . . . . . . . . . 58

Figura 5.1.1 Extracción de características a partir de señales EEG. . . . . . . . . . . . 60

Figura 5.2.1 Clasificador lineal. . . . . . . . . . . . . . . . . . . . . . . . . 67

Figura 6.1 .1 Proceso de sinapsis. . . . . . . . . . . . . . . . . . . . . 72

Figura 6.3.1 Neurona biológica. . . . . . . . . . . . . . . . . . 73

Figura 6.3.2 Neurona artificial. . . . . . . . . . . . . . . . . . . . . . 73

Figura 6.4.1 Activación Binaria. . . . . . . . . . . . . . . . . . . . . . . . 74

Figura 6.4.2 Activación Lineal. . . . . . . . . . . . . . . . . . . . . . 75

Figura 6.4.3 Activación Sigmoidal. . . . . . . . . . . . . . . . . . . . 75

Figura 6.4.4 Modelo de neurona artificial individual. . . . . . . . . . . . . . . . 75 
Figura 6.4.5 Capa de Neuronas. . . . . . . . . . . . . . . . . . . . . 76

Figura 6.4.6 Modelo de perceptrón. . . . . . . . . . . . . . . . . . . . . . . . . 77

Figura 6.4.7 Modelo Red Feedforward, MADALINE _ . . . . . . . . . . . . . 78

Figura 6.5.1 Etapas del algoritmo OP-ELM. . . . . . . . . . . . . . . . . . 81

Figura 7.1.1 Disposición de los electrodos para la adquisición de las bioseñales. . . . . . 87

Figura 7.1.2 Cinco segundos de señal EEG capturada en un experimento de imaginación de movimiento en el canal C3. . . . . . . . . . . . . . . . . 88

Figura 7.1.3 Esquema temporal experimento $1 . \ldots \ldots$. . . . . . . . . 88

Figura 7.1.4 La comparación de la media de los tres métodos. . . . . . . . . . . . . . . 92

Figura 7.1.5 La comparación de la media de los 5 usuarios. . . . . . . . . . . . . . . 93

Figura 7.2.1 Etapas realizadas en cada sesión. ․ . . . . . . . . . . . . . . 95

Figura 7.2.2 Posición de los electrodos para caracterizar el EOG. . . . . . . . . . . . . 96

Figura 7.2.3 Esquema temporal de las pruebas. Pruebas con realimentación (a) y sin realimentación (b). . . . . . . . . . . . . . . . . . . . . . . . . . 97

Figura 7.2.4 Diagrama de barras de los valores máximos de la Tabla 7.2.1, obtenidos con núcleos lineal, sigmoide, gaussiano y lsg. . . . . . . . . . . . . . . . 99

Figura 7.2.5 Diagrama de barras de los valores máximos de la Tabla 7.2.2 para cada sujeto, obtenidos con núcleos lineal, sigmoide, gaussiano y lsg. . . . . . . . 102

Figura 7.2.6 Diagrama de barras de los valores máximos de la Tabla 7.2.3 para cada sujeto, obtenidos con núcleos lineal, sigmoide, gaussiano y lsg. . . . . . . . 104

Figura 7.2.7 Diagrama de barras de los valores máximos de la Tabla 7.2.3 para cada sujeto, obtenidos con núcleos lineal, sigmoide, gaussiano y lsg. . . . . . . 106 


\section{Capítulo 1}

\section{Introducción}

Cualquier forma natural de comunicación o de control en el cuerpo humano requiere de los nervios periféricos y de los músculos. El proceso comienza con la intención del usuario de realizar un movimiento y esta intención desencadena un complejo proceso en el cual ciertas áreas del cerebro se activan, y por ende las señales cerebrales. Estas se envían a través del sistema nervioso periférico hacia los músculos correspondientes, que a su vez realizan el movimiento necesario requerido [1].

Sin embargo, una Interfaz Cerebro Ordenador (o BCI, del inglés Brain Computer Interface) adquiere y analiza las señales electroencefalográficas (EEG) para proporcionar una vía directa de comunicación y control desde el cerebro del ser humano hacia una computadora o máquina $[2,3]$. A lo largo de los años se han formulado diversas definiciones de los sistemas BCI. Se considera que fue Vidal [176] en 1973 el que dio la primera de ellas “... los sistemas BCI procesan el EEG espontáneo así como las respuestas evocadas ante estímulos acotados en el tiempo bajo distintas condiciones con el fin de controlar dispositivos externos". Más tarde, Wolpaw en 2002 en uno de sus trabajos publicó una definición muy citada en la que afirmaba que los sistemas BCI “...dotan al cerebro de un nuevo canal de comunicación y control no muscular".

Los sistemas basados en BCI forman actualmente un campo de la ciencia en pleno auge con multitud de grupos de investigación activos en todo el mundo, principalmente en EEUU, Europa o Japón. El número de artículos publicados sobre tecnología de interfaz neuronal ha aumentado exponencialmente en la última década así como las áreas de uso. En estos artículos, las aplicaciones más importantes para los sistemas BCI son la comunicación, la rehabilitación del movimiento en articulaciones del movimiento, el control ambiental, en vehículos automatizados y el entretenimiento.

Sin embargo, hay otras aplicaciones muy interesantes para mejorar el rendimiento cognitivo de personas, tales como habilidades del habla e incluso la calidad de vida, tratando de manera específica la reducción del dolor. De esta manera, la tecnología BCI se ha aplicado como un tratamiento 
para trastornos mentales tales como la epilepsia, el déficit de atención, la esquizofrenia, la depresión, la adicción al alcohol [132] o la pedofilia [133].

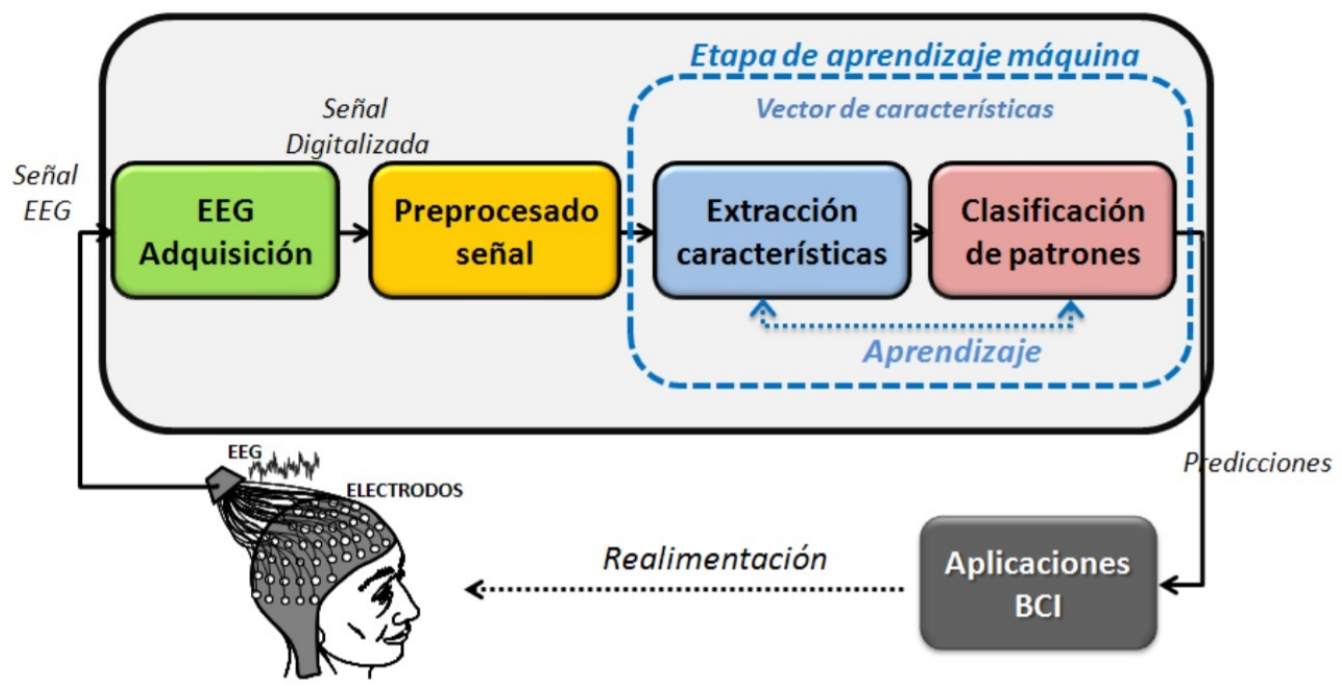

Figura 1.0.1: Esquema General de Sistema BCI

La Figura 1.0.1 muestra un esquema general de un sistema BCI compuesto por 5 bloques principales: 1) Tarea mental; 2) Adquisición de señal EEG; 3) Técnicas de extracción de características; 4) Clasificación de patrones; 5) Aplicaciones BCI y realimentación.

Tal y como se puede ver en la figura anterior, un sistema BCI puede ser presentado como un sistema de reconocimiento de patrones. En un primer paso, que evidentemente es vital para el correcto funcionamiento del sistema, el usuario debe desarrollar alguna tarea mental según un paradigma implementado. Por ejemplo, en un paradigma de Imaginación de Movimiento (MI) en el que se emplean las manos, el usuario debe imaginar el movimiento de la mano izquierda o derecha según unas señales predefinidas del sistema o de un elemento a controlar. La actividad cerebral realizada generará unos potenciales eléctricos del orden de micro voltios, que mediante electrodos ubicados en las zonas de interés, según la tarea y el paradigma implementado, se adquiere y se discretiza.

A continuación, se realiza un preprocesado de la señal adquirida. Su función es dejar la señal de forma que pueda ser procesada correctamente eliminando las componentes de la señal no deseadas, tales como ruido, o artefactos biológicos debidos a la actividad eléctrica del cuerpo, como por ejemplo, señales de electromiograma (movimientos musculares), electro-oculograma (movimientos oculares), o electrocardiograma (los propios del corazón). En una tercera etapa, se aplican técnicas de extracción de características para obtener información discriminatoria de la señal EEG. Estas características se agrupan en vectores que serán clasificados en la etapa de clasificación de 
patrones. De esta forma, se realiza una identificación entre los vectores de características recibidos y la tarea mental del usuario en ese momento, (imaginación del movimiento de la mano derecha o izquierda).

Estas predicciones se envían a la etapa de aplicación donde el sistema BCI utiliza las predicciones para controlar diversos equipos o dispositivos para mostrar una señal de realimentación al usuario. Esta realimentación se considera muy valiosa, pues permite a los usuarios ver en tiempo real los efectos que tienen en el sistema sus pensamientos y así aprenden a modular sus señales cerebrales en función de la salida que deseen obtener.

\subsection{Definición del problema}

Aunque todas las partes son importantes en los sistemas BCI, es obvio que un buen diseño del bloque de aprendizaje automático es necesario para obtener un buen rendimiento. La calidad de las predicciones del sistema dependerán tanto de las características extraídas como del algoritmo de clasificación empleado. Para extraer características, se han empleado numerosas técnicas, como por ejemplo densidad de potencia espectral (o PSD, del inglés Power Spectral Density), parámetros de Hörjh (H), coeficientes adaptativos autorregresivos (o AAR del inglés Adaptive Autoregressive coefficients), patrones espaciales comunes (o CSP, Common Spatial Patterns) o combinaciones de diferentes métodos. Además, en la etapa de clasificación se han aplicado muchos clasificadores diferentes tales como clasificadores lineales, redes neuronales, clasificadores bayesianos y también combinaciones de ellos, bajo diferentes estrategias de muestreo para mejorar los resultados de precisión de clasificación. Sin embargo, no hay una conclusión sobre cuál es la mejor manera de diseñar la etapa de aprendizaje automático ya que cada autor decide qué pasos y técnicas aplicar en cada trabajo.

Por otra parte, el éxito de estos sistemas depende tanto del sistema implementado, como de la habilidad del usuario a la hora de manejarlo. Por ello, para obtener un mejor rendimiento, debe haber una adaptación mutua entre el hombre y la máquina. La adaptación de la máquina se suele realizar al inicio de cada sesión de trabajo, para ello, se realizan unas pruebas iniciales en las que el usuario intenta manejar el sistema varias veces mediante la realización de tareas mentales predefinidas en el orden que le indica el sistema y seguidamente, con esta pequeña base de datos inicial, se realiza el entrenamiento del clasificador mediante el ajuste de sus parámetros para adaptarlo lo máximo posible al usuario. Sin embargo, la adaptación de los usuarios al sistema es bastante más compleja. Se ha observado, que cuando un grupo suficientemente grande de sujetos trata de interactuar con estos sistemas por primera vez mediante paradigmas de imaginación de movimiento, de 
forma natural, hay algunos de estos sujetos que obtienen mejor resultado; siendo estos sensiblemente mayores que la media del grupo y sin embargo, hay algunos sujetos que aunque se sometan a un proceso de entrenamiento sistemático nunca llegará controlar el sistema de forma satisfactoria.

En un experimento de MI en BCI se espera una precisión entre el $80 \%$ y el $90 \%$ después de 6-9 sesiones de entrenamiento de 20 minutos. Sin embargo, y según el estado del arte, ciertos sujetos pueden presentar dificultades para utilizar los sistemas BCI basados en MI y, en estos casos, los rendimientos de clasificación son bastante pobres, incluso usando múltiples sesiones de entrenamiento. De hecho, se estima que casi un $20 \%$ de la población tiene serias dificultades para interactuar con sistemas BCI basados en este tipo de paradigmas. Por lo tanto, es normal encontrar resultados en la literatura, que se han obtenido con una selección previa de sujetos que han obtenido un buen rendimiento en el control de sistemas BCI en sesiones previas.

\subsection{Objetivos}

Esta Tesis tiene dos objetivos principales. El primero, es probar el ELM con señales obtenidas de cinco usuarios noveles durante la realización de experimentos BCI con paradigmas de MI, que no tenían experiencia previa en el manejo de estos sistemas. Para poder comparar el rendimiento con clasificadores clásicos en BCI se ha empleado un método de extracción de características ampliamente conocido y probado en BCI. Es importante destacar que se descarta realizar ningún tipo de selección previa de usuarios.

El segundo objetivo, es probar métodos lineales de extracción de características ampliamente conocidos en BCI tales como PSD, Hjörth y AAR tanto de forma individual, como generando diferentes combinaciones entre ellas, junto con un ELM como clasificador de sistemas BCI basados en MI. La revisión de la literatura científica nos indica que esta combinación no se ha realizado con profundidad. 


\subsection{Estructura de la Tesis.}

Esta tesis, por tanto, se centra en los bloques de extracción de características y de clasificación de patrones, por lo que el resto de las etapas no se analizarán en profundidad, ya que no difieren de otros sistemas BCI existentes. A continuación se detallan los contenidos de los diferentes capítulos que forman esta Tesis:

- En el Capítulo 2 se describen las bioseñales y los fundamentos de la actividad eléctrica neuronal, lo que constituye una pieza fundamental para comprender el funcionamiento de un sistema BCI.

- En el Capítulo 3 se realiza una revisión de los métodos de Neuroimagen.

- El Capítulo 4 se centra en la descripción de los sistemas BCI. Se explican los fundamentos de los diferentes tipos de enfoques de estos sistemas y, se realiza una revisión de sus aplicaciones en distintos ámbitos. Finalmente, se describen los "BCI Competitions", que generaron unas bases de datos que se han convertido en un estándar para probar nuevos algoritmos y estrategias de extracción de características y clasificación.

- En el Capítulo 5 se estudian varios métodos de extracción y clasificación de características aplicados en sistemas BCI y que además han sido empleados en la parte experimental de esta Tesis.

- El Capítulo 6 hace una introducción a las redes neuronales y describe los fundamentos del ELM.

- El Capítulo 7 describe los experimentos realizados así como las conclusiones obtenidas del trabajo realizado.

- Finalmente, el Capítulo 8 lista las líneas futuras de investigación como continuación del trabajo desarrollado. Otro aspecto importante de este capítulo es que incluye un listado de publicaciones y revistas indexadas o no indexadas que han derivado directamente de este trabajo. 


\section{Capítulo 2}

\section{Bioseñales}

Se describe en este Capítulo un marco histórico que muestra a los científicos que desarrollaron la idea de representar las señales eléctricas del cerebro utilizando distintas técnicas para la época. Se describe también el tipo de señal utilizada en estos experimentos, denominada bioseñal o biopotencial.

\subsection{Marco histórico de las bioseñales}

La existencia de corrientes eléctricas en el cerebro fue descubierta en 1875 por el fisiólogo británico Richard Caton mediante el análisis de trabajos anteriores y el uso de técnicas invasivas con animales, es decir, implantando electrodos directamente sobre la superficie cerebral. Pero fue el psiquiatra alemán Hans Berger, quien primero analizó la actividad cerebral en 1924 e introdujo el término electroencefalograma para denominar a las variaciones de potencial de las señales recogidas del cerebro. Hans Berger observó que la actividad cambiaba de acuerdo a los distintos estados funcionales del cerebro, como son el estado de sueño o vigilia, de anestesia e incluso la falta de oxígeno o epilepsia.

En la tabla 2.1.1 se observan por año y autor los primeros estudios de potenciales eléctricos desde Luigi Galvani en 1770 quien realizó observaciones sobre la actividad eléctrica animal y en 1794 su obra científica giró en torno al galvanismo y a sus aplicaciones médicas. En 1830 Carlo Matteucci estudió también los fenómenos eléctricos mediante polarización de electrodos así como Emil du Bois-Reymond publicaba trabajos sobre fenómenos eléctricos en animales en 1848 y Richard Caton en 1875 describe que se pueden medir cambios eléctricos en los hemisferios cerebrales de conejos y monos, trabajo que prosiguió Danilevski en 1891. Posteriormente en 1895 y bajo la supervisión de Cybulski, Beck estudió la actividad cerebral en respuesta a estimulación de nervios periféricos, realizando uno de los primeros encefalogramas del córtex cerebral mediante procedimiento invasivo. 
Tabla 2.1.1: Resumen histórico de los hechos más importantes en la historia de la encefalografía.

\begin{tabular}{lc}
\hline \hline Año & Autor \\
\hline 1770 & Luigi Galvani \\
\hline 1794 & Luigi Giovanni Aldini \\
\hline 1830 & Carlo Matteucci \\
\hline 1848 & Emil du Bois-Reymond \\
\hline 1875 & Richard Caton \\
\hline 1891 & Vasili Yakovlevich Danilevski \\
\hline 1895 & Adolf Beck y Napoleón Cybulsky \\
\hline 1912,1913 & Pavel Kaufman y Pradvich Neminski \\
\hline 1924 & Hans Berger \\
\hline \hline
\end{tabular}

Ya en el siglo XX fueron Pavel Kaufman y Pradvich Neminski quienes fueron los primeros en establecer los potenciales eléctricos a través de un cráneo intacto, es decir, sin ser invasivo. Finalmente tenemos a Hans Berger, a quien se considera padre de la encefalografía moderna. En total, tenemos más de dos siglos de vida del estudio de bioseñales y su inclusión en diversas áreas de conocimiento.

Ya vistos los inicios, una definición de bioseñal podría ser la de indicador que un ser vivo produce, y que puede ser capturado utilizando determinadas técnicas y analizado posteriormente. Por ejemplo, la señal de electroencefalograma, es producto de la actividad eléctrica cerebral, tiene un rango de amplitud de $5 \mu \mathrm{V}$ a $300 \mu \mathrm{V}$ y un rango en frecuencia de $150 \mathrm{~Hz}$.

\subsubsection{Neurona como precursora de la bioseñal.}

Se considera importante incluir en la tesis alguna información o incluir conceptos referentes a las neuronas, sin las cuales un sistema BCI no tendría objeto de estudio. Es la neurona la unidad básica del sistema nervioso y tiene la capacidad de comunicarse con otras células, sean éstas nerviosas o no (músculos). Como es conocido, la información viaja entre neuronas por medio de impulsos eléctricos que se transmiten de unas a otras y estos impulsos se reciben de otras neuronas en las dendritas, pasan a través ellas hasta ser conducidas por el axón a los terminales de salida, los cuales pueden conectarse con otra neurona, fibras musculares o glándulas, ver Figura 2.1.1. 


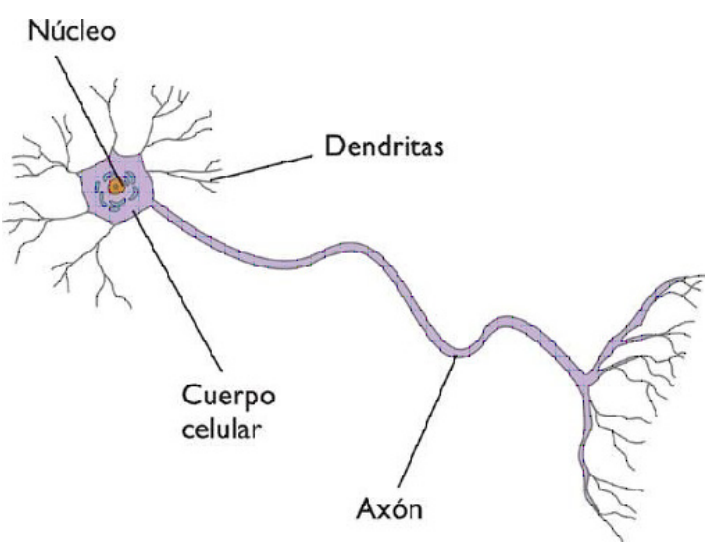

Figura 2.1.1: Representación de las partes de una neurona.

Fuente: http://2.bp.blogspot.com/

Cuando se produce un estímulo externo, el sistema nervioso actúa de la siguiente forma; cuando dicho estímulo es recibido en alguna región sensorial capturando alguna información, se transporta por el sistema nervioso (a través de las neuronas) hasta una componente integradora en donde se analiza. Esta componente elabora la respuesta, que es conducida a través de las neuronas hacia fibras musculares (respuesta motora) o hacia glándulas (secreción glandular). Hay que tener en cuenta que la actividad cerebral es producida por un número muy elevado de neuronas, actualmente un estudio publicado por la revista Nature en 2016 por la Dra. Suzana Herculano-Houzel [213] revela que hay aproximadamente 86 mil millones en un cerebro humano medio y cada una de las tareas que nuestro cuerpo puede realizar provoca una actividad cerebral con forma e intensidad diferentes, además de localizarse en distintas zonas del sistema nervioso.

\subsubsection{Potenciales eléctricos o biopotenciales.}

Con el desarrollo de la tecnología, en medicina moderna existen distintas formas de obtener información acerca de bioseñales procedentes del cuerpo humano. Así obtenemos por ejemplo medidas biológicas de temperatura corporal, presión arterial, concentración química de elementos o potenciales bioeléctricos (que es lo que nos ocupa en esta tesis).

Los potenciales bioeléctricos, también denominados biopotenciales provienen de la actividad electroquímica de un determinado tipo células excitables que se encuentran o forman parte de músculos, glándulas y sobre todo el tejido nervioso. Dicha actividad produce señales eléctricas que con el equipo necesario pueden ser medidas en forma de diferencia de potencial, importante en un sistema BCI. 


\subsubsection{Señales o ritmos que intervienen en el sistema BCI.}

Se comentan aquí brevemente cómo se producen estas señales debido a su importancia para comprender su posterior análisis. Si la neurona no envía ninguna señal, es decir, está en reposo, su potencial eléctrico interior es negativo con respecto al exterior de la célula formando un ion, es decir, lo que se denomina la producción de la señal eléctrica cerebral o también los "spikes. ${ }^{\circ}$ potenciales de acción.

A pesar de que las concentraciones de los diferentes iones intentarán equilibrase en todo momento a ambos lados de la membrana celular, esto no se producirá debido a que dicha membrana celular es semipermeable. En el estado de reposo, los iones de potasio $(\mathrm{K}+)$ pueden atravesar fácilmente la membrana, mientras que para los iones de cloro (CL-) y de sodio $(\mathrm{Na}+)$ es más difícil pasar.

Por otro lado, las moléculas proteicas, cargadas negativamente (A-) en el interior de la neurona, no pueden atravesar la membrana. Además de estos canales selectivos, existe una bomba (llamada bomba de sodio-potasio ATPasa) que utiliza energía para sacar 3 iones de sodio por cada 2 iones de potasio que bombea al interior de la neurona, lo que vuelve al interior más negativo respecto al exterior.

Finalmente, cuando se equilibran estas fuerzas, se obtiene un potencial de reposo entre el interior y el exterior de la célula de aproximadamente $-70 \mathrm{mV}$. En este estado de reposo hay relativamente más iones de sodio en el exterior de la neurona, y más iones de potasio en su interior. En la ilustración se observan las distintas concentraciones y los procesos descritos anteriormente.

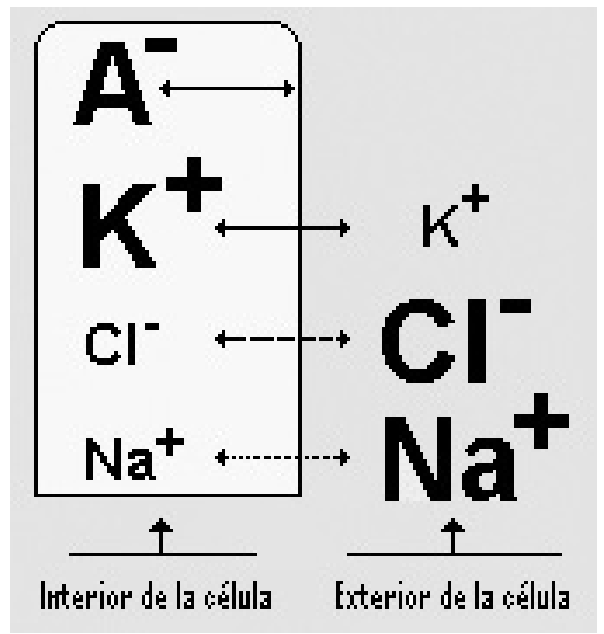

Figura 2.1.2: Esquema célula.

Fuente: http://faculty.washington.edu. 
La figura anterior muestra la concentración de elementos que participan en la generación del potencial de acción, dentro y fuera de la célula. Por otra parte el potencial de acción también conocido como impulso, (espiga o spike en inglés) es una explosión de la actividad eléctrica creada por una corriente despolarizadora e indica lo que sucede cuando la neurona transmite información por el axón.

Este potencial de acción activa los mecanismos de producción, transporte y liberación de neurotransmisores hacia la región de sinapsis, los cuales se utilizan para comunicarse con células adyacentes. Esto significa que cuando un evento (estímulo) hace variar el potencial de reposo y la despolarización alcanza un voltaje umbral cercano a los $-55 \mathrm{mV}$, la neurona lanza un potencial de acción. Si la neurona no alcanza este umbral crítico, no se producirá el potencial de acción.

Aclarar que cuando se alcanza el umbral, siempre se produce un potencial de acción estándar, es decir para cualquier neurona dada, el potencial de acción es siempre el mismo. Este fenómeno se produce por el intercambio de iones a través de la membrana celular.

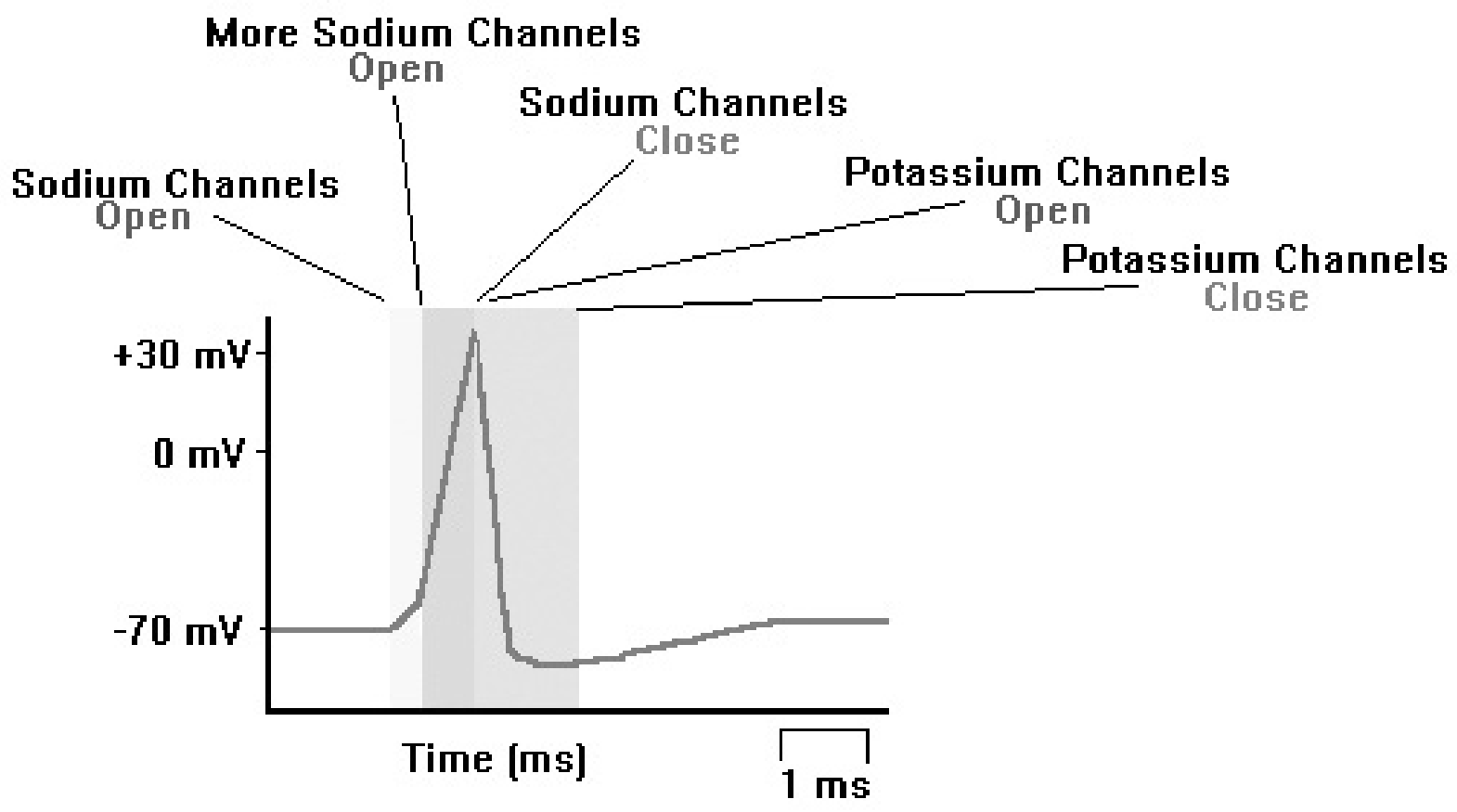

Figura 2.1.3: Esquema del potencial de acción con las diferentes etapas.

Fuente: UW Computing and Communications Faculty, http://faculty.washington.edu.

El proceso se resume en lo siguiente: Primero un estímulo abre los canales de sodio por lo que los iones de sodio entran rápidamente a la neurona volviéndose cada vez más positiva y se comienza a despolarizar hasta llegar al punto de máximo potencial el cual es de aproximadamente $30 \mathrm{mV}$. 
Luego se comienzan a cerrar los canales de sodio y se abren canales de potasio, los cuales son más lentos. Esto revierte la despolarización llegando por debajo de los $-70 \mathrm{mV}$ produciendo lo que se conoce como hiperpolarización, debido a que los canales de potasio tardan en cerrarse. Esto trae aparejado un período refractario durante el cual no se producirá otro potencial de acción estándar, posteriormente la neurona vuelve al estado de reposo habitual.

Lo que se busca al implantar electrodos en la corteza cerebral es poder medir la señal eléctrica que viaja por el axón. La captación de la señal eléctrica cerebral se puede realizar mediante técnicas invasivas y no invasivas. Las invasivas implican la implantación de electrodos sobre la corteza cerebral y las no invasivas conllevan la localización de electrodos sobre el cuero cabelludo.

Hoy día, los electrodos que se implantan integran circuitos amplificadores especiales los cuales adecuan la señal para ser entregada al ADC (Analog to Digital Converter). La integración de estos amplificadores de ultra bajo ruido, y ultra bajo consumo viene creciendo ya que cada vez los arrays de electrodos son más grandes. Algunos incluso ya realizan un prefiltrado y detección de "spikes"para facilitar la selección de los picos y la reducción de los datos a trasmitir a las etapas posteriores de procesamiento. Si bien existen otros circuitos para tratar la señal obtenida de los electrodos, tienen un nivel de ruido térmico inaceptable o su consumo es muy elevado como para ser totalmente implantado en grandes cantidades. Si la disipación de potencia es grande los tejidos que rodeen al implante sufrirán un aumento de temperatura y se dañarán. Actualmente se dispone de equipos precisos para realizar las medidas de señales de distintos órganos y que se resumen en la siguiente tabla:

Tabla 2.1.2: Técnicas, siglas y procedencia de los biopotenciales más importantes.

\begin{tabular}{lc}
\hline \hline Técnica & Sigla/ Lugar del cuerpo de donde procede el Biopotencial \\
\hline Electrocardiografía & ECG/ Corazón \\
\hline Electromiografía & EMG/ Músculos específicos \\
\hline Electrorretinografía & ERG/ Ojo \\
\hline Electroneurografía & ENG/ Sistema Nervioso periférico \\
\hline Electroencefalografía & EEG/ Cerebro \\
\hline \hline
\end{tabular}

La Tabla 2.1.2 resume la técnica utilizada y la señal del cuerpo que recoge, así como la nomenclatura utilizada para nombrar la señal medida. Tal y como se puede ver la Electrocardiografía, Electromiografía y la Electroneurografía, representan las señales del corazón, Músculos, Ojos y del 
Sistema Nervioso respectivamente. La Electroencefalografía, se encarga pues, de recoger la actividad eléctrica generada por las estructuras del cerebro y es la técnica sobre la que se trabaja en esta tesis. 
Capítulo 2. Bioseñales 


\section{Capítulo 3}

\section{Revisión de métodos de Neuroimagen.}

Aquí se describen los principales métodos de obtención de la señal de biopotenciales generados por el cerebro. Además se relacionarán con los utilizados en los sistemas BCI.

\subsection{Técnicas actuales.}

La siguiente figura muestra los principales métodos de neuroimagen.

\begin{tabular}{|c|c|c|c|c|c|c|}
\hline Método & $\begin{array}{c}\text { Tipo de } \\
\text { actividad }\end{array}$ & $\begin{array}{c}\text { Medida } \\
\text { Directa/ } \\
\text { Indirecta }\end{array}$ & $\begin{array}{c}\text { Resolución } \\
\text { temporal }\end{array}$ & $\begin{array}{c}\text { Resolución } \\
\text { espacial }\end{array}$ & $\begin{array}{l}\text { Tipo de } \\
\text { riesgo }\end{array}$ & Portabilidad \\
\hline EEG & Eléctrica & Directa & $\sim 0.05 \mathrm{~s}$ & $\sim 10 \mathrm{~mm}$ & No invasiva & Portable \\
\hline MEG & Magnética & Directa & $\sim 0.05 \mathrm{~s}$ & $\sim 5 \mathrm{~mm}$ & No invasiva & No-portable \\
\hline ECoG & Eléctrica & Directa & $\sim 0.003 \mathrm{~s}$ & $\sim 1 \mathrm{~mm}$ & Invasiva & Portable \\
\hline $\begin{array}{c}\text { Grabación } \\
\text { Intracortical }\end{array}$ & Eléctrica & Directa & $\sim 0.003 \mathrm{~s}$ & $\begin{array}{l}\sim 0.5 \mathrm{~mm} \\
\sim 0.1 \mathrm{~mm} \\
\sim 0.05 \mathrm{~mm}\end{array}$ & Invasiva & Portable \\
\hline fMRI & Metabólica & Indirecta & $\sim 1 \mathrm{~s}$ & $\sim 1 \mathrm{~mm}$ & No-invasiva & No-portable \\
\hline NIRS & Metabólica & Indirecta & $\sim 1 \mathrm{~s}$ & $\sim 5 \mathrm{~mm}$ & & \\
\hline
\end{tabular}

Figura 3.1.1: Métodos de neuroimagen.

La Figura presenta tanto la nomenclatura del método, como el tipo de actividad que estudia (si es eléctrica, magnética o metabólica), el tipo de medida (directa o indirecta), la resolución temporal y espacial de la misma. También si se trata de una técnica invasiva o no invasiva y si puede realizarse o no fuera de un espacio concreto, por cuestiones técnicas asociadas al equipamiento. Tal y como se puede ver, se presentan 6 métodos de captación de la actividad cerebral, que son: ElectroEncefaloGrama (EEG); Magnetoencefalograma (MEG); Electrocorticograma (ECoG); Grabación Intracortical, Imágenes por Resonancia Magnética Funcional (fMRI) y; Espectropía de Infrarrojo 
Cernano (NIRS). Seguidamente, para su mejor comprensión, se realiza una descripción de cada una de ellos:

\subsubsection{Electroencefalografía (EEG).}

El EEG mide la actividad cerebral eléctrica causada por el flujo de corrientes eléctricas durante las excitaciones sinápticas de las dendritas en las neuronas y es extremadamente sensible a los efectos de las corrientes secundarias [5]. Las señales de EEG se registran fácilmente de forma no invasiva a través de electrodos colocados en el cuero cabelludo, por lo que es con diferencia la modalidad de grabación más extendida. Sin embargo, proporciona señales de muy mala calidad ya que las señales tienen que cruzar el cuero cabelludo, el cráneo y muchas otras capas. Esto significa que las señales de EEG en los electrodos son débiles y difíciles de adquirir. Además, esta técnica se ve afectada por el ruido de fondo generado dentro del cerebro o externamente sobre el cuero cabelludo por lo que requiere de filtrado.

El sistema de grabación EEG consta de electrodos, amplificadores, convertidor A/D y un dispositivo de grabación. Los electrodos adquieren la señal del cuero cabelludo, los amplificadores procesan la señal analógica para ampliar la amplitud de las señales del EEG, de manera que el convertidor A/D puede digitalizar la señal de una manera más precisa. Por último, el dispositivo de grabación, que puede ser un ordenador personal (PC) o similar, almacena y muestra los datos.

La señal del EEG se mide como la diferencia de potencial a lo largo del tiempo entre la señal o el electrodo activo y el electrodo de referencia. Un tercer electrodo adicional, conocido como electrodo de masa, se utiliza para medir la tensión diferencial entre los puntos de referencia y los puntos activos. Por lo tanto, la configuración mínima para la medición del EEG consiste en un electrodo activo, una referencia y un electrodo de masa. Las configuraciones multicanal pueden comprender hasta 128 o 256 electrodos activos [8]. Estos electrodos suelen estar hechos de cloruro de plata ( $\mathrm{AgCl}$ ) [9] y La impedancia de contacto entre el electrodo y el cuero cabelludo debe estar entre $1 k \Omega$ y $10 k \Omega$ para registrar una señal precisa [169]. La interfaz entre el tejido y el electrodo no sólo es resistiva sino también capacitiva, por lo que se comporta como un filtro paso bajo. Además, la impedancia depende de varios factores como la capa de interfaz, la superficie del electrodo y la temperatura [169]. Por ello es habitual utilizar geles conductores que crean una trayectoria conductiva entre la piel y cada electrodo reduciendo la impedancia para obtener una mejor medida de tensión. Sin embargo, el uso del gel es algo molesto, ya que requiere un mantenimiento continuo para asegurar una señal de calidad relativamente buena. Los electrodos que no necesitan el uso de geles, se denominan electrodos "secosz han sido fabricados con materiales como titanio y acero inoxidable [170]. Estos tipos de electrodos pueden ser incluso electrodos activos "secos", es decir, que integran circuitos de preamplificación para tratar con impedancias muy altas entre el electrodo 
y la piel $[170,10]$. Los electrodos pasivos "secos", no tienen circuitos activos integrados, pero están conectados a amplificadores de EEG con una alta ganancia de entrada [11].

La amplitud de las señales biológicas eléctricas es del orden de los $\mu V$. En consecuencia, la señal es muy sensible al ruido electrónico. Fuentes externas, como por ejemplo la línea eléctrica, pueden generar ruido de fondo. Por ello, se deben tener en cuenta en el diseño de los equipos los efectos del ruido, utilizando técnicas como el apantallamiento para evitar las interferencias electromagnéticas o la reducción de la señal de modo común, entre otros [170].

El EEG comprende un conjunto de señales que pueden clasificarse según su frecuencia. Se han definido rangos de frecuencia bien conocidos según la distribución sobre el cuero cabelludo o la importancia biológica. Estas bandas de frecuencia se denominan Alfa, Beta, Gamma, Delta y Theta, respectivamente. A continuación se detallan las características pertinentes de estas bandas, haciendo hincapié en el margen de frecuencias en que trabajan:

- Las ondas Delta se encuentra por debajo de $4 \mathrm{~Hz}$, y su amplitud en los seres humanos disminuye a medida que estos envejecen. Los ritmos Delta generalmente sólo se observan en adultos en estado de sueño profundo y son inusuales en adultos en estado de vigilia. Una gran cantidad de actividad delta en adultos despiertos es anormal y está relacionada con enfermedades neurológicas [171]. Debido a la baja frecuencia, es fácil confundir las ondas Delta con señales de artefactos (ruidos producidos dentro del propio cuerpo humano), las cuales son causadas por los músculos grandes del cuello o de la mandíbula.

- Las ondas Theta se encuentran dentro del rango de 4 a $7 \mathrm{~Hz}$. En un adulto despierto normal, sólo se puede registrar una pequeña cantidad de frecuencias Theta. Se puede observar una mayor cantidad de estas en niños pequeños, niños mayores y adultos en estados somnolientos, meditativos o de sueño [171]. Al igual que las ondas Delta, una gran parte de la actividad Theta en los adultos despiertos está relacionada con enfermedades neurológicas [171]. La banda Theta también se ha asociado a una amplia gama de procesos cognitivos como el cálculo mental [12], o la conciencia consciente [13].

- Los ritmos Alfa se encuentran sobre la región occipital del cerebro [14]. Estas ondas se encuentran dentro del rango de 8 a $12 \mathrm{~Hz}$. Su amplitud aumenta cuando los ojos se cierran y el cuerpo se relaja y, se atenúan cuando los ojos se abren y se realiza un esfuerzo mental [15]. Estos ritmos reflejan principalmente el procesamiento visual en la región occipital del cerebro y también pueden estar relacionados con la función cerebral de la memoria [16]. Tal y como se ha dicho anteriormente, existen pruebas de que la actividad Alfa puede estar asociada con el esfuerzo mental, sin 
embargo, el esfuerzo mental creciente causa una supresión de la actividad alfa, particularmente desde las áreas frontales [17]. En consecuencia, estos ritmos pueden ser señales útiles para medir el esfuerzo mental.

- Los ritmos de Mu pueden encontrarse en el mismo rango que los ritmos Alfa, aunque existen importantes diferencias fisiológicas entre ambos. En contraste con los ritmos Alfa, los ritmos $\mathrm{Mu}$ están fuertemente relacionados con las actividades motoras y, en algunos casos, parecen correlacionarse con los ritmos Beta $[14,18]$.

Como se explicó anteriormente, el EEG se registra por medio de electrodos. Los electrodos colocados sobre el cuero cabelludo se distribuyen habitualmente basándose en el sistema International 10-20 [20], que ha sido estandarizado por la American Electroencephalographic Society. El sistema 10-20 utiliza dos puntos de referencia sobre la cabeza para definir la ubicación del electrodo. Uno de estos puntos de referencia es el nasion, situado en la parte superior de la nariz al mismo nivel que los ojos. El otro punto de referencia es el inion, que se encuentra en el bulto óseo de la base del cráneo. Los planos transversales y medianos dividen el cráneo de estos dos puntos. Las posiciones de los electrodos se determinan marcando estos planos a intervalos de $10 \%$ y $20 \%$ (Ver Figura 3.1.2). Las letras en cada ubicación corresponden a regiones cerebrales específicas de tal manera que A representa el lóbulo de la oreja, $\mathrm{C}$ la región central, Pg la nasofaringeal, $\mathrm{P}$ el parietal, F la frontal, Fp la polar frontal, y $\mathrm{O}$ el área occipital.
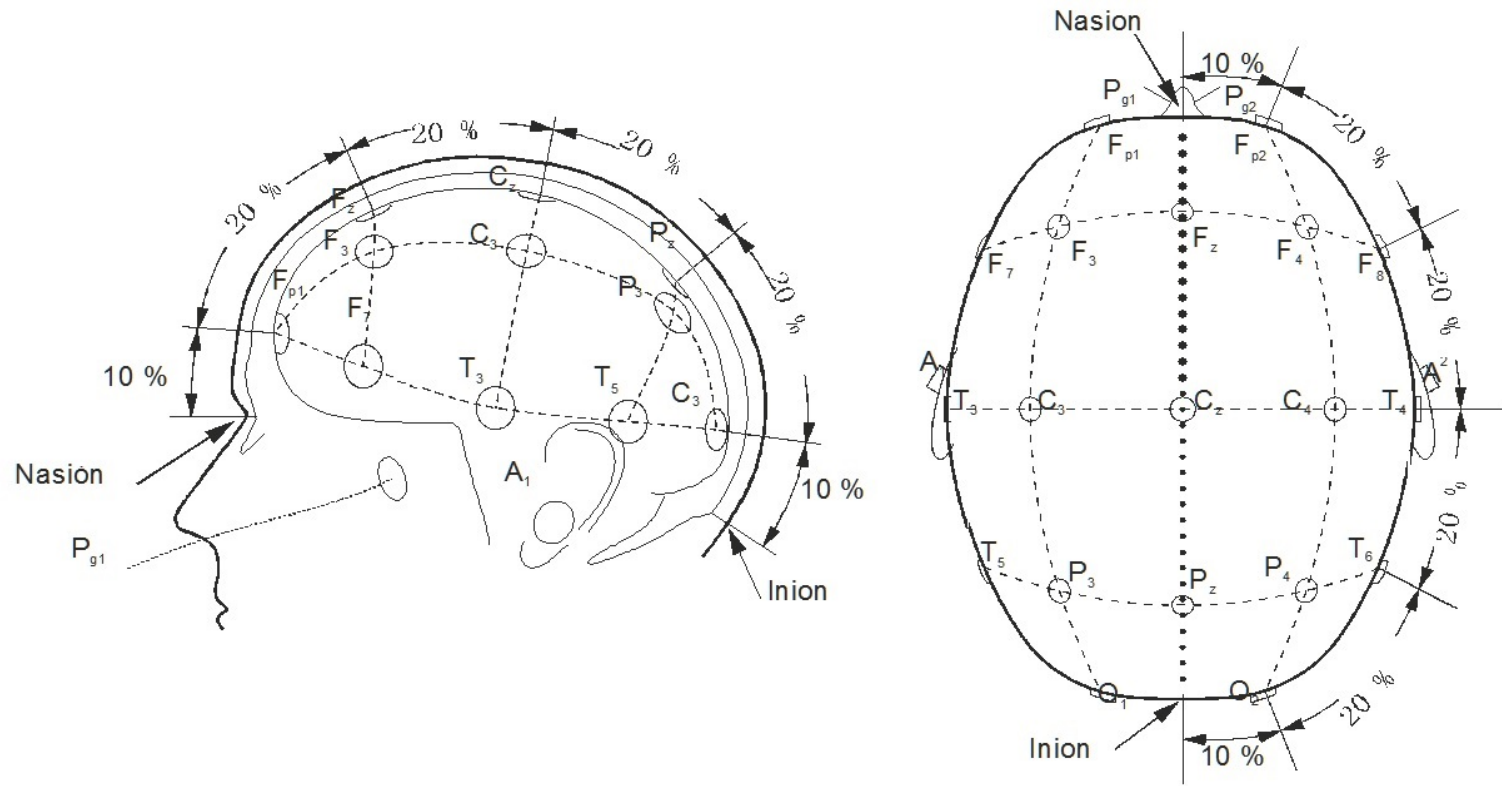

Figura 3.1.2: Colocación de electrodos sobre el cuero cabelludo.

Fuente: Adaptado de https://www.researchgate.net/ 


\subsubsection{Magnetoencefalografía (MEG).}

El MEG es una técnica de neuroimagen no invasiva que registra la actividad magnética del cerebro por medio de inducción magnética. MEG mide las corrientes intracelulares que fluyen a través de dendritas que producen campos magnéticos medibles fuera de la cabeza [21]. Los procesos neurofisiológicos que producen señales de MEG son idénticos a los que producen señales de EEG. Sin embargo, mientras que el EEG es extremadamente sensible a las fuentes de corriente secundarias, el MEG es más sensible a las corrientes primarias [5]. La ventaja del MEG es que los campos magnéticos están menos distorsionados por el cráneo y el cuero cabelludo que los campos eléctricos [22].

Los campos magnéticos son detectados por dispositivos que son extremadamente sensibles a las perturbaciones magnéticas producidas por la actividad neuronal [23]. El equipo electrónico que mide la actividad cerebral magnética se enfría a casi -273 grados centígrados para facilitar la conductividad del sensor. El MEG requiere un apantallamiento eficaz contra interferencias electromagnéticas y el equipo electrónico se instala dentro de una sala blindada magnéticamente, que atenúa los efectos de los campos magnéticos de fuentes externas, lo que impide su portabilidad.

El MEG proporciona señales con mayor resolución espacio-temporal que el EEG, lo que reduce el tiempo de entrenamiento necesario para controlar un BCI e incluso se ha utilizado con éxito para localizar regiones activas dentro del cerebro [24]. A pesar de estas ventajas, el MEG no se utiliza a menudo en el diseño de BCI porque la tecnología MEG es demasiado voluminosa y costosa para convertirse en una modalidad de adquisición adecuada para un uso digamos diario. En 2005, Lal y otros [25] presentaron el primer BCI basado en MEG. Aunque se han realizado estudios adicionales [22, 26, 27, 28, 29], los BCI basados en MEG, comparados con los BCI basados en EEG, se encuentran todavía en una etapa temprana.

\subsubsection{Electrocorticografía (ECoG.)}

El ECoG es una técnica que mide la actividad eléctrica en la corteza cerebral por medio de electrodos colocados directamente en la superficie del cerebro. En comparación con el EEG, el ECoG proporciona una mayor resolución temporal y espacial, así como mayores amplitudes y una menor vulnerabilidad a artefactos como parpadeos y movimiento ocular [30]. Sin embargo, el ECoG es una modalidad de grabación invasiva que requiere una craneotomía para implantar una rejilla de electrodos, lo que implica riesgos significativos para la salud. Por esta razón, los primeros estudios sobre ECoG fueron en animales. Estudios tempranos que incluyeron animales evaluaron la estabilidad a largo plazo de las señales del cerebro que el ECoG podría adquirir [31, 32, 33, 34]. Los 
resultados mostraron que los electrodos implantados podían proporcionar señales estables durante varios meses. Sin embargo, la estabilidad a largo plazo de las señales adquiridas por el ECoG es actualmente incierta. Experimentos más recientes con primates han demostrado que el ECoG puede funcionar a un alto nivel durante meses sin ningún tipo de desviación en la precisión o recalibración [35].

En humanos, el ECoG se ha utilizado para el análisis de las ondas Alfa, Beta [36] y ondas Gamma [37, 38] producidas durante la imaginación de movimiento (MI) voluntario. Con respecto al uso de ECoG en sistemas BCI, Levine y otros [40] diseñaron un BCI que clasificaba el MI en base a la identificación de los potenciales relacionados con eventos (ERP) usando ECoG. Leuthardt y otros [41] mostraron por primera vez que un sistema BCI basado en ECoG podía proporcionar información para controlar un cursor unidimensional, ya que esta información es más precisa y se adquiere más rápidamente que por BCI basado en EEG. Algunos años más tarde, Schalk y otros [42] presentaron un BCI basado en ECoG más avanzado que permitía al usuario controlar un cursor bidimensional.

Los resultados de todos estos estudios podrían hacer más factible que las personas con discapacidades de movimiento severas utilicen los BCI basados en ECoG para sus necesidades de comunicación y control de dispositivos.

\subsubsection{Grabación o registro intracortical.}

El registro intracortical de neuronas es una técnica de neuroimagen que mide la actividad eléctrica dentro de la materia gris del cerebro. Es una modalidad de grabación invasiva que necesita implantar matrices de microelectrodos dentro de la corteza para capturar los potenciales eléctricos de las neuronas.

Se pueden obtener tres señales mediante el registro neuronal intracortical: actividad unitaria (SUA), actividad multiunidad (MUA) y potencial de campo local (LFPs) [21]. El SUA se obtiene mediante el filtrado paso alto $(>300 \mathrm{~Hz})$ de la señal de una sola neurona. El MUA se obtiene de la misma manera, pero las señales pueden provenir de múltiples neuronas. Los LFPs se extraen por filtrado paso bajo $(<300 \mathrm{~Hz})$ de la actividad neuronal en las proximidades de una punta de electrodo. Los LFPs son señales analógicas mientras que los SUA y MUA miden la actividad de pico de neuronas individuales y pueden reducirse a eventos discretos en el tiempo [21].

La grabación intracortical de la neurona proporciona una resolución espacial y temporal mucho más alta que la grabación EEG. Por lo tanto, las señales intracorticales pueden ser más fáciles de 
usar que las señales EEG. Sin embargo, la calidad de la señal puede verse afectada por la reacción del tejido cerebral al microelectrodo de registro implantado [41] y por los cambios en la sensibilidad del microelectrodo, que pueden dañarse progresivamente a lo largo del tiempo [42] y pueden ser necesarias recalibraciones periódicas de la sensibilidad de los electrodos [43].

Los estudios iniciales han demostrado que las grabaciones neuronales intracorticales pueden indicar la naturaleza de un movimiento y su dirección. Estos estudios no revelan si los mismos patrones estarán presentes cuando los movimientos reales no se hacen (lo que hacemos en nuestro estudio). En ese sentido, Taylor y Schwartz $[45,46]$ experimentaron con macacos rhesus, que realizaron movimientos reales y virtuales de brazos en un ordenador. Los resultados sugieren que los mismos patrones persisten. Los estudios más recientes con monos investigaron el control de dispositivos protésicos para la interacción directa en tiempo real con el entorno físico [47, 48, 49, 50].

Por lo que se refiere a la aplicación del registro intracortical de neuronas en sistemas BCI, se ha informado de que las matrices de microelectrodos, como la Utah Intracortical Electrode Array (UIEA) son un medio adecuado para proporcionar un control simultáneo y proporcional de un gran número de dispositivos externos [44]. Además, Kennedy y otros [49] utilizaron señales de control cortical para diseñar un BCI que permitía a los usuarios controlar el movimiento del cursor y la flexión de un dedo cibernético en una mano virtual.

\subsubsection{Imágenes por resonancia magnética funcional (fMRI).}

fMRI es una técnica de neuroimagen no invasiva que detecta cambios en el volumen sanguíneo cerebral, flujo sanguíneo cerebral y niveles de oxigenación durante la activación neuronal por medio de campos electromagnéticos. Se realiza generalmente utilizando escáneres que aplican campos electromagnéticos de intensidad del orden de 3 o 7 Teslas. La principal ventaja del uso de fMRI es la alta resolución espacial. Por esa razón, se ha aplicado la resonancia magnética fMRI para localizar las regiones activas dentro del cerebro [51]. Sin embargo, la fMRI tiene una resolución temporal baja de aproximadamente $1 \mathrm{o} 2$ segundos. Además, la respuesta hemodinámica introduce un retardo fisiológico de 3 a 6 segundos [52]. La fMRI parece no ser adecuada para la comunicación rápida en sistemas de $\mathrm{BCI}$ y es altamente susceptible a los artefactos producidos por ejemplo por movimiento de la cabeza.

En los sistemas de BCI, la resonancia magnética fMRI se utiliza típicamente para medir el nivel de oxígeno en sangre dependiente (BOLD) durante la activación neuronal [53] y aunque la señal BOLD no está directamente relacionada con la actividad neuronal, sí existe una correspondencia entre ambas [54]. El uso de fMRI en la tecnología de BCI es relativamente reciente, los datos obte- 
nidos por esta técnica se procesan offline y requiere de un hardware demasiado voluminoso y caro.

\subsubsection{Espectroscopia Infrarroja Cercana (NIRS).}

La NIRS es un método de espectroscopia óptica que emplea luz infrarroja para caracterizar las fluctuaciones no invasivas adquiridas en el metabolismo cerebral durante la actividad neuronal. La luz infrarroja penetra en el cráneo a una profundidad de aproximadamente $1-3 \mathrm{~cm}$ por debajo de su superficie, donde la intensidad de la luz atenuada permite medir las alteraciones en las concentraciones de oxihemoglobina y deoxihemoglobina.

Debido a la penetración superficial de la luz en el cerebro, esta técnica de neuroimagen óptica se limita a la capa cortical externa. Una de las principales limitaciones del NIRS es la naturaleza de la respuesta hemodinámica, ya que los cambios vasculares ocurren un cierto número de segundos después de su actividad neuronal asociada [56]. La resolución espacial del NIRS es bastante baja, en el orden de $1 \mathrm{~cm}$ [57]. Sin embargo, NIRS ofrece un bajo costo, alta portabilidad y una resolución temporal aceptable en el orden de 100 milisegundos [58]. Un sistema NIRS consiste en una fuente de luz, un dispositivo electrónico de conducción, un detector de luz, dispositivos de procesamiento de señales y un dispositivo de grabación. La fuente de luz es un diodo emisor infrarrojo (IRED) en contacto directo con el cuero cabelludo.

El dispositivo electrónico de conducción es un circuito electrónico que controla el IRED para modular la luz y el detector de luz es un fotodiodo situado justo al lado de la fuente de luz. Los dispositivos de procesamiento de señales son amplificadores y filtros que procesan la señal eléctrica y reducen el ruido causado por la luz ambiental. El dispositivo de grabación es un PC o cualquier otro dispositivo que digitalice, almacene y muestre la señal. Lo que complica este método es asegurar un buen acoplamiento de la luz de las fuentes ópticas y detectores que se producen hacia y desde la cabeza del sujeto, debido a los movimientos de la cabeza o la obstrucción del cabello que pueden empeorar el rendimiento y la calidad de la señal [56]. Aunque el NIRS es una modalidad de medición relativamente nueva, promete ser una potente modalidad de neuroimagen para aplicarse en BCI [59, 61]. Esta modalidad de neuroimagen podría ser una buena alternativa al EEG, ya que no se requiere gel conductor ni electrodos corrosivos. No obstante, las velocidades de comunicación en los BCI basados en NIRS son limitadas debido a los retrasos inherentes de la respuesta hemodinámica. Algunos estudios ya han demostrado la viabilidad de la detección de tareas mentales mediante respuestas ópticas derivadas del NIRS [55, 60, 147, 61]. 


\section{Capítulo 4}

\section{Sistemas Cerebro-ordenador (Brain Computer Interface)}

\subsection{Introducción.}

Si tenemos en cuenta que todas las tareas cognitivas que ejecuta nuestro sistema nervioso parten del cerebro, no debería ser un obstáculo poder realizar una acción de movimiento por no disponer, en su caso, de alguna extremidad que lo impida físicamente, pues si somos capaces de captar la señal del cerebro que activa ese movimiento en la extremidad, podremos activar el mecanismo necesario para hacer realidad ese movimiento de forma artificial mediante dispositivos externos.

Quizá algún pensamiento de este tipo motivó que a principios del siglo XX, en 1906 concretamente, al médico español Ramón y Cajal (1852-1934) le valiera el premio Nobel de Medicina (compartido con Camillo Golgi ,1843-1926) una revolucionaria teoría sobre la organización y estructura del cerebro. Esta se basaba en que el cerebro se compone de una serie de células independientes, las neuronas, que se pueden comunican entre sí mediante unos contactos funcionales denominados sinapsis). Era el principio básico de la estructura del sistema nervioso. Este y otros estudios permitieron asentar las bases de la Electroencefalografía.

Posteriormente, el profesor Hans Berger (1873-1941), por su parte, fue el primer científico que realizó un electroencefalograma a un ser humano en 1924 y también probó la existencia de los ritmos Alfa y Beta (parte de las ondas cerebrales) en 1929.

William Grey Walter (1910-1977) perfeccionó el funcionamiento de la máquina de electroencefalografía inicial de Berger, añadiéndole más electrodos, tubos CRT y amplificadores. Así consiguió la representación de mapas de actividad cerebral, localizando la intensidad y frecuencia de los diversos ritmos (ondas) y fue, sin dudad, una herramienta útil en el diagnóstico clínico de enferme- 
dades mentales como por ejemplo la epilepsia.

También científicos como el japonés Hirai Tomio (1927-1933) estudió que mediante la meditación trascendental Zen se podían modificar las señales (ondas) cerebrales, lo que impulsó el desarrollo del biofeedback. Aunque es Neal Millar quien es considerado el padre del biofeedback, que es la técnica donde el paciente puede modificar su actividad cerebral a voluntad mediante una serie de dispositivos o estímulos externos (visuales o auditivos).

Entre los primeros estudios dedicados a este tipo de técnicas hay varios, como Joe Kamiya y David Nowlis en 1970 o Mulholland y Brown también en 1970 que proponen experimentos donde el sujeto aprendía a modificar la energía del ritmo alfa de forma voluntaria usando como biofeedback estímulos auditivos.

Más adelante, en 1974, Sterman, desarrolló un sistema de autocontrol mediante biofeedback de otros ritmos como el ritmo sensorimotor o ritmo mu (pieza fundamental en esta Tesis). En resumen, si con la ayuda del feedback (realimentación) un paciente era capaz de modificar voluntariamente su patrón de actividad cerebral, puede por tanto generar información y si se puede registrar, codificar y procesar se pueden generar códigos o comandos para dar una serie de órdenes, por ejemplo a dispositivos. Esto constituye la base de un sistema bidireccional cerebro ordenador, y de aquí nacen los sistemas BCI.

\subsection{Descripción de un sistema BCI.}

Un sistema BCI es, por tanto, un sistema de comunicación de hardware y software que permite a los seres humanos interactuar con su entorno, sin la participación de nervios y músculos periféricos, mediante el uso de señales de control generadas por la actividad electroencefalográfica [2]. El BCI crea un nuevo canal no muscular para transmitir las intenciones de una persona a dispositivos externos como computadoras, sintetizadores de voz, aparatos de asistencia y prótesis neuronales [4]. Esto resulta especialmente atractivo para las personas con discapacidades motoras graves, pues estos dispositivos mejorarían su calidad de vida y, al mismo tiempo, reduciría el coste de los cuidados intensivos.

Con el fin de implementar estos sistemas, se suele recurrir a esquemas similares al recogido en la Figura 4.2.1. Dentro de ellos, se incluye un sistema de inteligencia artificial o de reconocimiento de patrones compuesto de varias etapas consecutivas: Adquisición de señales, Preprocesamiento o mejora de señales, Extracción de Características, Clasificación e Interfaz de Control y Realimenta- 
ción [1].

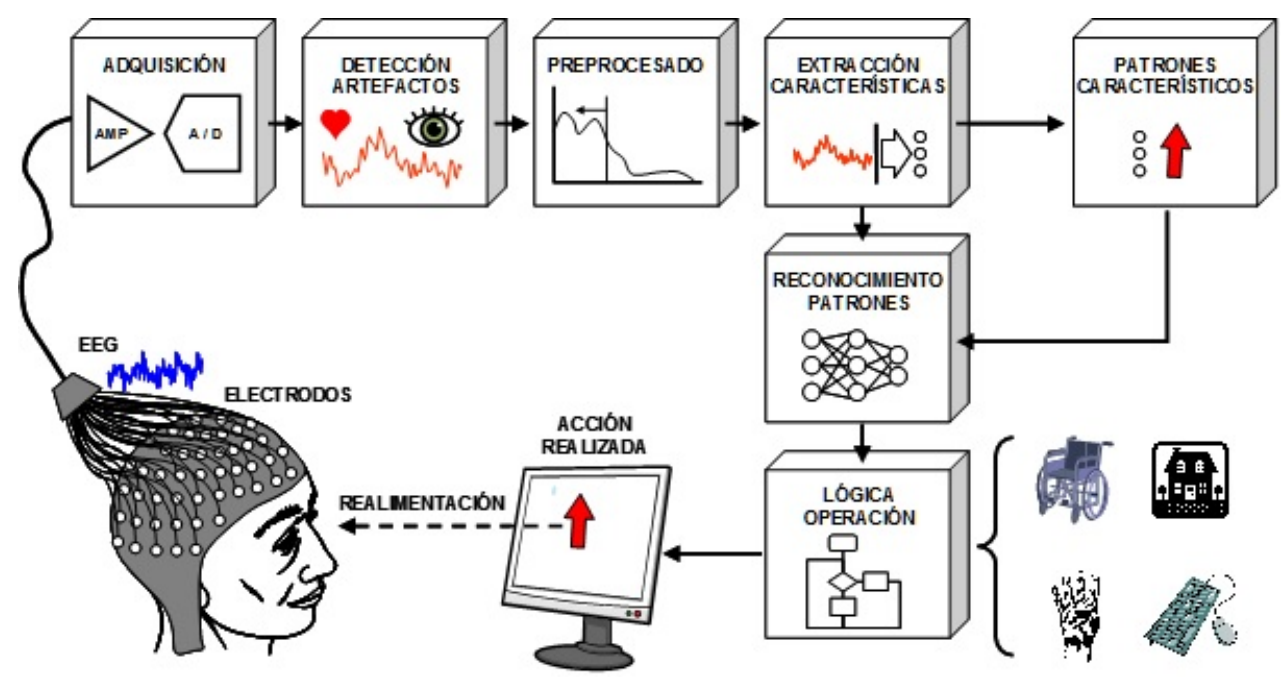

Figura 4.2.1: Ejemplo de un sistema BCI completo.

La etapa de Adquisición de Señal captura las señales cerebrales y también puede llevar a cabo la reducción del ruido y el procesamiento de artefactos. En esta etapa se suelen emplear electrodos que se ubican sobre el cuero cabelludo (en técnicas no invasivas) siguiendo un patrón predefinido en función de las tareas o estímulos que recibe el usuario.

La etapa de Detección de Artefactos trata de detectar y eliminar artefactos tanto fisiológicos, producidos por el mismo usuario, como externos, como por ejemplo el ruido de la red eléctrica. En ocasiones estas tareas se encuentran incluidas dentro de la etapa de Preprocesado. La etapa de preprocesamiento trata de preparar las señales en una forma adecuada para el posterior procesado.

El siguiente paso es la Extracción de Características, que trata mediante diversas técnicas y algoritmos de identificar y extraer la información discriminatoria de las señales cerebrales que se han registrado. Una vez extraídas las características, se conforma un vector que contiene información efectiva y discriminante de las señales observadas. Se debe tener en cuenta en este punto, que no es tarea fácil extraer la información adecuada, pues las señales cerebrales de interés para el sistema, se mezclan con otras señales provenientes de un conjunto finito de actividades cerebrales, que se superponen en el tiempo y el espacio. Además, la señal cerebral no es estacionaria y, también puede estar distorsionada por artefactos si no han sido totalmente eliminados en etapas anteriores. Idealmente, el vector de características debe tener una baja dimensionalidad, a fin de no incrementar la complejidad de esta etapa ni la del clasificador que le sigue. Para ello, se implementan técnicas de reducción o de selección de características. Sin embargo, el conseguir una baja dimensionalidad no debe de provocar una pérdida de información relevante. 
La etapa de Clasificación trabaja con las señales teniendo en cuenta los vectores de características relevantes de la señal. Por lo tanto, la elección de buenas características discriminatorias es esencial para lograr un reconocimiento efectivo del patrón, a fin de descifrar las intenciones del usuario. En este bloque se implementan múltiples técnicas de clasificación y estrategias de validación. Además, es habitual realizar un ajuste tanto de esta etapa como en ocasiones de la anterior con el objetivo de aumentar los rendimientos en clasificación de las señales de cada usuario.

A continuación, el sistema genera la salida correspondiente al estado cerebral detectado, que dependerá de la lógica de operación utilizada. Los comandos pueden servir para realizar acciones con cualquier dispositivo conectado, como una silla de ruedas o un ordenador. Finalmente, se cierra un bucle al recibir el usuario la información sobre la acción realizada por el sistema, por medio de una pantalla que presenta el resultado del sistema, u observando las acciones implementadas por la lógica de control.

\subsection{Tipos de señales de control en BCIs.}

El propósito de un BCI es interpretar las intenciones del usuario mediante la monitorización de la actividad cerebral. Las señales cerebrales implican numerosos fenómenos simultáneos relacionados con las tareas cognitivas. La mayoría de ellos son todavía incomprensibles y sus orígenes desconocidos. Sin embargo, los fenómenos fisiológicos de algunas señales cerebrales han sido decodificados de tal manera que las personas pueden aprender a modularlas a voluntad, para permitir a los sistemas de BCI interpretar sus intenciones. Estas señales se consideran posibles señales de control en los BCI.

Numerosos estudios han descrito un vasto grupo de señales cerebrales que podrían servir como señales de control en los sistemas de BCI. Sin embargo, sólo las señales de control empleadas en los sistemas BCI actuales serán discutidas a continuación: Potenciales Visuales Evocados (VEP, del inglés Visual Evoked Potential), Potenciales Corticales Lentos (SCP del inglés Slow Cortical Potential), Potenciales Evocados (P300) y Ritmos Sensoriales. La Tabla 4.3.1 resume todas las señales de control empleadas en sistemas BCI junto con el fenómeno fisiológico asociado, la necesidad de entrenamiento y la Tasa de Transferencia de información que pueden aportar.

Tal y como se puede observar, la mayor transferencia de información se obtiene con VEP, con 60-100 bits/min, seguido de los Ritmos Sensoriales con 3-35 bits/min. Lo que no sindica que no son sistemas rápidos. Por otra parte, es interesante destacar que SCP y los Ritmos sensoriales requieren 


\begin{tabular}{|c|c|c|c|}
\hline Señal & Fenómeno Fisiológico & Entrenamiento & $\begin{array}{c}\text { Tasa de transferencia de la } \\
\text { información }\end{array}$ \\
\hline VEP & $\begin{array}{c}\text { Modulaciones de la señal cerebral en la corteza } \\
\text { visual }\end{array}$ & No & $60-100 \mathrm{bits} / \mathrm{min}$ \\
\hline $\mathrm{SCP}$ & $\begin{array}{l}\text { Los voltajes lentos cambian en las señales } \\
\text { cerebrales }\end{array}$ & $\mathrm{Si}$ & $5-12 \mathrm{bits} / \mathrm{min}$ \\
\hline P300 & Picos positivos debido a estímulos infrecuentes & No & $20-25 \mathrm{bits} / \mathrm{min}$ \\
\hline $\begin{array}{l}\text { Ritmos } \\
\text { sensorial- } \\
\text { motores }\end{array}$ & $\begin{array}{l}\text { Modulaciones en ritmos sensorialimotores } \\
\text { sincronizados con actividades motoras }\end{array}$ & $\mathrm{Si}$ & $3-35 \mathrm{bits} / \mathrm{min}$ \\
\hline
\end{tabular}

Figura 4.3.1: Tipos de Señales de Control aplicadas a sistemas BCI, Fenómeno Fisiológico, Necesidad de Entrenamiento y Tasa de transferencia de la información.

de entrenamiento, mientras que las otras señales no lo necesitan.

A continuación se puede encontrar una descripción más extensa de los distintos tipos de señales usados en BCI.

\subsubsection{Potenciales Visuales Evocados (VEPs).}

Los VEPs son modulaciones de la actividad cerebral que se producen en la corteza visual después de recibir un estímulo visual [62]. Estas modulaciones son relativamente fáciles de detectar ya que la amplitud de los VEPs aumenta enormemente a medida que el estímulo se acerca al campo visual central [148].

Pueden clasificarse según tres criterios diferentes [63]: i) por la morfología de los estímulos ópticos, ii) por la frecuencia de la estimulación visual y iii) por la estimulación de campo. Según el primer criterio, los VEPs pueden ser causados por el uso de estimulación flash o mediante patrones gráficos como celosía de tablero de damas, puerta y mapa de puntos aleatorios. De acuerdo con la frecuencia, los VEPs también pueden clasificarse como VEPs transitorios (TVEPs) y como VEPs de estado estable (SSVEPs). Las TVEP se producen cuando la frecuencia de estimulación visual es inferior a $6 \mathrm{~Hz}$, mientras que los SSVEPs se producen en reacción a estímulos de una frecuencia más alta $[62,64]$. Por último, de acuerdo con el tercer criterio, los VEPs pueden dividirse en VEPs de campo entero, VEPs de campo medio y VEPs de campo parcial, dependiendo del área de estímulo en pantalla. Por ejemplo, si sólo la mitad de la pantalla muestra gráficos, la otra mitad no mostrará ninguna estimulación visual, y la persona mirará al centro de la pantalla, lo que inducirá un VEP de medio campo. 
Los TVEP pueden ser provocados por cualquier cambio en el campo visual. Los que se usan con mayor frecuencia son: (i) los TVEPs de destello que son causados por luces intermitentes; (ii) los TVEPs de inicio/desconexión de patrones que son causados por dejar que un patrón aparezca abruptamente en un fondo difuso; y (iii) los TVEPs de retroceso de patrones que son causados por la inversión de la fase de un patrón, es decir, los TVEPs de retroceso de patrones, un tablero de ajedrez que cambia los cheques de negro a blanco y de blanco a negro abruptamente [65].

Las respuestas evocadas varían según el estímulo presentado. Los TVEPs flash presentan una serie de picos negativos y positivos. Los picos más prominentes son negativos (N2) y positivos (P2) en torno a los siguientes valores $90 \mathrm{~ms}$ y $120 \mathrm{~ms}$ respectivamente [65]. Los TVEPs de inicio/desconexión de patrones tienen tres picos principales: C1 (positivo, $75 \mathrm{~ms}$ ), C2 (negativo, 125 ms), y C3 (positivo, $150 \mathrm{~ms}$ ) [65]. Los programas TVEP de reversión de patrones suelen presentar un pico negativo a $75 \mathrm{~ms}$, un pico positivo a $100 \mathrm{~ms}$ y un pico negativo a $135 \mathrm{~ms}$ [65].

por otra parte, los SSVEPs son provocados por el mismo estímulo visual. En este caso, el estímulo cambia a una frecuencia superior a $6 \mathrm{~Hz}$. Si el estímulo es un destello, SSVEP muestra una forma de onda sinusoidal, cuya frecuencia fundamental es la misma que la frecuencia intermitente del estímulo. Si el estímulo es un patrón, el SSVEP ocurre a la velocidad inversa y en sus armónicos [66]. A diferencia de la TVEP, los componentes de frecuencia discreta constituyentes de los SSVEPs permanecen estrechamente constantes en amplitud y fase durante largos períodos de tiempo [67]. Los SSVEPs son menos susceptibles que los TVEPs a los artefactos producidos por parpadeos y movimientos de los ojos [68] y a la contaminación por ruido electromiográfico [69]. De hecho, las TVEP no se utilizan normalmente para BCI.

Los BCI basados en SSVEP permiten a los usuarios seleccionar un objetivo mediante una mirada. El usuario fija visualmente la atención en un objetivo y el BCI lo identifica a través del análisis de características SSVEP. Considerando al sistema BCI como canal de comunicaciones, los BCI basados en SSVEP pueden clasificarse en tres categorías dependiendo de la modulación de secuencia de estímulo específica en uso [158]: BCI modulados en tiempo (t-VEP), BCI modulados en frecuencia (f-VEP) y BCI modulados en código pseudoaleatorio (c-VEP). Las VEP que reaccionan a diferentes secuencias de estímulo deben ser ortogonales o casi ortogonales entre sí en algún dominio para garantizar una identificación fiable del objetivo [158]. En un BCI t-VEP, las secuencias de destello de diferentes objetivos son ortogonales en el tiempo. Es decir, las secuencias de destello para diferentes objetivos son estrictamente no solapadas o estocásticas. En un f-VEP BCI, cada objetivo es destellado a una frecuencia única, generando una secuencia periódica de respuestas evocadas con la misma frecuencia fundamental que sus armónicos. En un BCI c-VEP se utilizan secuencias pseudoaleatorias. La duración de los estados ON y OFF de la señal de inicio de cada 
prueba viene determinada por una secuencia pseudoaleatoria. Las modulaciones de señal pueden optimizar la velocidad de transferencia de información. De hecho, la modulación de código proporciona la mayor velocidad de comunicación. La siguiente Figura 4.3.2 resume las características de cada tipo de VEP en función de su modulación y las características más relevantes.

\begin{tabular}{c|l}
\hline Modulación VEP & \multicolumn{1}{c}{ Características relevantes } \\
\hline \multirow{3}{*}{ t-VEP } & -Tasa de transferencia de información relativamente baja ( $<30 \mathrm{bits} / \mathrm{min})$ \\
& -Es necesaria una señal sincrónica- \\
& -No requiere formación del usuario \\
\hline \multirow{3}{*}{ f-VEP } & -Alta velocidad de transferencia de información (30-60 bits $/ \mathrm{min})$ \\
& -Configuración sencilla del sistema \\
& -No requiere formación del usuario \\
& -Más adecuado para la aplicación con pocas opciones \\
\hline \multirow{3}{*}{$\mathrm{c}-\mathrm{VEP}$} & -Tasa de transferencia de información muy alta $(>100 \mathrm{bits} / \mathrm{min})$ \\
& -Es necesaria una señal sincrónica \\
& -Formación del usuario requerida \\
& -Más adecuado para la aplicación con muchas opciones \\
\hline
\end{tabular}

Figura 4.3.2: Modulaciones VEP y características principales.

La aplicación típica de BCI basada en VEP muestra estímulos intermitentes, como dígitos o letras, en una pantalla para inducir SSVEPs mientras el usuario observa uno de los símbolos. El usuario puede mover su mirada a los dígitos o letras intermitentes, para comunicarse con el ordenador [69]. La ventaja de este tipo de señal de control es que requiere muy poco entrenamiento. Sin embargo, presenta el inconveniente de que el usuario tiene que mirar la pantalla y mantener los ojos fijos en un punto. Por lo tanto, las VEP no son adecuadas para pacientes en estadios avanzados de esclerosis lateral amiotrófica o con movimientos incontrolables de los ojos o el cuello. Se han introducido algunos BCI independientes basados en SSVEP que son controlados por la atención del usuario para superar este inconveniente [71,72].

Los SSVEP generalmente se obtienen a través de diodos emisores de luz (LEDs) o pantallas de cristal líquido (LCD). Los LEDs superan a los estimuladores LCD pero necesitan un hardware más complejo. Los estimuladores LED ofrecen una mayor versatilidad, ya que la frecuencia de parpadeo y la fase de cada LED pueden controlarse independientemente mediante un dispositivo lógico programable [70].

En estos sistemas la decisión del tipo de estimulación a realizar se puede tomar sobre la base del número de electrodos que ofrece el equipamiento de adquisición de señal EEG disponible [74]. En general, las pantallas de LCD son óptimas para equipos con pocos electrodos (menos de 10 
electrodos), porque inducen menos cansancio ocular que las pantallas obsoletas de CRT (tubos de rayos catódicos). Para equipos con un número intermedio de electrodos (10-20), las pantallas LCD son óptimas, pero para equipos más complejos, se prefieren los Leds.

\subsubsection{Potenciales corticales lentos (SCPs).}

Los SCPs son cambios de tensión lentos en el EEG que duran de un segundo a varios segundos. Los SCPs pertenecen a la parte de las señales del EEG que tienen frecuencias inferiores a $1 \mathrm{~Hz}$ [73]. Los SCPs están asociados con cambios en el nivel de actividad cortical. Los SCPs negativos se correlacionan con el aumento de la actividad neuronal, mientras que los SCPs positivos coinciden con la disminución de la actividad en las células individuales [75]. Estas señales cerebrales pueden ser auto-reguladas tanto por usuarios sanos como por pacientes paralizados para controlar dispositivos externos mediante sistemas BCI.

Las variaciones del SCP se pueden utilizar para mover un cursor y seleccionar los objetivos presentados en una pantalla de ordenador [76], por lo que las personas pueden ser entrenadas para generar cambios voluntarios de SCPs utilizando un dispositivo de traducción de pensamiento [77]. El dispositivo de traducción de pensamiento es una herramienta utilizada para la auto-regulación en el entrenamiento SCP, que muestra marcas visuales y auditivas para que el usuario pueda aprender a cambiar el SCP. El dispositivo de traducción del pensamiento se compone típicamente de un cursor en una pantalla, de tal manera, que la posición vertical del cursor refleja constantemente la amplitud de los cambios de SCP. Aunque la mayoría de los dispositivos de traducción muestran realimentación continua, es posible entrenar la automodulación SCP en ausencia de ella [77].

El éxito en el entrenamiento de autorregulación de SCP depende de numerosos factores, tales como el estado psicológico y físico del paciente, su motivación, su contexto social o la relación entre el capacitador y el paciente [76]. Se sabe que la capacidad de aprendizaje del usuario afecta drásticamente al entrenamiento de modulación SCP. Por lo tanto, se recomienda encarecidamente la formación en autorregulación a los pacientes en la fase inicial de una enfermedad progresiva [76]. Además, las habilidades iniciales de modulación SCP tienen un efecto en el rendimiento futuro después de la formación [78]. Por lo tanto, el valor de los SCP como señal de control adecuada para cada paciente sólo puede determinarse sobre la base de ensayos iniciales. Otros factores, como la calidad del sueño, el dolor y el estado de ánimo también influyen en el rendimiento de la autorregulación [76].

La autorregulación de los SCP se ha probado ampliamente en pacientes que sufren de ELA $[77,78,79]$. Las tasas de precisión típicas alcanzadas en la clasificación de SCPs son aceptables y 
varían entre el $70 \%$ y el $80 \%$, pero las tasas de información proporcionadas por el BCI basado en SCP son relativamente bajas. Además, se requiere una formación más prolongada para utilizar BCI basada en SCP y es probable que los usuarios necesiten una práctica continua durante varios meses. Sus efectos no son idénticos para todos los pacientes y, sin duda, es necesario seguir investigando para establecer normas generales al respecto.

\subsubsection{P300 Potenciales evocados.}

Los potenciales evocados P300 son picos positivos en el EEG debido a estímulos auditivos, visuales o somato-sensoriales infrecuentes. Estas respuestas endógenas P300 se obtienen unos 300 ms después de atender a un estímulo extraño entre varios estímulos frecuentes [81, 82]. Algunos estudios han demostrado que cuanto menos probable sea el estímulo, mayor será la amplitud del pico de respuesta [153]. El uso de BCI basados en P300 no requiere de entrenamiento. Sin embargo, el rendimiento puede reducirse porque el usuario se acostumbra al estímulo infrecuente y consecuentemente disminuye la amplitud P300 [83].

Una aplicación típica de un BCI basada en potenciales evocados visuales P300 comprende una matriz de letras, números u otros símbolos o comandos [81, 84, 85]. Las filas o columnas de esta matriz parpadean al azar mientras se monitoriza el EEG. El usuario mira el símbolo deseado y cuenta cuántas veces parpadea la fila o columna que contiene la selección deseada. El P300 sólo se obtiene cuando la fila o columna deseada parpadea. Por lo tanto, el sistema BCI utiliza este efecto para determinar el símbolo de destino. Debido a la baja relación señal/ruido en las señales de EEG, la detección de los símbolos objetivo de una sola prueba es muy difícil. Por ello, las filas o columnas deben parpadear varias veces para cada opción. Las épocas correspondientes a cada fila o columna se promedian sobre las pruebas, con el fin de mejorar su precisión. Sin embargo, estas repeticiones disminuyen el número de opciones por minuto, por ejemplo, con 15 repeticiones, sólo se escriben dos caracteres por minuto [81]. Aunque la mayoría de las aplicaciones basadas en potenciales evocados P300 emplean estímulos visuales, los estímulos auditivos se han utilizado para las personas con discapacidad visual [86].

Tal y como se ha comentado anteriormente, los BCI basados en P300 proporcionan una tasa muy baja de transmisión de información porque el clasificador basado en un promedio es demasiado simple, y la precisión de la detección potencial del P300 es demasiado baja [87]. En consecuencia, se requieren demasiados ensayos para seleccionar un solo símbolo en la matriz. Se puede mejorar la precisión de los $\mathrm{BCI}$ basados en $\mathrm{P} 300$, al tiempo que se utiliza un clasificador más complicado que una media simple para garantizar que el número de repeticiones no se vea afectado [87, 89]. Otros estudios han demostrado que la precisión de detección de los potenciales evocados por el 
visual P300 también depende de las propiedades de la matriz visual, tales como las dimensiones o colores de los símbolos. El rendimiento disminuye cuando se utilizan matrices con símbolos más pequeños [88], y aumenta cuando se utiliza una matriz de parpadeos cromáticos verde y azul, en lugar de una gris y negra $[89,90]$.

Las tasas de transmisión de la información proporcionadas por el BCI basado en P300 también pueden mejorarse considerando el BCI como un sistema de transmisión ruidoso. Por lo tanto, BCI puede beneficiarse del uso de códigos de corrección de errores [91]. Sin embargo, la optimización del código únicamente de acuerdo con la distancia máxima de Hamming mínima, implica un aumento en la frecuencia objetivo de los estímulos objetivo, lo que podría violar las limitaciones fisiológicas que dificultan la clasificación de los ERP individuales, debido a la superposición y a los efectos refractarios. Además, el solapamiento y los efectos refractarios son generalmente la principal fuente de error en estos tipos de BCI [92]. Algunos enfoques novedosos recientes han intentado reducirlos, superponiendo los objetivos sobre un tablero de damas [93] o utilizando métodos alternativos de estímulo basados en el movimiento [92].

Además, el rendimiento de un BCI basado en P300 mejora sustancialmente cuando los sujetos miran fijamente al elemento deseado [94]. Por lo tanto, el rendimiento de los BCIs visuales basados en P300 no sólo depende del potencial evocado por el P300, sino también de la respuesta VEP que, a su vez, depende en gran medida de la dirección de la mirada.

\subsubsection{Ritmos Sensorimotores (ritmos $\mu$ y $\beta$ )}

Los ritmos sensorimotores comprenden los ritmos $\mu$ y $\beta$, que son oscilaciones de la actividad cerebral localizadas en la banda mu $(7-13 \mathrm{~Hz})$, también conocida como banda Rolandic, y banda beta $(13-30 \mathrm{~Hz})$, respectivamente. Ambos ritmos están asociados de tal manera que algunos ritmos Beta son ritmos mu armónicos, aunque algunos ritmos beta también pueden ser independientes [95].

La amplitud de los ritmos sensorimotores varía cuando la actividad cerebral está relacionada con cualquier tarea motora, aunque no se requiere movimiento real para modular la amplitud de los mismos [96, 97].

Los ritmos sensorimotores se han utilizado para controlar los BCIs, porque las personas pueden aprender a generar estas modulaciones voluntariamente [93, 98]. Los ritmos sensorimotores pueden soportar dos tipos de modulaciones de amplitud conocidas como desincronización relacionada con eventos (ERD) y sincronización relacionada con eventos (ERS), que se generan mediante estimulación sensorial, comportamiento motor e imágenes mentales [19]. El ERD implica una supresión 
de amplitud del ritmo y el ERS implica un realce de amplitud.

Los ritmos sensorimotores están relacionados con la imaginación de movimiento motor sin ningún movimiento real [97]. Esto permite utilizarlos para el diseño de los BCI endógenos, que son más útiles que los BCI exógenos. Sin embargo, el autocontrol de los ritmos sensorimotores no es fácil, y la mayoría de las personas tienen dificultades con la imaginación de movimiento de su cuerpo. Las personas tienden a imaginar imágenes visuales de movimientos reales relacionados, que no son suficientemente útiles para un sistema de BCI, porque los patrones de estos ritmos difieren de la imaginación de movimiento real.

La capacitación de los usuarios debe enfatizar las experiencias kinestésicas (capacidad para usar el cuerpo para expresar sentimientos e ideas, así como la habilidad para producir o transformar cosas con las manos) en lugar de las representaciones visuales de las acciones [99]. El entrenamiento en imaginación de movimiento se basa tradicionalmente en la realimentación visual o auditiva [4]. Este tipo de entrenamiento pide a los usuarios que realicen una determinada tarea y luego se extraen los ritmos sensorimotores y se clasifican comparándolos con una referencia.

Finalmente, la realimentación visual o auditiva se proporciona al participante de acuerdo con el éxito del resultado. Este tipo de entrenamiento ha sido ampliamente utilizado, aunque generalmente su efectividad no era muy alta [100]. Hwang y otros [99] presentaron un entrenamiento de imaginación de movimiento más efectivo basado en un sistema que mostraba la actividad cortical en tiempo real como realimentación, lo que permitía a los usuarios observar su propia actividad cortical a través de un sistema de monitoreo en tiempo real.

Los ritmos sensorimotores han sido ampliamente investigados en la investigación del BCI. Los sistemas de BCI bien conocidos como Wadsworth [4], Berlín [100] o Graz [101] utilizan ritmos sensorimotores como señales de control. Estos BCI pueden funcionar en modo síncrono o asíncrono. Los últimos avances en el campo de los BCIs basados en ritmos sensorimotores han demostrado que es posible predecir los movimientos voluntarios humanos antes de que ocurran basados en las modulaciones de dichos ritmos [102]. Además, esta predicción podría realizarse sin que el usuario realice ningún movimiento.

En esta Tesis se ha trabajado con sistemas BCI basados en ritmos sensorimotores.

\subsection{Tipos de BCI.}

Los BCI pueden clasificarse en (i) exógenos o endógenos y (ii) síncronos o asíncronos. Los tipos de BCI se resumen en la Figura 4.4.1, junto con la información relacionada con las señales cere- 
brales que pueden ser moduladas para transmitir información, así como las ventajas y desventajas. Además, los sistemas BCI pueden clasificarse en dependientes e independientes [2]. Esta distinción no será detallada en esta revisión porque es muy similar a la distinción exógena y endógena. Las ventajas y desventajas en ambas taxonomías son análogas.

\begin{tabular}{|c|c|c|c|}
\hline Tipo de BCI & Señales cerebrales & Ventajas & Inconvenientes \\
\hline BCI Exogenos & $\begin{array}{l}\text { - SSVEP } \\
\text { - P300 }\end{array}$ & $\begin{array}{l}\text {-Formación mínima } \\
\text {-Configuración fácil y rápida de la señal } \\
\text { de control } \\
\text {-Alta velocidad de bits ( } 60 \mathrm{bits} / \mathrm{min}) \\
\text {-Sólo se requiere un canal EEG }\end{array}$ & $\begin{array}{l}\text {-Atención permanente a estímulos externos } \\
\text {-Puede causar cansancio en algunos usuarios }\end{array}$ \\
\hline BCI Endogenos & $\begin{array}{l}\text { - SCPs } \\
\text { - Ritmos sensorimotores }\end{array}$ & $\begin{array}{l}\text {-Independiente de cualquier estimulación } \\
\text {-Funcionamiento a voluntad } \\
\text {-Útil para usuarios con órganos } \\
\text { sensoriales afectados } \\
\text {-Adecuado para aplicaciones de } \\
\quad \text { control de cursor }\end{array}$ & $\begin{array}{l}\text {-Entrenamiento que requiere mucho tiempo } \\
\text { (meses o semanas) } \\
\text {-No todos los usuarios pueden obtener el control. } \\
\text {-Grabaciones de EEG multicanal necesarias para un } \\
\text { buen rendimiento } \\
\text {-Velocidad de bits inferior ( } 20-30 \mathrm{bits} / \mathrm{min})\end{array}$ \\
\hline
\end{tabular}

Figura 4.4.1: Ventajas e inconvenientes de los tipos BCI Exógenos y Endógenos.

Tal y como se ha mencionado anteriormente, según la naturaleza de las señales utilizadas como entrada, los sistemas BCI pueden clasificarse como exógenos o endógenos. El BCI exógeno utiliza la actividad neuronal obtenida en el cerebro mediante un estímulo externo como las PEV o los potenciales evocados auditivos [103]. Los sistemas exógenos no requieren un entrenamiento intensivo ya que sus señales de control, SSVEPs y P300, se obtienen de forma fácil y rápida.

Además, la señal de control puede obtenerse por un solo canal de EEG y pueden alcanzar una velocidad de transferencia de información de hasta 60 bits/min. Por otra parte, el BCI endógeno se basa en la autorregulación de los ritmos y potenciales cerebrales sin estímulos externos [103]. A través del entrenamiento y de la realimentación, los usuarios aprenden a generar patrones cerebrales específicos que pueden ser decodificados por el BCI, tales como modulaciones en los ritmos sensorimotores [104] o los SCPs [76]. La ventaja de un BCI endógeno es que el usuario puede manejar el sistema BCI a su libre albedrío y mover un cursor a cualquier punto en un espacio bidimensional, mientras que un BCI exógeno limita al usuario a las opciones presentadas. Además, los sistemas BCI endógenos son especialmente útiles para usuarios con ELA avanzada o cuyos órganos sensoriales están afectados.

También se ha comentado anteriormente que según la modalidad de procesamiento de datos de entrada, los sistemas BCI pueden clasificarse como síncronos o asíncronos. Los BCI síncronos analizan las señales cerebrales durante las ventanas temporales predefinidas. Mientras que cualquier 
señal cerebral fuera de la ventana predefinida es ignorada. Por lo tanto, el usuario sólo puede enviar comandos durante períodos específicos determinados por el sistema BCI. Por ejemplo, el "Graz

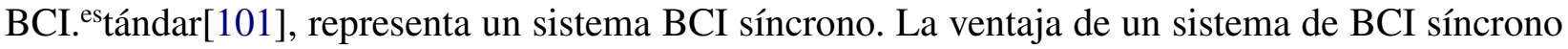
es que el inicio de la actividad mental se conoce de antemano y se asocia con una señal específica [105]. Además, los pacientes también pueden realizar parpadeos y otros movimientos oculares fuera de los tiempos de interés, con lo que se evita la generación de artefactos. Esto simplifica el diseño y la evaluación del BCI síncrono.

Los BCIs asíncronos analizan continuamente las señales cerebrales sin importar cuando el usuario actúa. Ofrecen un modo más natural de interacción hombre-máquina que los BCI síncronos. Sin embargo, los BCI asíncronos son más exigentes y complejos en cuanto a la computación. La Figura 4.4.2 resume las diferencias entre BCI síncronos y asíncronos comentados anteriormente.

\begin{tabular}{|c|l|l|}
\hline Tipo de BCI & \multicolumn{1}{|c|}{ Ventajas } & \multicolumn{1}{c|}{ Inconvenientes } \\
\hline BCI síncrono & $\begin{array}{l}\text {-Diseño más sencillo y evaluación del rendimiento } \\
\text {-El usuario puede evitar la generación de artefactos ya que puede } \\
\text { realizar parpadeos y otros movimientos oculares cuando no se } \\
\text { analizan las señales cerebrales. }\end{array}$ & -No ofrece un modo de interacción natural \\
BCI asíncrono & $\begin{array}{l}\text {-Sin necesidad de esperar señales externas } \\
\text {-Ofrece un modo de interacción más natural }\end{array}$ & -Diseño mucho más complicado \\
& -Evaluación más difícil \\
\hline
\end{tabular}

Figura 4.4.2: Principales Ventajas e Inconvenientes de los BCIs síncronos y asíncronos.

En esta Tesis, en los experimentos realizados se ha utilizado un sistema Síncrono, con las ventajas e inconvenientes que ello conlleva.

\subsection{Aplicaciones de los sistemas BCI.}

Los sistemas BCI ofrecen a sus usuarios nuevos canales de comunicación y control sin intervención de nervios y músculos periféricos. Por lo tanto, muchos investigadores se enfocan en construir aplicaciones de BCI, con la esperanza de que esta tecnología pueda ser útil para aquellos con discapacidades motoras severas. Varias aplicaciones de BCI han sido desarrolladas recientemente gracias a los importantes avances en el campo del BCI basado en EEG. Las señales EEG son utilizadas por la mayoría de las aplicaciones BCI, porque ofrecen una calidad de señal aceptable que combina un bajo coste y equipos fáciles de usar.

Las principales poblaciones objetivo de las aplicaciones de BCI se dividen en tres clases. El primer grupo incluye a los pacientes que han perdido todo el control motor porque pueden estar en 
una etapa terminal de ELA o sufrir parálisis cerebral severa. El segundo grupo está formado por los pacientes de Locked-In State (LIS) que están casi completamente paralizados, pero con movimiento voluntario residual, como movimiento ocular, parpadeos o tics en el labio. El tercer grupo de usuarios potenciales de BCI incluye a las personas con discapacidad física y aquellas con un control neuromuscular sustancial, particularmente el habla y/o el control manual.

Los sistemas BCI tienen poco que ofrecer al tercer grupo, porque pueden enviar la misma información mucho más rápida y fácilmente a través de otras interfaces. A pesar de esto, los BCI son cada vez más utilizados por las personas sanas en entornos de neuromarketing y en videojuegos como herramienta para revelar información afectiva de los usuarios, que no puede ser tan fácilmente obtenida a través de interfaces convencionales. Asimismo, el BCI se utiliza para algunas personas que sufren de trastornos neurológicos como esquizofrenia o depresión.

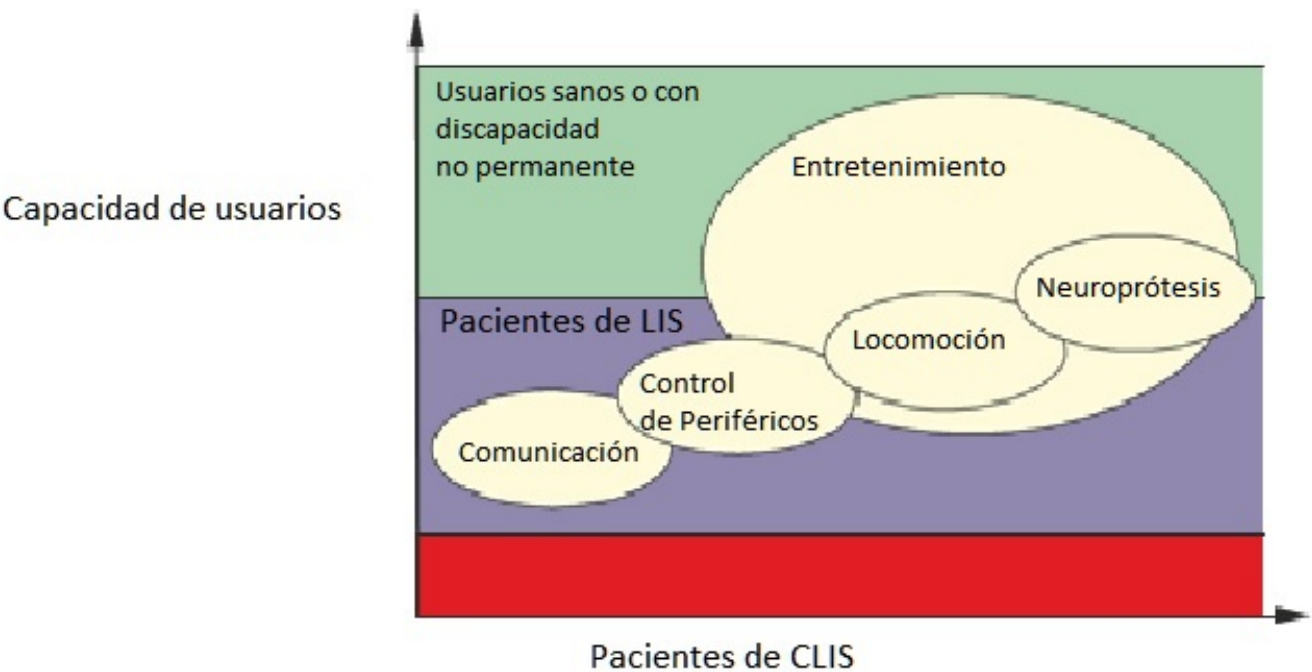

Figura 4.5.1: Tasa de transferencia de información BCI en relación con las capacidades del usuario.

Se debe tener en cuenta que el nivel de deterioro de la población objetivo está relacionado con el rendimiento de un sistema de BCI. Kübler, en [103] informa de una fuerte correlación entre la deficiencia física y el rendimiento del BCI. De hecho, los pacientes con CLIS no pudieron controlar un sistema BCI mientras que los que padecían LIS consiguieron controlarlo. La Figura 4.5.1 muestra la relación entre las áreas de aplicación de BCI y las tasas de transferencia de información de BCI y las capacidades del usuario.

En ella se observa la relación entre las áreas de aplicación de BCI, las tasas de transferencia de información de BCI y las capacidades del usuario. El Eje horizontal representa la tasa de transferencia de información que haría la aplicación controlable, mientras que el Eje vertical representa 
de forma creciente el grado de capacidad del usuario.

Actualmente no está claro si la tecnología de BCI superará a otras tecnologías establecidas que incluyen dispositivos oculares o musculares. En la actualidad, estos últimos tienden a ser más fáciles de usar y ofrecen una mejor relación coste/beneficio [106, 107]. Por ejemplo, la detección del movimiento ocular es más rápida, fácil y precisa que la detección de modulaciones ERP, ya que por ejemplo se puede obtener una tasa de ortografía de 10 palabras por minuto con un movimiento ocular, por medio de un eye-tracker [108]. A ese respecto, se han propuesto sistemas híbridos de BCI para mejorar el desempeño. Los sistemas híbridos son la combinación de dos tipos diferentes de BCI o la combinación de un BCI con otra tecnología asistencial existente [109]. A menos que el rendimiento de los sistemas de BCI mejore considerablemente, el BCI como tecnología de asistencia sólo puede ser especialmente atractiva para las personas con discapacidades graves, cuando otras tecnologías no son adecuadas.

En la actualidad, los pacientes con LIS y los que probablemente desarrollarán CLIS constituyen los principales candidatos para la BCI. A pesar de las bajas tasas de transferencia de información proporcionadas por el BCI, el alto grado de discapacidad entre los pacientes con SIL los obliga a utilizarlo en lugar de interfaces convencionales más fiables, como los sistemas basados en el músculo o la visión. Las limitaciones del control de la vista en algunos pacientes con SIL son un problema importante, porque están obligados a utilizar BCIs que no dependan del control de la visión [77, 78], además, estas limitaciones hacen que alguna aplicación BCI sean más difícil de implementar, como conducir una silla de ruedas.

Hoy en día, hay un gran número de aplicaciones muy diferentes, como procesadores de texto, navegadores web adaptados, control cerebral de una silla de ruedas o neuroprótesis, y juegos, entre otros. Sin embargo, la mayoría de las aplicaciones han sido diseñadas exclusivamente para fines de formación o demostración. A pesar de los avances significativos más recientes en la tecnología BCI, todavía existen muchos desafíos para emplear el control de BCI en tareas del mundo real [79], que son: (i) la tasa de transferencia de información proporcionada por los BCI es demasiado baja para una conversación interactiva natural, incluso para sujetos experimentados y sistemas de BCI bien afinados; (ii) la elevada tasa de error complica aún más la interacción; (iii) los sistemas BCI no pueden ser utilizados de forma autónoma por personas con discapacidad, porque los sistemas de BCI requieren que los asistentes apliquen electrodos o dispositivos receptores de señales antes de que la persona con discapacidad pueda comunicarse; (iv) un usuario de BCI puede ser capaz de apagar el sistema de BCI por medio de la actividad cerebral, pero por lo general no puede volver a encenderlo, lo que se denomina el problema del "toque de Midas"; y (v) manejar las aplicaciones de BCI exige una alta carga cognitiva que normalmente pueden lograr los usuarios en un entorno 
de laboratorio tranquilo, pero no en el mundo real. Sin embargo, a pesar de todas estas dificultades, ya se han dado los primeros pasos en el camino hacia un uso independiente y a largo plazo de los BCI en el hogar [5].

Antes de describir el uso práctico de las aplicaciones BCI, conviene tener en cuenta la distinción entre BCI y sus aplicaciones [7]. Como herramienta que ejecuta una función específica, las especificaciones BCI particulares corresponden a la forma en que realiza esa función. Por lo tanto, estas especificaciones pueden aplicarse a una gran variedad de aplicaciones, aunque la función no varíe. Lo importante en la evaluación del BCI es su desempeño al ejecutar su función específica. Por el contrario, las aplicaciones se describen en términos de las herramientas que emplean y los propósitos a los que sirven. Por lo tanto, la evaluación del BCI se centra en el grado de cumplimiento de su propósito. En otras palabras, el término BCI se refiere al sistema que registra, analiza y traduce la entrada en comandos y el término aplicación denota el entorno en el que se aplican los comandos de salida estimados del BCI. En consecuencia, los procedimientos de evaluación de los sistemas de BCI y sus aplicaciones difieren en cada caso. Las siguientes subsecciones describen brevemente las aplicaciones BCI, clasificadas en cinco áreas principales: comunicación, restauración de motora, control ambiental, locomoción y entretenimiento.

\subsubsection{Comunicación.}

Las aplicaciones BCI para la comunicación están orientadas principalmente para solventar discapacidades graves de comunicación resultantes de enfermedades neurológicas. Este tipo de aplicación representa probablemente la investigación más apremiante en el campo de BCI, ya que la actividad comunicativa es esencial para los seres humanos. Las aplicaciones para fines de comunicación delinean una operación que normalmente muestra un teclado virtual en pantalla, donde el usuario selecciona una letra del alfabeto mediante BCI. El elemento distintivo de cada aproximación suele ser el BCI y el tipo de señal de control.

El control voluntario de los SCPs puede ser utilizado para la selección de cartas. Con un entrenamiento intensivo, los pacientes completamente paralizados son capaces de producir cambios positivos y negativos en su SCP para impulsar el movimiento vertical de un cursor [77]. Basándose en este tipo de señal de control, Birbaumer y otros [78] desarrollaron un dispositivo de ortografía con una pantalla, que usaba un cursor para seleccionar las letras del alfabeto. Los ensayos que incluyeron a dos pacientes en estadios avanzados de ELA mostraron que alcanzaron una tasa de aproximadamente dos caracteres por minuto al escribir mensajes de texto. Otros tipos de señales de control, como la detección de parpadeos [80], que normalmente representan un artefacto en señales de EEG o la clasificación tareas mentales, también se utilizan para seleccionar los bloques o carac- 
teres en un teclado virtual.

Ambos enfoques son casi los mismos, aparte de la señal de control. En ambos casos, el teclado virtual consistió en un total de 27 símbolos, 26 letras inglesas más el espacio para separar las palabras, organizados en una matriz de tres filas por nueve columnas. Asimismo, ambas solicitudes se basaban en el mismo protocolo de redacción de una sola carta, que requería tres pasos. En primer lugar, el teclado entero se dividió en tres bloques, cada uno con nueve letras. A continuación, el usuario puede seleccionar un conjunto de nueve letras produciendo un parpadeo de una, dos o tres veces [80].

En [108] se diseña una escritura de letras basada en el paradigma Graz-BCI estándar, que también incluía un teclado virtual. El protocolo de selección de letras era muy similar a los enfoques discutidos anteriormente, excepto que todo el alfabeto constaba de 32 letras y estaba dividido en dos mitades en cada paso. En este caso, el usuario elige un subconjunto de letras por modulación EEG mediante imaginación de movimiento de manos y piernas. La tasa de ortografía alcanzada por tres usuarios sanos varió entre 0,5 y 0,85 letras por minuto. Se trata de una tasa inferior a la de los casos anteriores, sin embargo, parece fácil aumentar el número de letras escritas por minuto simplemente ampliando el número de clases a más de dos.

Los potenciales cerebrales relacionados con eventos P300 son también muy populares en las aplicaciones de ortografía de letras BCI. Se ha demostrado que los BCI basados en P300 son adecuados para pacientes con ELA en las etapas temprana y media de la enfermedad [81]. Además, este tipo de BCI es muy útil porque la respuesta del P300 se produce espontáneamente y, por lo tanto, no requiere un entrenamiento sustancial. Además, los avances recientes con los deletreadores basados en P300 han permitido el desarrollo de aplicaciones comerciales disponibles para el público en general [83].

Uno de los deletreadores P300 más conocidos fue diseñado por Farwell y Donchin en 1988 [80]. En este deletreador, las 26 letras del alfabeto, junto con otros símbolos y comandos, se muestran en pantalla en una matriz de 6x6 (Figura 4.5.2) con filas y columnas aleatoriamente intermitentes. A continuación, el usuario centra la atención en la pantalla y se concentra sucesivamente en los caracteres a escribir, mientras se monitoriza la respuesta del EEG. Se extraen dos P300 para cada elemento buscado en la matriz, cuando la fila o columna deseada parpadea, permitiendo así que el sistema identifique el símbolo deseado. Los resultados de los ensayos ortográficos de Farwell-Donchin que involucraron a 4 personas sanas dieron una tasa de ortografía aceptable de aproximadamente 2 caracteres por minuto. 


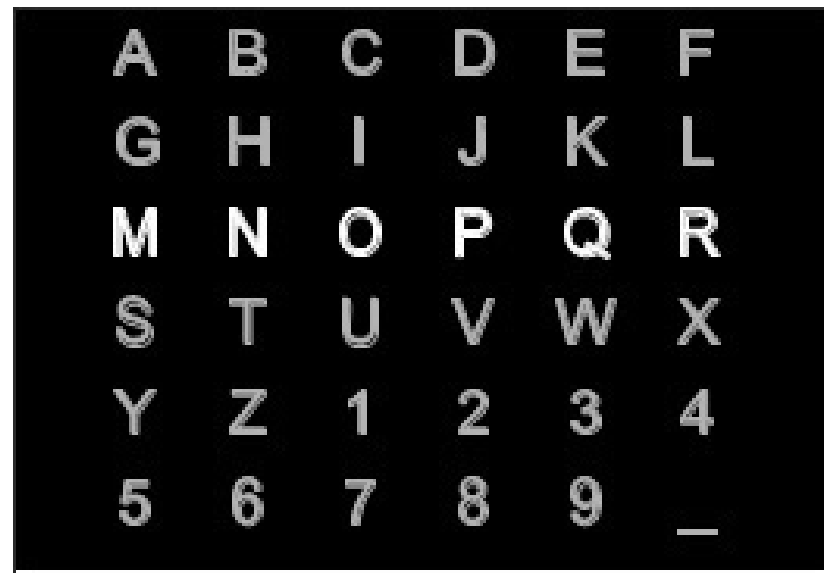

Figura 4.5.2: Deletreador original P300. Matriz de símbolos mostrada en un ordenador de pantalla que sirve como teclado o dispositivo protésico (adaptado de [123]).

\begin{tabular}{|c|c|c|c|c|c|c|c|c|c|c|c|c|}
\hline \multirow{2}{*}{$\begin{array}{c}\text { Basado } \\
\text { en }\end{array}$} & \multicolumn{10}{|c|}{ Funcionalidades } & \multirow[b]{2}{*}{ Sujetos } & \multirow[b]{2}{*}{ Precisión } \\
\hline & $\begin{array}{c}\text { Requiere } \\
\text { entrena- } \\
\text { miento }\end{array}$ & $\begin{array}{l}\text { Requiere } \\
\text { supervisión }\end{array}$ & $\begin{array}{c}\text { Selección } \\
\text { de } \\
\text { hipervincu- } \\
\text { los }\end{array}$ & $\begin{array}{l}\text { Filtrado de } \\
\text { hipervincu- } \\
\text { los }\end{array}$ & Marcadores & Historial & $\begin{array}{c}\text { Barra de } \\
\text { URL }\end{array}$ & $\begin{array}{l}\text { Modo de } \\
\text { lectura }\end{array}$ & $\begin{array}{l}\text { Implementa } \\
\text { ratón }\end{array}$ & $\begin{array}{c}\text { Distancias } \\
\text { mediante } \\
\text { pixeles }\end{array}$ & & \\
\hline \multirow{2}{*}{$\begin{array}{c}\text { Potenciales } \\
\text { Corticales } \\
\text { Lentos } \\
\text { (SCP) }\end{array}$} & \multirow{2}{*}{ Sí } & \multirow{2}{*}{ Sí } & \multirow{2}{*}{$\begin{array}{c}\text { Mediante } \\
\text { selección } \\
\text { binaria }\end{array}$} & \multirow{2}{*}{ No } & \multirow{2}{*}{ Sí } & \multirow{2}{*}{ No } & \multirow{2}{*}{ Sí } & \multirow{2}{*}{$\begin{array}{l}\text { Tiempo } \\
\text { impuesto } \\
\text { por el } \\
\text { supervisor }\end{array}$} & \multirow{2}{*}{ No } & \multirow{2}{*}{ No } & 4 ELA & \multirow{2}{*}{$\begin{array}{c}\text { No } \\
\text { especifica- } \\
\text { do }\end{array}$} \\
\hline & & & & & & & & & & & 2 sanos & \\
\hline \multirow{2}{*}{$\begin{array}{c}\text { Potenciales } \\
\text { Evocados } \\
\text { P300 }\end{array}$} & \multirow{2}{*}{ Sí } & \multirow{2}{*}{ No } & \multirow{2}{*}{$\begin{array}{l}\text { Etiquetado } \\
\text { con uno o } \\
\text { dos } \\
\text { caracteres }\end{array}$} & \multirow{2}{*}{ No } & \multirow{2}{*}{ No } & \multirow{2}{*}{ No } & \multirow{2}{*}{ Si } & \multirow{2}{*}{ Si } & \multirow{2}{*}{ No } & \multirow{2}{*}{ No } & 3 ELA & $72 \%$ \\
\hline & & & & & & & & & & & 10 sanos & $90 \%$ \\
\hline $\begin{array}{c}\text { Potenciales } \\
\text { Evocados } \\
\text { P300y } \\
\text { N2PC }\end{array}$ & Sí & No & $\begin{array}{c}\text { Mediante } \\
\text { desplaza- } \\
\text { miento del } \\
\text { cursor }\end{array}$ & No & $\begin{array}{c}\text { No } \\
\text { orientado a } \\
\text { personas } \\
\text { discapacita- } \\
\text { das }\end{array}$ & $\begin{array}{c}\text { No } \\
\text { orientado a } \\
\text { personas } \\
\text { discapacita- } \\
\text { das }\end{array}$ & Sí & Sí & Sí & Si & 4 sanos & $93 \%$ \\
\hline $\begin{array}{c}\text { Potenciales } \\
\text { Evocados } \\
\text { P300y } \\
\text { ritmos } \\
\text { sensorio- } \\
\text { motores } \\
\end{array}$ & Sí & No & $\begin{array}{l}\text { Mediante } \\
\text { desplaza- } \\
\text { miento del } \\
\text { cursor }\end{array}$ & Si & $\begin{array}{c}\text { Ocho } \\
\text { marcadores } \\
\text { populares } \\
\text { en la página } \\
\text { inicial }\end{array}$ & No & Sí & No & Sí & No & 7 sanos & $93,21 \%$ \\
\hline $\begin{array}{c}\text { Potenciales } \\
\text { Evocados } \\
\text { mVEP }\end{array}$ & Sí & No & $\begin{array}{c}\text { No } \\
\text { especifica- } \\
\text { do }\end{array}$ & No & $\begin{array}{c}\text { No } \\
\text { especifica- } \\
\text { do }\end{array}$ & $\begin{array}{c}\text { No } \\
\text { especifica- } \\
\text { do }\end{array}$ & Sí & $\begin{array}{c}\text { No } \\
\text { especifica- } \\
\text { do }\end{array}$ & No & No & 12 sanos & $93 \%$ \\
\hline
\end{tabular}

Figura 4.5.3: Características comparativas de distintos navegadores web controlados mediante señales de EEG.

Otras aplicaciones importantes BCI relacionadas con la comunicación son los navegadores de Internet adaptados a usuarios con discapacidades graves porque, en la última década, Internet se ha convertido en una parte muy importante de la vida cotidiana, ver Figura 4.5.3. En esta área, "Descartes. ${ }^{\text {es }}$ uno de los primeros navegadores web controlados por EEG que pueden ser operados por SCPs [110]. Su interfaz de navegador se basa en ordenar los enlaces alfabéticamente en un 
árbol de decisión dicotómico, donde el usuario selecciona o rechaza cada ítem, produciendo cambios positivos o negativos de SCP.

Descartes presenta la deficiencia de que sólo puede navegar por un número limitado de páginas, porque el usuario recibe una serie de enlaces predefinidos ordenados en un árbol al inicio de la navegación web. Además, los enlaces gráficos no pueden ser elegidos ya que se utiliza una etiqueta textual para identificar el enlace. Un prototipo más avanzado, llamado "Nessi”, supera estas deficiencias gracias a una mejor interfaz de usuario [111] donde marcos coloreados se colocan alrededor de los enlaces o elementos que pueden seleccionarse en la página web. Más recientemente, los potenciales evocados también se utilizan para mejorar la funcionalidad del navegador. Mugler y otros [83] construyeron un navegador de Internet con control P300 donde todas las opciones se presentan como iconos en una matriz de 8x8. Jinghai y otros [62] desarrollaron un navegador basado en VEPs.

\subsubsection{Rehabilitación del movimiento.}

Las lesiones de la médula espinal u otras enfermedades neurológicas con pérdida asociada de funciones sensoriales y de movimiento disminuyen drásticamente la calidad de vida del paciente. La rehabilitación del movimiento puede aliviar el sufrimiento psicológico y social del paciente. El restablecimiento del movimiento, como el agarre, es factible en pacientes a través de neuroprótesis guiadas por estimulación eléctrica funcional (FES).

El FES compensa la pérdida de funciones voluntarias provocando contracciones musculares artificiales. Las corrientes eléctricas generan potencial de acción y causan una contracción muscular [112]. El BCI basado en EEG puede utilizarse para generar una señal de control para el funcionamiento del FES, ya que las señales del EEG no se ven afectadas por la activación eléctrica de los músculos de las extremidades superiores [113].

Gracias a la fusión de BCI y FES, Pfurtscheller y otros [101] desarrollaron una aplicación en la que un paciente tetrapléjico que sufría una lesión la médula espinal, era capaz de controlar las manos paralizadas para agarrar un cilindro. En esa aplicación, el paciente generó ondas cerebrales $\beta$ en el EEG mediante imaginación del movimiento del pie. A continuación, el BCI analizó y clasificó la señal y la salida se utilizó para controlar el dispositivo FES que activó la extremidad. Además, el FES se ha utilizado para el entrenamiento de rehabilitación después de un accidente cerebro-vascular, como describe Hu y otros [114], con el fin de involucrar el esfuerzo neuromuscular del propio usuario durante el entrenamiento. 
Se ha demostrado que el FES es una forma efectiva de rehabilitar el movimiento. No obstante, la FES requiere el uso de movimientos residuales, que no son posibles en pacientes con lesiones graves. Por esta razón, algunos grupos han comenzado a explorar enfoques que combinan neuroprótesis y BCI sin intervención de FES. Pfurtscheller y otros [115] demostraron que un paciente tetrapléjico, cuya actividad muscular residual de las extremidades superiores estaba restringida al bíceps izquierdo, debido a una lesión de la médula espinal superior, podía controlar efectivamente una prótesis de mano usando señales producidas por MI.

Algunos años más tarde, el mismo grupo validó el acoplamiento de los BCIs basados en EEG y una neuroprótesis implantada, dando evidencia adicional de que el BCI es una opción viable para el control de una neuroprótesis [119]. En este estudio, un sistema BCI clasificó patrones de EEG que implicaban disminuciones de potencia en ciertas bandas de frecuencia específicas. Estos patrones fueron generados por el usuario a partir de imágenes mentales de su mano izquierda a partir de paradigma de MI.

Sin embargo, el BCI basado en MEG es demasiado caro para aplicaciones generalizadas. Por esta razón, Broetz y otros [116] propusieron una combinación de BCI basados en MEG y EEG.

En experimentos similares, Caria y otros [117] reafirmaron el éxito de una combinación de entrenamiento en BCI y fisioterapia. Este estudio fomenta la investigación adicional sobre el papel de los BCI en la plasticidad cerebral y la recuperación después de un accidente cerebrovascular.

\subsubsection{Control de periféricos.}

Uno de los principales objetivos de las aplicaciones basadas en la BCI es conseguir la máxima independencia para el paciente, a pesar de cualquier discapacidad de movimiento. Las personas que sufren discapacidades severas a menudo están confinadas en casa y por esta razón, las aplicaciones de control se centran en aparatos domésticos como la televisión o las luces. Además de mejorar la calidad de vida de las personas con discapacidades graves, los dispositivos de asistencia hacen que las tareas del cuidador sean menos intensivas, se reduzcan los costes y la vida de los familiares sea menos molesta.

Cincotti y otros [6] presentaron un estudio piloto sobre la integración de la tecnología BCI en el entorno doméstico, permitiendo controlar periféricos típicos como un teclado, el ratón o un joystick y como dispositivos de salida, el sistema BCI permitió el uso de un grupo básico de electrodomésticos como luces, televisores y equipos estéreo, una cama motorizada, una alarma acústica, un timbre para abrir la puerta y un teléfono, así como cámaras inalámbricas para monitorear el ambiente circundante. 


\subsubsection{Locomoción.}

También se han estudiado aplicaciones BCI que permiten a las personas discapacitadas controlar un medio de transporte. Gracias a estas aplicaciones, las personas que sufren de paraplejia o con otras deficiencias físicas pueden conducir de forma autónoma una silla de ruedas, haciéndolas más autónomas y mejorando su calidad de vida. La portabilidad es una necesidad para este tipo de aplicaciones, por lo tanto, se impone el uso de un BCI basado en el registro EEG.

Las señales de EEG suelen ser muy ruidosas y variables, como se comentó en capítulos anteriores, lo que significa un tiempo relativamente largo entre comandos que será de incertidumbre para realizar un movimiento preciso. Por lo tanto, el principal reto es lograr una precisión suficiente en la conducción y alcanzar el control en tiempo real, a pesar de las tasas de transferencia de información no demasiado altas que proporciona un sistema BCI.

Por esta razón, algunos estudios sobre los BCI propusieron técnicas invasivas para registrar las señales de EEG, ya que lograron una mayor resolución espacial y una reducción del ruido. Serruya y otros [118] experimentaron con monos implantando una guía de electrodos en la corteza motora. Estos experimentos iniciales mostraron que los monos eran capaces de mover el cursor de un ordenador a cualquier posición, abriendo nuevas aplicaciones humanas.

Sin embargo, los riesgos relacionados con los BCI invasivos llevan a la investigación hacia la creación de aplicaciones no invasivas para uso humano. Algunos experimentos piloto relacionados con la locomoción ilustran la factibilidad de utilizar señales EEG para el control continuo de un robot móvil en un entorno interior con varias salas, pasillos y puertas [119].

Los resultados de estos experimentos abrieron la posibilidad para las personas con discapacidad física de utilizar un BCI portátil basado en EEG para controlar sillas de ruedas. Tanaka y otros [153] presentaron en 2005 la primera aplicación del control de sillas de ruedas utilizando sólo EEG. En este estudio, el suelo circundante se dividió en cuadrados entre los que el usuario decidió moverse imaginando movimientos de la extremidad izquierda o derecha. Impulsada por las decisiones del usuario, la silla de ruedas se desplazaba de un cuadrado a otro, las pruebas con seis sujetos sanos fueron bastante alentadoras y demostraron la viabilidad del control de las sillas de ruedas únicamente mediante el uso de señales de EEG, aunque para garantizar una mayor precisión se introducen BCI síncronos basados en P300 para garantizar una mayor precisión, Rebsamen y otros [120] emplearon dos BCI más rápidos basados en $\mathrm{P} 300$ y los ritmos $\mu / \beta$, lo que permitió al usuario detener la silla de ruedas con mayor rapidez [121]. Ambas aplicaciones fueron probadas con personas sin discapacidad. 


\subsubsection{Entretenimiento.}

Las aplicaciones de BCI orientadas al entretenimiento han tenido una prioridad menor en este campo. Hasta ahora, la investigación sobre la tecnología de BCI se ha centrado en aplicaciones de asistencia, como los dispositivos ortográficos, el control de sillas de ruedas o las neuroprótesis y no en aplicaciones con fines de entretenimiento.

Sin embargo, el interés por las aplicaciones de entretenimiento ha surgido en los últimos años debido a los importantes avances de esta tecnología. De hecho, las mejoras en su desempeño han abierto el camino para extender el uso del BCI a las personas sin discapacidades. Los BCIs crean una nueva modalidad de interacción que puede convertir los videojuegos en experiencias aún más desafiantes y atractivas.

Además, el BCI puede proporcionar una forma de acceder al conocimiento sobre las experiencias del usuario, mejorando así los juegos a través de la información de la actividad cerebral. Los BCIs pueden informar cuando el jugador está aburrido, ansioso o frustrado con el objetivo de utilizar este conocimiento para diseñar futuros juegos [175].
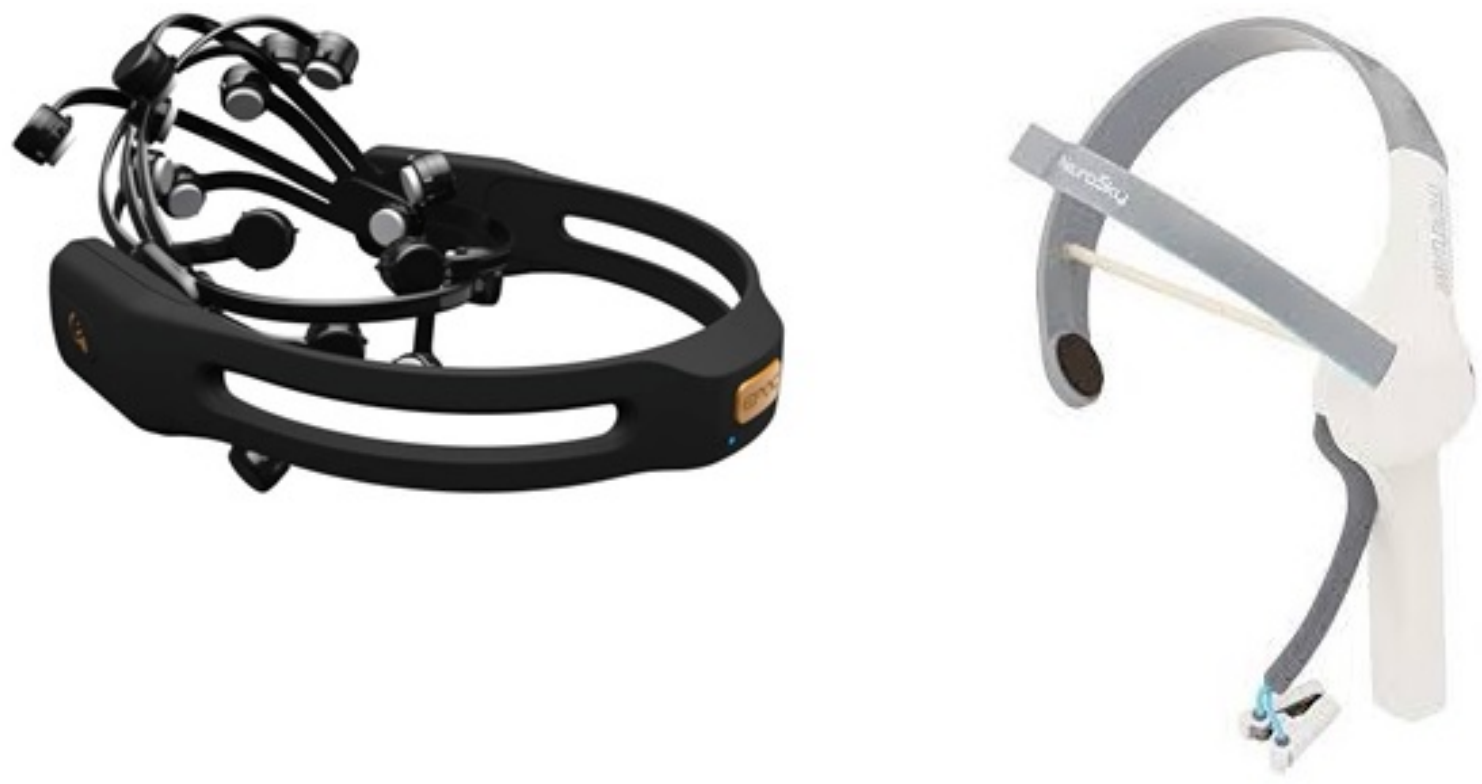

a)

b)

Figura 4.5.4: (a) Emotiv EPOC neuroheadset ; (b) Neurosky Mindwave .

Fuente: https://www.emotiv.com/epoc/ ; http://neurosky.com/ 
Todos los ejemplos anteriores incluían juegos experimentales que sólo se han encontrado útiles en un contexto de investigación. Sin embargo, hay algunas empresas que están preparando juegos comerciales de BCI para futuros mercados. Emotiv ya ha desarrollado numerosos juegos basados en BCI, como Cortex Arcade y Spirit Mountain Demo Game, entre otros. Además, la empresa vende un BCI de bajo coste con 14 electrodos, los denominados EPOC (Figura 4.5.4 (a)), que pueden adquirirse con una interfaz de programación de aplicaciones (API). Gracias a esta API, el desarrollo basado en aplicaciones BCI se hace mucho más simple. La compañía Neurosky también comercializa el Mindwave (Figura 4.5.4 (b)) con aplicaciones de software que pueden responder a las ondas cerebrales o estados mentales del usuario. Asimismo, proporciona un conjunto de herramientas de software para los desarrolladores. Además, grandes empresas de software como Microsoft han mostrado interés en la investigación sobre BCI, explorando el desarrollo de aplicaciones piloto novedosas que utilizan BCI [174].

\subsubsection{Otras aplicaciones de BCI.}

Los sistemas de BCI también se han utilizado en una amplia variedad de aplicaciones más allá de las áreas tradicionales de comunicación, restauración motora, control ambiental, locomoción y entretenimiento. La capacidad de la retroalimentación del BCI para inducir plasticidad cortical puede ser la base para aplicaciones médicas. Los usuarios pueden adquirir control selectivo sobre ciertas áreas del cerebro mediante neurofeedback, con el objetivo de inducir cambios de comportamiento en el cerebro. El neurofeedback proporcionado por un sistema de BCI puede mejorar el rendimiento cognitivo [122, 123], las habilidades del habla [124], el afecto [125] y se ha utilizado en el tratamiento de trastornos mentales, como la epilepsia [127, 128], el déficit de atención [129], la esquizofrenia [130], la depresión [131], la dependencia del alcohol [132], o la pedofilia [133].

Por otra parte, las grabaciones de señales cerebrales se pueden utilizar para evaluar el estado de salud y enfermedad [134]. La oportunidad de examinar las señales cerebrales también se puede explotar comercialmente. El Neuromarketing es un campo de investigación relativamente joven que aplica métodos neurocientíficos a la investigación de marketing. Hasta la fecha, se han realizado pocos estudios de neuromarketing, aunque se han encontrado algunas pruebas que sugieren que la neuroimagen podría tener un rol en varias áreas de marketing [135, 136, 137, 138].

El Neuromarketing puede proporcionar una compensación más eficiente entre costes y beneficios. Los conceptos de producto podrían probarse mediante el neuromarketing, eliminando los conceptos que no son prometedores al inicio del proceso de fabricación. Esto conduciría a una distribución más eficiente, porque sólo se desarrollarían los productos más prometedores. Además, el neuromarketing puede ser una fuente de información más precisa sobre las preferencias subyacen- 
tes de los usuarios, en lugar de datos de estudios de investigación de mercado estándar [139], por lo que puede revelar información oculta sobre las verdaderas preferencias de los consumidores que no puede ser explícitamente expresada o deducida, como por ejemplo medir la respuesta del cerebro a los anuncios publicitarios y, por lo tanto, cuantificar la eficacia de las campañas publicitarias.

A pesar de ser un campo emergente, varias empresas como Neurofocus [139], Neuroconsult [140], Neuro Insight [152] o EmSense [142], entre otras, ofrecen actualmente servicios de neuromarketing. También está atrayendo cada vez más atención entre los investigadores el hecho que se hayan planteado algunas cuestiones éticas relacionadas con esta tecnología, en la medida en que puede ser capaz de manipular el cerebro y el comportamiento del consumidor [138].

\subsection{Competiciones en BCI.}

Desde el año 2001, se ha llevado a cabo cada dos años una serie de competiciones en BCI en las que cualquier investigador podía demostrar la eficiencia de su sistema BCI empleando una serie de señales cerebrales proporcionadas por algunos de los más importantes grupos de investigación sobre BCI. Hasta ahora se han celebrado cuatro ediciones de esta competición BCI I, II (también llamada 2003), III y IV. Se ofrecen varios conjuntos de señales recogidas de algunos usuarios que están separadas en dos partes. Por un lado, se encuentra un subconjunto de señales etiquetadas en las que se conoce el estado mental del usuario, que sirven como señales de entrenamiento. Por otro lado, se tienen señales sin etiquetar, que sirven para conocer el rendimiento del método propuesto una vez que la competición ha terminado.

Las competiciones BCI son un mecanismo que impulsa la investigación en BCI. Se ofrecen diferentes tipos de señales: potenciales $\mathrm{P} 300$ o también llamados potenciales cognitivos, SCP o potenciales corticales lentos y ritmos $\mu \mathrm{y} \beta$. Estas competiciones proporcionan un conjunto de señales que pueden ser utilizadas por todos los investigadores de la comunidad científica. Esto hace mucho más sencilla la comparación de los diferentes métodos de reconocimiento de patrones presentados por los investigadores. Además, facilita la replicación de los estudios.

La forma de las señales que se recogen en estas competiciones, están asociadas a dos factores fundamentales:

- El estado mental en el que se encuentra el sujeto

- La actividad sensorial que se experimenta en el momento de la toma de los datos.

Estas competiciones poseen a su vez un paradigma o modelo para la realización de las pruebas donde se describe la forma de adquirir los datos por parte de los participantes. En particular, este 
conjunto de datos ha sido empleado en el Experimento 2, tanto para la validación de los algoritmos de extracción como para los algoritmos de clasificación empleados en esta Tesis.

\subsection{Estado del arte en plataformas software para el desarrollo de sistemas Brain Computer Interface}

Esta sección proporciona un análisis de las plataformas software (SW) a disposición del público para el desarrollo e implementación de interfaces cerebro-ordenador (Brain Computer Interfaces, en adelante BCI). Se identifican siete grandes plataformas para BCI y se describen a su vez sus características más relevantes, así como la disponibilidad en diferentes sistemas operativos, licencias, lenguajes de programación y compiladores. Estas siete plataformas son: BCI2000, OpenViBE, BCILAB, BCI++, TOBI, xBCI, BF++. Adicionalmente, se describen otras dos plataformas, Pyff y AsTeRICS, que se emplean para la generación y presentación de estímulos durante la realización de experimentos con sistemas BCI.

\subsubsection{Introducción.}

Desde los primeros comienzos de la tecnología BCI en la década de los 70 [176], muchos grupos de investigación han desarrollado esta primera idea en prototipos funcionales, que en la actualidad ya están siendo utilizados fuera de los laboratorios con fines complementarios a los meramente científicos, por ejemplo, en hospitales e incluso en hogares [5]. En los últimos años, y gracias a la disponibilidad de ordenadores personales cada vez más potentes (en cuanto a sus capacidades de cómputo se refiere) y la disposición de entornos de desarrollo software (SW) más versátiles e intuitivos, el número de investigadores en el ámbito de la tecnología BCI ha crecido enormemente. Las plataformas SW orientadas específicamente hacia el desarrollo de sistemas BCI deben ofrecer funcionalidades y herramientas que permitan implementar cada una de las etapas o módulos que componen un sistema BCI, tales como la adquisición de datos, la extracción de características, la clasificación y los correspondientes módulos de presentación y realimentación (representación gráfica o actuadores). Muchos laboratorios han desarrollado su propio conjunto de herramientas (programas) a lo largo de los años en base a requisitos diferentes, lenguajes de programación y usuarios potenciales.

Estas herramientas suelen ser de código cerrado, es decir, que no está disponible al público para su uso o modificación, ya que se utilizan principalmente para la creación rápida de prototipos y pruebas internas. Por otra parte, estas herramientas necesitan de una amplia documentación que 
normalmente no es accesible para otros usuarios, sin previa adquisición y pago del producto.

No obstante, fuera de los laboratorios de empresas privadas, han surgido varias plataformas para BCI que sí están a disposición de científicos o usuarios: están enfocadas a su libre uso disponiendo del código abierto (open source) y licencias GNU públicas, facilitando la modificación y la inclusión de aportaciones de terceros a nuestras creaciones. Incluso muchas de estas plataformas para BCI son a su vez multiplataforma, con lo que no se limitan a sistemas operativos específicos o requieren software comercial. Esta sección proporciona una visión general de las principales plataformas disponibles en la actualidad para BCI.

\subsubsection{Plataformas SW para BCI.}

A continuación, en las diferentes secciones de esta apartado se analiza y compara un total de nueve plataformas SW para el desarrollo y la implementación de sistemas BCI (ver figura siguiente).

\begin{tabular}{|l|l|l|}
\hline Plataforma & \multicolumn{1}{|c|}{ SO } & \multicolumn{1}{|c|}{ Licencia } \\
\hline BCI2000 & W, X & GPL \\
\hline OpenViBE & W, L & LGPL \\
\hline BCILAB & W, X, L & GPL \\
\hline BCI ++ & W & GPL \\
\hline TOBI & W, L & GPL, LGPL \\
\hline xBCI & W, X, L & GPL \\
\hline BF ++ & W & Free \\
\hline
\end{tabular}

Figura 4.7.1: Relación de Plataformas SW para el Desarrollo de Sistemas BCI (W, Windows; X, Mac OS X; L, Linux). 


\subsubsection{BCI2000.}

Es una plataforma de software de propósito general para la investigación en BCI [214]. También se puede utilizar para una amplia variedad de adquisición de datos, la presentación del estímulo y aplicaciones para monitorizar las ondas cerebrales. Esta plataforma está mantenida actualmente por un equipo de seis científicos y programadores, junto con una comunidad de colaboradores que amplían constantemente las capacidades del BCI2000, por ejemplo, añadiendo soporte para nuevos dispositivos BCI. El impacto que BCI2000 ha tenido en la comunidad científica destaca a partir de abril de 2011, donde ha sido adquirido por más de 900 usuarios en todo el mundo o en que un artículo original que describe el sistema BCI2000 [177] se ha citado cerca de 400 veces. Además diversas publicaciones muestran aplicaciones reportadas hasta la fecha utilizando señales de magneto-encefalografía (MEG) y electrocorticográfica (ECOG). También ha permitido desarrollar la primera $\mathrm{BCI}$ multidimensional utilizando señales de $\mathrm{ECoG}$, el sistema $\mathrm{BCI}$ más rápido en los seres humanos, las primeras aplicaciones de la tecnología BCI en pacientes con accidente cerebro vascular crónico, el uso de técnicas BCI para controlar asistencia tecnologías y un largo etcétera. BCI2000 ha permitido desarrollar aplicaciones BCI de ayuda a discapacitados. El éxito generalizado y su continuo crecimiento de la plataforma BCI2000 es una fuerte evidencia de su utilidad.

\subsubsection{OpenViBE.}

Es una plataforma de software libre y de código abierto para el diseño, prueba y uso de interfaces cerebro-ordenador [215]. OpenViBE consiste en un conjunto de módulos de software que se pueden integrar con facilidad y eficiencia para desarrollar BCIs completamente funcionales. Es difícil estimar con fiabilidad el número de usuarios de OpenViBE, ya que no hace falta registro para descargar y utilizar el software en cuestión, aunque se proporciona la lista en el sitio web que incluye universidades, institutos de investigación y centros médicos de todo el mundo. También se utiliza en una gran variedad de proyectos que incluyen socios industriales o médicos, videojuegos o herramientas de ayuda a personas con discapacidad.

\subsubsection{BCILAB.}

BCILAB [216] se define como un 'toolbox' de código abierto basada en MATLAB para la investigación avanzada en BCI. Sus interfaces gráficas y de secuencias de comandos de usuario proporcionan acceso a una amplia colección de métodos establecidos, así como las novedades más recientes. Se especializa en pruebas en tiempo real, la evaluación de nuevas aplicaciones BCI, y la comparativa de los métodos de BCI. El diseño de BCILAB está menos centrado en aplicaciones 
clínicas/comerciales, aunque hay versiones compiladas de BCILAB que están disponibles para ejecutar versiones independientes para BCI.

\subsection{6. $\mathrm{BCI}++$.}

Proporciona un conjunto de herramientas para el rápido desarrollo de interfaces cerebro-ordenador y la interacción de persona-ordenador [217]. El primer módulo HIM (módulo de interfaz de hardware) se ocupa de la adquisición de la señal, el almacenamiento, la visualización y el procesamiento en tiempo real. El segundo módulo se llama Aenima y proporciona una interfaz gráfica de usuario (GUI). Destacar la posibilidad de implementación de un sistema BCI basado en Arduino que adquiere hasta 16 canales a $256 \mathrm{~Hz}$, y a su vez muestra cómo implementar nuevos dispositivos. También puede implementarse para tabletas y Smartphone.

\subsubsection{TOBI.}

Es en realidad un conjunto de interfaces que conectan partes de diferentes sistemas BCI [218]. Estas interfaces transmiten los datos en bruto, características extraídas, salidas del clasificador y eventos de una manera estandarizada. Por lo tanto facilita la distribución de la investigación entre diferentes sistemas y plataformas BCI. Los módulos están interconectados por diferentes interfaces, etiquetados como TiA, TiB y TiC (interfaz de TOBI A, B, y C). Cada interfaz transmite determinados tipos de señales que se utilizan en los sistemas BCI. El software de interfaz de usuario se basa en un motor gráfico muy sofisticado que ofrece una experiencia realista al usuario y que garantiza a su vez la versatilidad y eficiencia en el desarrollo de aplicaciones.

\subsection{8. $\quad x B C I$.}

Es una plataforma genérica para el desarrollo BCI online [219]. Ofrece a los usuarios una herramienta de desarrollo del sistema fácil de usar y reduce el tiempo necesario para desarrollarlo. De sus características destacamos el diseño extensible y modular sistema, el desarrollo de sistemas basados en GUI o el soporte multiplataforma. La plataforma consta de varios módulos funcionales (componentes), que pueden ser utilizados para realizar un sistema BCI específico. Cada componente es completamente independiente (como un plugin) y pueden ser añadidos o modificado sin necesidad de compilar toda la plataforma, demás que pueden ser distribuidos por separado. 


\subsection{9. $\mathrm{BF}++$.}

Su objetivo es proporcionar herramientas para la aplicación, modelado y análisis de datos de los sistemas BCI. Es altamente escalable y multiplataforma [220]. Está implementado utilizando diferentes lenguajes de programación, tales como $\mathrm{C}++$, XML (Lenguaje de Marcas eXtensible), para el almacenamiento, y UML (Lenguaje Unificado de Modelado), para la descripción y documentación. En $\mathrm{BF}++$, los dos elementos principales son el transductor, que es responsable de la adquisición de señales neurofisiológicos y su clasificación, y la interfaz de control, que procesa la salida del clasificador y controla los dispositivos periféricos. Esta plataforma se ha ampliado recientemente al añadir comportamiento dinámico y una descripción del modelo de uso de los diagramas de secuencia de UML.

\subsubsection{Pyff.}

Es una plataforma para el desarrollo rápido de paradigmas experimentales y la realización experimentos neuro-científicos. Usa Python como lenguaje de programación, es multiplataforma y proporciona la parte específica del BCI correspondiente a la presentación del estímulo [221].

\subsubsection{AsTeRICS.}

Esta plataforma permite construir de manera fácil y económica lo que se denomina como tecnologías de asistencia [223], con lo que se trata de un sistema parecido al anterior donde se trata la presentación del estímulo, pudiendo controlar dispositivos diversos como webcam, interruptores, teclados y otros dispositivos conectables a PC.

Como conclusión, esta sección permite a cualquier usuario interesado (investigadores, programadores y usuarios finales) identificar plataformas SW en función de sus necesidades para el desarrollo de sistemas BCI. 


\subsection{Sistema BCI utilizado (Hardware)}

Esta Tesis Doctoral contiene dos experimentos realizados para demostrar el rendimiento de los Clasificadores ELM bajo diversas circunstancias. El Experimento 1 presenta señales propias, es decir, no descargadas de ninguna base de datos, mientras que el Experimento 2 prueba el rendimiento del ELM bajo diversas configuraciones y circunstancias con señales provenientes del BCI Competitions IV, pues son señales de referencia en el área de BCI. En esta Sección se realiza una descripción del equipamiento empleado hardware y del paradigma temporal empleado para la adquisición de la señal de EEG realizada en el Experimento 1.

\subsubsection{Hardware g.USBAmp}

El g.USBamp es un amplificador de bioseñales de alto rendimiento y precisión a la vez que un sistema de adquisición y procesamiento de señales, Ver Figura 4.8.1. Permite la investigación de las actividades cerebral, cardiaca y muscular, los movimientos oculares, la respiración, la respuesta galvánica de la piel y muchos otros parámetros fisiológicos y físicos. Debido a sus especificaciones técnicas y diversas opciones en el software, este instrumento se ha convertido en un estándar para muchos campos distintos de investigación, incluyendo la neuropsicología, la investigación médica y por supuesto la investigación en BCI.

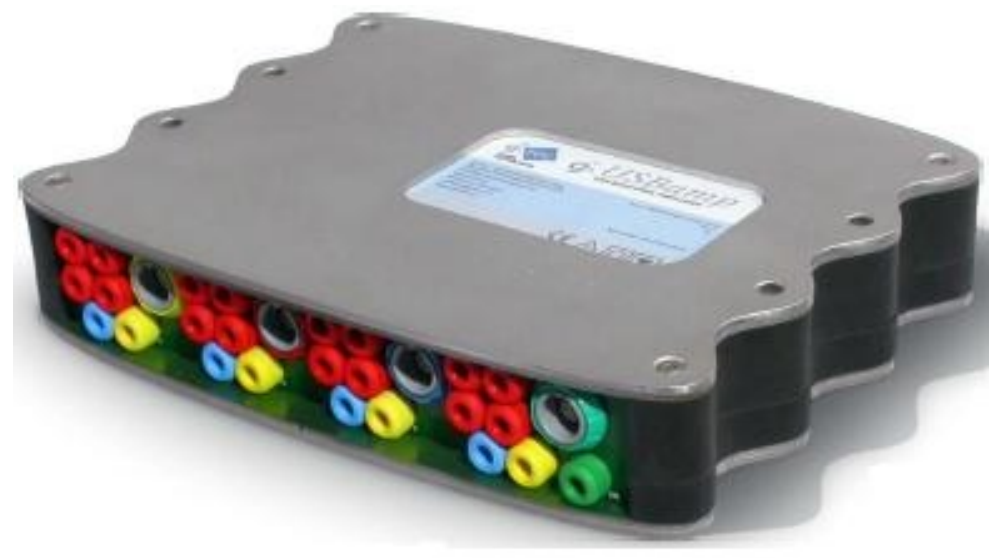

Figura 4.8.1: g.USBAmp.

El g.USBamp se compone de 16 canales de adquisición de bioseñales muestreadas simultáneamente con 24 bits y un total de 4 tierras independientes que garantizan que las señales adquiridas no interfieran entre ellas. Es posible ensamblar un sistema multicanal con más de 16 canales a través de múltiples dispositivos g.USBAmp. Un cable de sincronización garantiza que todos los dispositivos sean muestreados con la misma frecuencia. 
El amplificador tiene un rango de entrada de $\pm 250 \mathrm{mV}$, lo que permite la grabación de señales de DC sin saturación. Además posee entradas y salidas digitales que permiten la grabación de canales de disparo junto con los canales de bioseñales para compartir de manera sencilla los resultados del análisis. Los aspectos a destacar del uso de este hardware para sistemas BCI son los siguientes:

- 16 canales de alto rango por unidad (acoplamiento en DC), 4 tierras independientes, grabación de cualquier tipo de señal (EEG / ECoG / ECG / EMG / EOG /...), conexión de varios sensores, ampliación de unidades hasta 32/48/64 canales.

- Resolución de 24 bits con muestreo simultáneo de todos los canales con un máximo de 38,4 $\mathrm{kHz}$, filtración de señales digitales y procesamiento previo. - Trabaja con electrodos pasivos y activos, 8 entradas de disparo digitales, 4 salidas digitales.

- Filtros de corte (Notch), filtros pasa banda digitales internos, unidad de calibración integrada y medición de impedancias.

- Fácil configuración y puesta en marcha a través del software y alta velocidad en el procesamiento de datos en línea disponibles para SIMULINK y para LabVIEW.

\subsubsection{Casco gEEGcap.}

Para la sujeción de los electrodos se emplea un casco fabricado con malla elástica que presenta huecos tal y como se observa en la Figura 4.8.2. Los electrodos se ubicarán en las zonas de interés, que vendrán determinadas por el paradigma empleado y las tareas a realizar por el usuario a lo largo del estudio. Es importante destacar que la situación de los huecos, siguen el sistema de referencia estándar 10/20. 


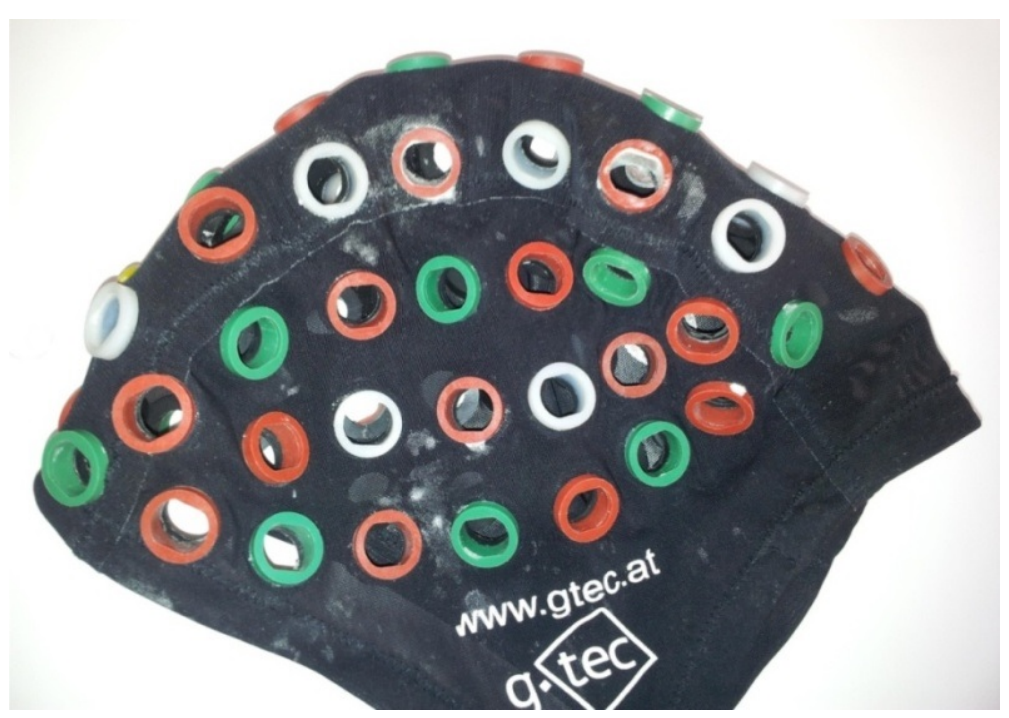

Figura 4.8.2: Casco gEEGcap para la inserción de electrodos de la firma Gtec según el sistema estándar 10/20.

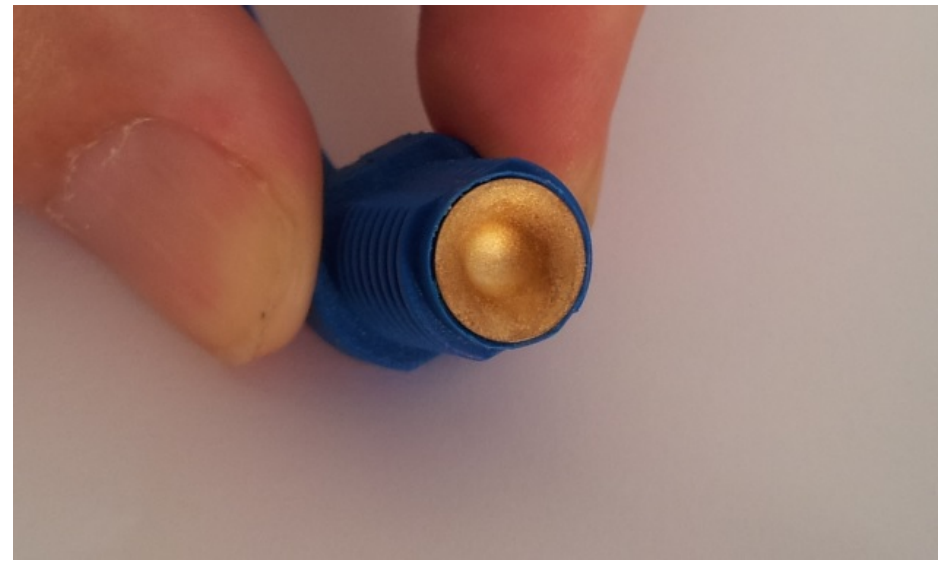

Figura 4.8.3: Imagen de electrodo utilizado.

Para conseguir la correcta sujeción del casco a la cabeza y evitar el desplazamiento de los electrodos sobre el cuero cabelludo, se emplean cascos de diversos tamaños en función del tamaño de la cabeza y, unas tiras elásticas a modo de tirantes, que unen el casco con una banda previamente puesta alrededor del pecho el usuario.

\subsubsection{Electrodos Ag/AgCl (Plata/Cloruro de Plata).}

Se han empleado electrodos pasivos (que no integran electrónica) de $\mathrm{Ag} / \mathrm{AgCl}$, como los que se pueden ver en la Figura 4.8.3. El electrodo estándar de $\mathrm{Ag} / \mathrm{AgCl}$, está diseñado para medidas 
de alta fiabilidad en zonas superficiales, es decir, de forma no invasiva. Su instalación no es directa, pues este tipo de electrodo, requiere primero de la aplicación de un gel abrasivo que limpie y elimine la piel muerta de la zona sobre la que se ubicará y, seguidamente, la aplicación de un gel conductor que lo recubra totalmente y que reduzca la impedancia entre electrodo y cuero cabelludo.

El electrodo está diseñado para poder ser encajado en el casco, y requiere de una limpieza exhaustiva tras cada uso para evitar su deterioro.

\subsubsection{Paradigma utilizado.}

El equipo gTec dispone de la implementación de un paradigma desarrollado en Simulink (MATLAB). La ilustración 4.8.4 muestra de forma gráfica la secuencia temporal del mismo.

Los distintos ítems del experimento que viene implementado se describen a continuación:

- El experimento comienza con una cruz fija que se muestra en el centro del monitor.

- Después de dos segundos se reproduce una señal auditiva de advertencia en forma de un 'beep' y una señal de disparo se fija en la salida del bloque paradigma.

- Desde el segundo 3 hasta el segundo 4,25 una flecha (estímulo), apuntando hacia abajo o hacia la derecha se muestra en el monitor. 


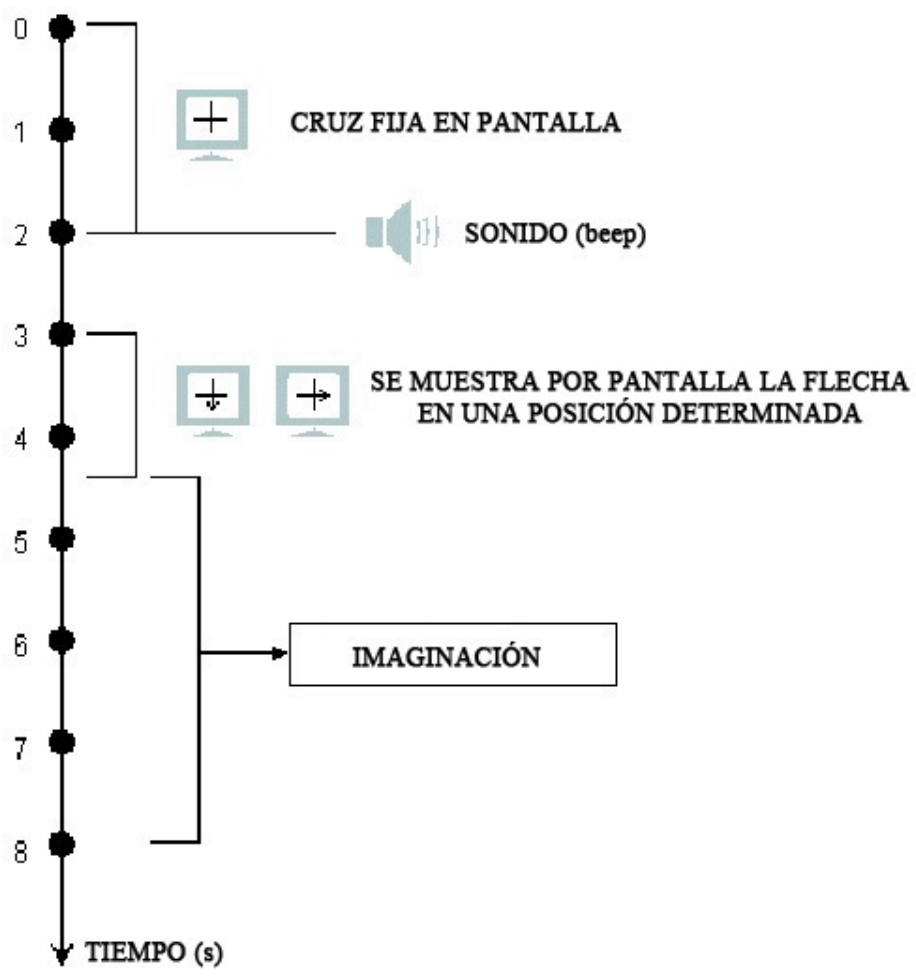

Figura 4.8.4: Esquema temporal del paradigma que provee el equipo de la firma gTec para la realización de experimentos de BCI basados en Imaginación de Movimiento.

Habitualmente en un experimento de este tipo, al sujeto que lo realiza se le pide que imagine el movimiento de la mano derecha, o izquierda en función de a donde apunta la flecha y, que mantenga esa imaginación durante 4 segundos.

Si el experimento se realizó con realimentación, una barra horizontal indica el resultado de la clasificación. La barra se extiende hacia el lado derecho si interpreta que el usuario imagina el movimiento de la mano derecha y hacia la izquierda si interpreta que imagina el movimiento de la otra mano. El experimento dura 8 segundos y el tiempo entre dos iteraciones es aleatorio, en un rango de 0,5 a 2,5 segundos para evitar la adaptación. 


\section{Capítulo 5}

\section{Extracción y Clasificación de características.}

Tal y como se ha descrito en los Capítulos anteriores, los sistemas BCI se componen de varias etapas. En esta tesis se le presta especial atención en aras de la claridad, a las etapas de Extracción de Características y de Clasificación. En este Capítulo se pretenden presentar cuales son los métodos de computación empleados en los Experimentos realizados.

\subsection{Extracción de Características.}

La extracción de características intenta cuantificar de manera numérica los atributos de interés de las señales EEG. En otras palabras, durante la extracción de características se calculan un conjunto de variables numéricas a partir de las señales EEG, previamente adquiridas, y estas variables son recogidas un vector de datos o patrón. Así, se puede considerar la extracción de características como la compresión de datos que elimina la información irrelevante y conserva la información relevante de los datos en bruto. Por lo tanto, es evidente que la extracción de un conjunto adecuado de características es crucial para el funcionamiento preciso de un sistema BCI. Unas buenas características que discriminen de manera efectiva las señales son esenciales para el éxito de cualquier sistema de reconocimiento de patrones y su posterior clasificación.

Es habitual utilizar una técnica para realizar esta tarea, pero no tiene porqué ser solo una. En ocasiones, ver Figura 5.1.1, es posible utilizar diferentes métodos de extracción de características a la vez para aprovechar la información complementaria que pueda aportarnos cada método [10,11] y, no uno solo, como hacen la mayoría de las publicaciones en BCI.

Dependiendo del método empleado y de si se han combinado varios de ellos, se pueden generar vectores de características de gran tamaño. Por ello, suele ser habitual incorporar una etapa de selección o de proyección de características para obtener las más apropiadas para la clasificación. 


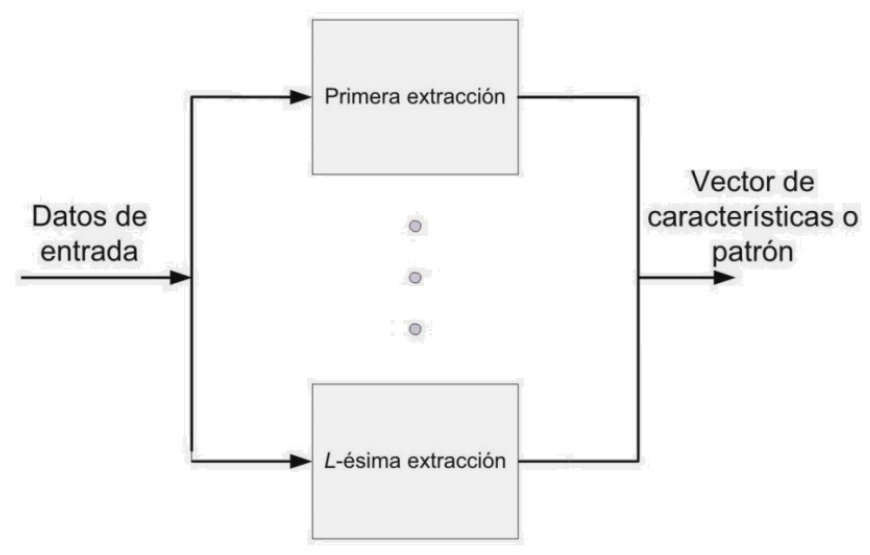

Figura 5.1.1: Extracción de características a partir de señales EEG.

Para conseguir unas tasas de reconocimiento elevadas en la posterior etapa de clasificación, hay una serie de aspectos que se deben considerar para seleccionar los métodos de extracción de características:

- El tipo de señal que se captura, es decir, que paradigma es el que tiene que realizar el usuario y, por lo tanto, que "tarea" provoca su generación.

- Ofrecer una buena capacidad de discriminación (lo ideal, es un número reducido de clases y una gran separación entre ellas).

- Ser insensible a las variables externas (como el ruido y la interferencia).

- Ser relativamente rápido si la aplicación es en tiempo real.

Siguiendo la bibliografía de referencia en sistemas BCI [155], en este trabajo se han implementado los siguientes métodos de extracción por su relevancia para paradigmas de imaginación de movimiento:

- Densidad Espectral de Potencia (PSD, Power Spectral Density).

- Parámetros de Hjörth.

- Modelado adaptativo autorregresivo (AAR, Adaptive Auto Regressive). 
A continuación se describen los 3 métodos anteriores, así como los Patrones Espaciales Comunes, a pesar de no haber sido implementado en esta tesis, debido a la gran relevancia que ha tenido en los últimos años.

\subsubsection{Densidad Espectral de Potencia(PSD).}

La función de densidad espectral de potencia o PSD, es una función matemática que nos muestra como está distribuida la potencia o la energía sobre las distintas frecuencias de las que está formada su espectro [193]. En otras palabras, muestra en qué frecuencias las variaciones son fuertes y en qué frecuencias las variaciones son débiles. El cálculo de las características espectrales mediante la función PSD se realiza directamente con la transformada rápida de Fourier o FFT, (del inglés Fast Fourier Transform.) trabajando en las bandas $\alpha(8-13 \mathrm{~Hz})$ y $\beta(13-30 \mathrm{~Hz})$. Así en las bandas $\alpha$ y $\beta$ vienen dadas por:

$$
\begin{aligned}
P_{\alpha} & =\frac{F F T^{*}\left(E E G_{\alpha}\right) \times F F T\left(E E G_{\alpha}\right)}{p^{2}},(5,1) \\
P_{\beta} & =\frac{F F T^{*}\left(E E G_{\beta}\right) \times F F T\left(E E G_{\beta}\right)}{p^{2}},(5,2)
\end{aligned}
$$

donde $p$ es el número de muestras de la ventana temporal, $F F T\left(E E G_{\alpha}\right)$, denota la transformada rápida de Fourier en la banda $\alpha$ y $F F T^{*}\left(E E G_{\alpha}\right)$ es el complejo conjugado. La misma notación es empleada para la banda $\beta$ de la señal EEG.

\subsubsection{Parámetros de Hjörth.}

Los parámetros desarrollados por B. Hjörth, originalmente denominados descriptores normalizados de pendiente (NSD, del inglés Normalized Slope Descriptors), se aplican fundamentalmente a señales del tipo EEG. Los parámetros de Hjörth más utilizados son: la actividad, la movilidad y la complejidad [156]. Estos tres parámetros se definen a partir de diversos momentos estadísticos de la densidad espectral de potencia, que en el caso de los momentos de orden 0,2 y 4 se obtienen con:

$$
\begin{aligned}
& m_{0}=\frac{1}{p} \sum_{i=1}^{p} x_{i},(5,3) \\
& m_{2}=\frac{1}{p} \sum_{i=1}^{p} d_{i}=\frac{1}{p} \sum_{i=1}^{p}\left(x_{i}-x_{i-1}\right),(5,4) \\
& m_{4}=\frac{1}{p} \sum_{i=1}^{p}\left(d_{i}-d_{i-1}\right)^{2}=\frac{1}{p} \sum_{i=1}^{p}\left(x_{i}-2 x_{i-1}+x_{i-2}\right)^{2}
\end{aligned}
$$


Donde $x_{i}$ es la muestra i-ésima de la señal EEG obtenida tras la adquisición y el preprocesado, considerando que la región de interés de la señal $E E G$ está compuesta por $p$ muestras.

La actividad $h_{0}$ se define cómo el momento de orden 0:

$h_{0}=m_{0},(5,6)$

la movilidad $h_{1}$, se define como:

$h_{1}=\sqrt{\frac{m_{2}}{m_{0}}},(5,7)$

y la $h_{2}$ es:

$h_{2}=\sqrt{\frac{m_{4}}{m_{2}}-\frac{m_{2}}{m_{0}}},(5,8)$

\subsubsection{Modelo adaptativo autorregresivo (AAR).}

Un modelo autorregresivo (AR) es una técnica de modelado paramétrico que describe la muestra actual de la señal como una combinación lineal de las $m$ muestras anteriores más un término de error. Los parámetros AR se calculan bajo la su posición de que la señal es estacionaria en cada segmento. Cuando los coeficientes de la combinación lineal varían con el tiempo se habla de modelos AR adaptativos [157], (AAR, del inglés Adaptive AutoRegressive).

De manera general, y considerando una señal EEG denotada por $s(t)$ en el dominio temporal, su modelo AR de orden $m$ se puede expresar con la siguiente ecuación:

$$
s(t) \approx s(t)+a_{1} s(t-1)+\cdots+a_{m} s(t-m),(5,9)
$$

donde $m$ es el orden del modelo y $\left[1, a_{1}, \ldots, a_{m}\right]$ es el vector de coeficientes del modelo lineal. Por lo tanto, tal y como vemos en (5.9), cada muestra de la señal de entrada es predicha por la suma ponderada de las m muestras anteriores, según el vector de coeficientes del modelo AR.

Durante la etapa de diseño de un modelo AR es necesario determinar dos parámetros: la longitud de la ventana de datos (es decir, duración de la señal sobre la que se ajustan los coeficientes del modelo) y el orden del modelo (es decir, el número de coeficientes). Actualmente, en la literatura no existe un único criterio aceptado para la selección de estos dos parámetros, que deben ser seleccionados en función de la experiencia previa del investigador y los datos $E E G$ analizados 
[154]. Así, por ejemplo, Schlögl considera un modelo con $m=3$ [194], Ince utiliza $m=6$ [195] y McFarland emplea $m=16$ [196].

En realidad, los modelos AR pueden proporcionar estimaciones espectrales para los segmentos de cualquier duración. Sin embargo, esto no significa que las señales se puedan resolver con precisión infinita, es decir que la predicción sea exacta aumentando el orden del modelo. Adicionalmente, el modelado AR se acompaña de una serie de restricciones conectadas con importantes hipótesis analíticas:

- El proceso no debe ser anticipante (hipótesis de recursividad temporal); lo que quiere decir que los valores de una variable en un momento $t$ no de penderán de los que ésta misma tome en $t+n$.

- La magnitud de los coeficientes está limitada en valor absoluto, así, por ejemplo, en el caso de un AR con $m=1$, el coeficiente autorregresivo de un proceso estocástico estacionario ha de ser inferior a 1 en valor absoluto, en el caso de un AR con $m=2$ es la suma de los dos coeficientes la que no puede exceder la unidad.

Por último, cabe destacar una evolución del modelado AR: el modelado adaptativo autorregresivo (AAR). La principal diferencia es que en el modelado AAR los parámetros (valores del vector de coeficientes del modelo) no son constantes y varían con el tiempo de forma adaptativa, por lo que estos parámetros describen el comportamiento temporal de la señal y la nueva ecuación queda tal y como se presenta a continuación:

$$
s(t+1) \approx s(t)+a_{1}(t) s(t-1)+\cdots+a_{m}(t) s(t-m),(5,10)
$$

En esta ecuación, $m$ sigue siendo el orden del modelo y $\left[1, a_{1}(t), \ldots, a_{m}(t)\right]$ son los parámetros variables del modelado AAR. Los algoritmos de estimación de los parámetros AAR tienen la ventaja de realizar una estimación temporal de alta resolución con un bajo coste computacional, y son por lo tanto válidos para aplicaciones en tiempo real, además son especialmente útiles cuando no se aplica un promediado temporal de la señal [157]. Algunos de estos algoritmos son: Least-MeanSquares (LMS) [197, 198], Recursive-Least-Squares (RLS) [199], Recursive AR (RAR) [200] así como filtrado de Kalman [201]. Un filtro de Kalman realiza la propagación de la densidad de probabilidad para problemas en los que el sistema puede ser descrito mediante un modelo lineal y los ruidos en las mediciones son gaussianos. 


\subsubsection{Patrón Espacial Común (CSP).}

El Patrones Espaciales Comunes (CSP) es un algoritmo basado en el análisis de componentes principales de la señal. Aunque se ha utilizado principalmente en el reconocimiento facial, reconocimiento de objetos y detección de anomalías en el EEG, también se ha aplicado con éxito en estudios con BCI. El algoritmo CSP se basa en estadísticas multidimensionales que a menudo se han aplicado a la extracción y análisis de características de la señal EEG en métodos multicanal de dos clases. Según los fenómenos de ERD/ERS durante la imaginación de movimiento, la extracción de características mediante CSP es la siguiente: en primer lugar, las dos clases de la señal EEG basadas en la MI serán filtradas por CSP para crear una clase de señales (como la MI de la mano izquierda) con máxima varianza y una clase (como la MI de la mano derecha) con mínima varianza, haciendo una clara distinción entre los dos grupos. Los siguientes son los pasos específicos de la extracción de características de la señal del EEG usando CSP.

Supongamos que la señal EEG de las imágenes motoras se expresa como $E_{i}^{j}$, donde i es la muestra y j representa una de las dos categorías diferentes con el rango $j \epsilon 1,2$. La dimensión de la señal del EEG es $N \times T$, donde $N$ es el número de canales y $T$ el número de muestras registradas en el experimento. Los pasos para crear las dos clases de MI para la extracción de características de la señal EEG son los siguientes:

(1) Calcular la covarianza muestral de las dos clases de MI:

$$
R_{j}=\frac{E_{i}^{j} \cdot E_{i T}^{j}}{\operatorname{traza}\left(E_{i}^{j} \cdot E_{i T}^{j}\right)},(5,11)
$$

Donde $E_{i T}^{j}$ es la transpuesta de $E_{i}^{j}$ y $\operatorname{traza}\left(E_{i}^{j} \cdot E_{i T}^{j}\right)$ es la traza de la matriz, y $R_{j}$ representa la covarianza de la clase $\mathrm{j}$. La covarianza espacial se puede calcular como el promedio de todos los datos de la misma clase de covarianza de la señal EEG.

Suponiendo que los valores medios de covarianza de la muestra de MI de dos clases que se indican como $\bar{R} 1$ y $\bar{R} 2$, entonces la covarianza general puede expresarse de la siguiente manera:

$$
R_{c}=\bar{R} 1+\bar{R} 2,(5,12)
$$

(2) La descomposición de las características de $R_{c}$ por el análisis de los componentes principales es la siguiente:

$$
R_{c}=B \cdot \lambda \cdot B^{T},(5,13)
$$

donde $B$ es la matriz que contiene los vectores y $\lambda$ son los valores de características correspondientes. La desviación se puede uniformar mediante una matriz de blanqueamiento, y la matriz de 
blanqueamiento $P$ se define como:

$$
P=\lambda^{-1 / 2} \cdot B^{T},(5,14)
$$

La covarianza media de las dos clases de la señal EEG de las MI puede entonces ser cambiada como sigue con la matriz blanqueadora $\mathrm{P}$, aplicando:

$$
\begin{aligned}
& S_{1}=P \cdot \bar{R} 1 \cdot P^{T},(5,15) \\
& S_{2}=P \cdot \bar{R} 2 \cdot P^{T},(5,16)
\end{aligned}
$$

(3) La matriz de covarianza de las dos clases tiene los mismos vectores propios:

$$
\begin{aligned}
& S_{1}=U \cdot \lambda_{1} \cdot U^{T},(5,17) \\
& S_{2}=U \cdot \lambda_{2} \cdot U^{T},(5,18)
\end{aligned}
$$

Así que se pueden obtener los correspondientes valores característicos de las dos clases de matrices de covarianza, los cuales han sido expresados aquí como los valores $\lambda_{1} y \lambda_{2}$ que satisfacen la ecuación $\lambda_{1}+\lambda_{2}=I$, donde I es una matriz de identidad. Por lo tanto, según la fórmula anterior, si el valor de característica de $S_{1}$ es máximo, entonces el valor de característica del vector de característica correspondiente de $S_{2}$ es mínimo, y viceversa, con lo que las dos clases de la señal EEG son separables.

(4)Según el paso (3), $U$ se puede utilizar para distinguir los dos tipos diferentes de conjuntos de datos. Los vectores de característica representativos del primer-m y el último-m pueden ser elegidos para formar una matriz de los dos tipos de vectores de característica y la matriz de proyección puede ser expresada como:

$$
W=B^{T} \cdot P,(5,19)
$$

A continuación, la matriz proyectada de los dos tipos de la señal EEG de las imágenes motoras a través del filtro puede expresarse de la siguiente manera:

$Y=W \cdot E_{i}^{j},(5,20)$

Por último, la característica del coeficiente del logaritmo puede indicarse como: 


$$
f_{j}=\log \left(\frac{\operatorname{var}\left(Y_{j}\right)}{\sum_{k=1}^{k=2 m} \log \left(\operatorname{var}\left(Y_{k}\right)\right.}\right),(5,21)
$$

, donde $\mathrm{j}=1,2, \ldots, 2 \mathrm{~m}$ y $Y_{j}$ es el término en $\mathrm{j}$ de la linea correspondiente de $Y$ y $\operatorname{var}\left(Y_{j}\right)$ es la varianza.

En la extracción de la característica EEG utilizando el CSP tradicional, los datos se registran de un solo sujeto. Cuando el tamaño de la muestra para este sujeto es pequeño, los resultados de extracción de características a menudo son insatisfactorios, especialmente considerando que fácilmente los datos del EEG pueden ser influenciados por las emociones o condiciones físicas de los sujetos. Para resolver este problema, se ha utilizado el algoritmo de Patrón Espacial Común Regularizado (RCSP) para la extracción de características [202]. Este método introduce un parámetro de regularización para evitar los inconvenientes de una sola muestra y reducir las diferencias individuales.

\subsection{Clasificación de características.}

Se introducen a continuación de forma muy breve algunos clasificadores ampliamente usados en BCI.

El objetivo de la etapa de clasificación de un sistema BCI es el reconocimiento de las intenciones del usuario en base a un vector de características que representa las propiedades de la señal recogida a partir de la actividad cerebral. Este vector como se ha explicado en secciones anteriores es generado por la etapa de extracción de características. Para lograr clasificar los vectores de características con el fin de clasificar las señales cerebrales se han propuesto varios algoritmos tales como clasificadores basados en el vecino más cercano o clasificadores lineales.

\subsubsection{FLD (Discriminante lineal de Fisher).}

El discriminante lineal de Fisher (FLD) es un clasificador bastante simple que proporciona una precisión aceptable sin requisitos computacionales elevados. Este método de clasificación es muy común en la comunidad BCI y es una muy buena opción para el diseño de sistemas BCI online que requieran una respuesta rápida con recursos computacionales limitados. FLD se suele aplicar para clasificar los patrones encontrados en las señales cerebrales en dos clases y ofrece una precisión relativamente aceptable y se ha utilizado con éxito en numerosos sistemas BCI como dispositivos de escritura basados en respuestas P300, BCI multiclase o BCI síncronos, vistos anteriormente. Sin embargo, puede suceder que este clasificador lleve a conclusiones totalmente equivocadas cuando, 
entre los vectores de propiedades de entrenamiento que se emplean para construir el clasificador, existan valores atípicos o que hayan sido afectados severamente por el ruido.

Para un problema de dos clases, FLD supone que estas son linealmente separables. Según esta hipótesis, se define una función lineal que representa un plano en el espacio de características para distinguir la clase a la que pertenece el vector de características a clasificar. La clase a la que el vector de propiedades pertenece se decide en función del lado del plano en el que se encuentra el vector de la siguiente ilustración.

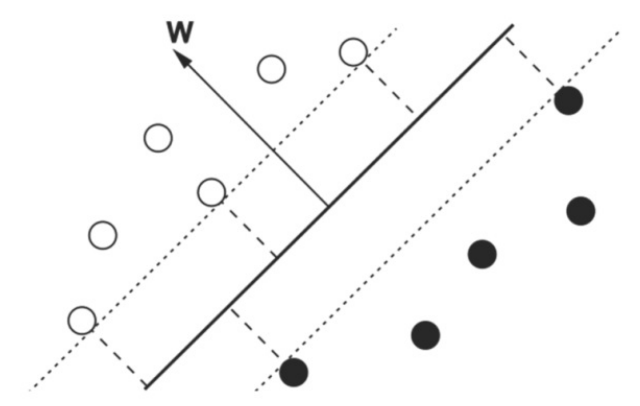

Figura 5.2.1: Clasificador lineal.

https://scielo.conicyt.cl/fbpe/img/bres/v40n4/fig05-02.jpg

La frontera de decisión es la línea continua. El margen del clasificador lineal es la mínima distancia de cualquier punto a la frontera de decisión. En este caso, el margen es la distancia entre las líneas punteadas y la línea continua.

El plano de decisión se puede representar matemáticamente como:

$$
g(x)=w^{T} x+w_{0},(5,22)
$$

donde $w$ es conocido como el vector de pesos, $x$ es el vector de características de entrada y $w_{0}$ es un umbral. El vector de propiedades de entrada $x$ se asigna a una clase u otra en función del signo de $g(x)$. Existen varios métodos para calcular $w$. Por ejemplo, se puede calcular como $w$ [203]:

$$
w=\widehat{\sum}_{c}^{-1}\left(\widehat{\mu}_{2}-\widehat{\mu}_{1}\right),(5,23)
$$

donde $\widehat{\mu}_{i}$ es la media de la clase $i$ y $\widehat{\sum}_{c}=\frac{1}{2}\left(\widehat{\sum}_{1}+\widehat{\Sigma}_{2}\right),(5,24)$, es la matriz de covarianza 
común, que se calcula como la media de las matrices de covarianza de las dos clases $\widehat{\sum}_{i}$. La estimación de la media y la covarianza se hace según:

$$
\begin{aligned}
& \widehat{\sum}=\frac{1}{n-1} \sum_{i=1}^{n}\left(x_{i}-\widehat{\mu}\right)\left(x_{i}-\widehat{\mu}\right)^{T},(5,25) \\
& \widehat{\mu}=\frac{1}{n} \sum_{i=1}^{n} x_{i},(5,26)
\end{aligned}
$$

siendo $x$ una matriz que contiene los $n$ vectores de propiedades $x_{1}, x_{2}, \ldots, x_{n} \in \mathbb{R}^{d}$ utilizados para construir el clasificador lineal.

Como mejoras de este clasificador, se han propuesto algunos algoritmos como Bayesian FLD (BFLD) [204], que se puede ver como una extensión del algoritmo FLD. BFLD resuelve el problema del pequeño tamaño de la muestra introduciendo un método estadístico conocido como regularización. La regularización es realizada a través del análisis bayesiano de los datos de entrenamiento y se emplea para prevenir un sobre-entrenamiento del clasificador a datos de dimensión alta y posiblemente algunos ruidosos. El sobre-entrenamiento no es deseable en un clasificador porque pierde generalidad. Cuando un clasificador está sobre-entrenado solo es capaz de clasificar los datos que se proporcionaron como entrenamiento o aquéllos que se parezcan en gran medida a ellos. El algoritmo BFLD clasifica con mayor precisión y más rápidamente que FLD, especialmente en aquellos casos en los que el número de propiedades es grande. Además, BFLD no consume mucho más tiempo de cálculo, que es un requisito esencial en sistemas BCI de tiempo real.

\subsubsection{SVM (Máquina de soporte vectorial).}

Una máquina de soporte vectorial (SVM, del inglés Support Vector Machine) es un clasificador que, de manera similar que FLD, construye un hiperplano o conjunto de hiperplanos, con el fin de separar los vectores de características en varias clases. Sin embargo, a diferencia del discriminante lineal, SVM selecciona los hiperplanos que maximizan los márgenes, es decir, la distancia de los vectores de propiedades a los hiperplanos [205]. Los vectores que se encuentran más cerca de estos hiperplanos se denominan vectores soporte.

Es muy habitual mapear los vectores de propiedades en un espacio multidimensional con dimensión más alta que el número de propiedades [206]. El teorema de Cover [207] afirma que un problema de clasificación complejo puede solucionarse con un clasificador lineal si se mapean los datos a un espacio de dimensión mayor. También, como sucede en el caso de clasificación mediante FLD, SVM utiliza la regularización con el fin de evitar el clasificador de acomodar conjuntos de datos posiblemente ruidosos. 
El método SVM se ha utilizado para clasificar vectores de características en problemas de dos clases [208, 210, 209], multiclase y también se ha utilizado con éxito para el diseño de un gran número de BCI síncronos.

SVM se considera un clasificador lineal, ya que para llevar a cabo la clasificación utiliza uno o varios hiperplanos. No obstante, es posible crear SVM que empleen límites de decisión no lineales por medio de un núcleo función .Por otra parte los SVM no lineales proporcionan un límite de decisión más flexible lo que puede aumentar la precisión de clasificación. El kernel que se utiliza generalmente en el campo de los BCI es la función de base de Gauss o radial:

$$
K(x, y)=\exp \left(\frac{-\|x-y\|^{2}}{2 \sigma^{2}}\right)
$$

El SVM con núcleo gaussiano se ha aplicado en BCI para clasificar los potenciales evocados P300 [211, 212]. 
Capítulo 5. Extracción y Clasificación de características. 


\section{Capítulo 6}

\section{Redes Neuronales.}

En este capítulo se realiza una introducción a las redes neuronales artificiales (RNA) y al algoritmo de entrenamiento Extreme Learning Machine (ELM). En esta Tesis, se ha utilizado el ELM para entrenar las redes neuronales para la clasificación de señales BCI.

Las RNAs simulan el comportamiento de las neuronas biológicas. Nuestro sistema nervioso se caracteriza por ser:

- Complejo: Es un sistema complejo y sofisticado que regula y coordina las funciones y actividades del cuerpo. Se divide en dos partes principales: El sistema nervioso central: compuesto por el cerebro y la médula espinal. El sistema nervioso periférico: compuesto por el resto de los elementos neuronales.

- No Lineal: Su comportamiento no se expresa como la suma de los comportamientos de sus descriptores.

- Paralelo: Procesa la información sintetizando e integrando la misma a través de procesos paralelos y simultáneos.

- Multifuncional: Está conformado por el cerebro, cerebelo, neuronas, tálamo y otras partes. Los elementos más importantes de él son las neuronas, sin embargo cada uno de los elementos tienen una función ligada a la estabilidad de las acciones que el cuerpo debe hacer.

- Vegetativo.

- Interacciona con el medio.

- (Estímulo/Respuesta) Cognitivo.

- Su unidad funcional es la neurona.

Es fundamental entender el funcionamiento biológico para comprender cómo trabajan las RNAs. A continuación se introducen conceptos básicos de la neurona biológica. 


\subsection{La Sinapsis.}

La transmisión de la información entre neuronas (impulso nervioso) es un fenómeno electro bioquímico (producido por enzimas) que se manifiesta como inversiones de voltaje. La transferencia del impulso nervioso entre neuronas implica la existencia de neurotransmisores (serotonina, dopamina) eyectados desde las ramificaciones del axón hacia los receptores de neurotransmisores de la siguiente célula.

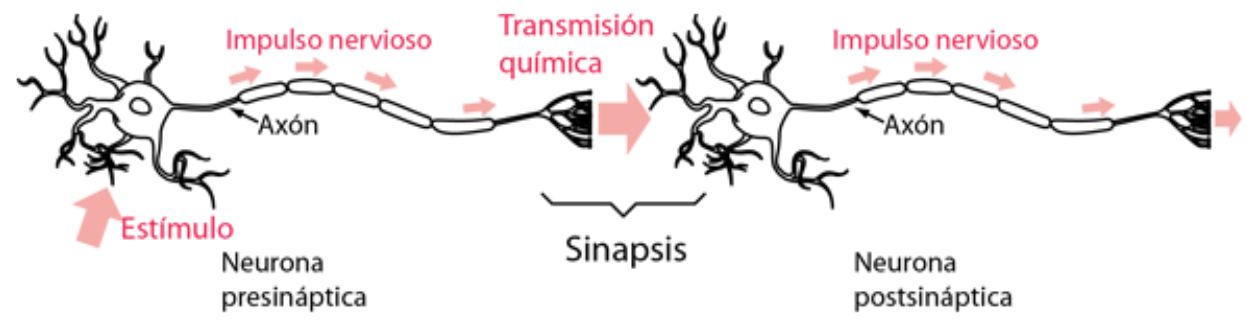

Figura 6.1.1: Proceso de sinapsis.

Fuente: http://hyperphysics.phy-astr.gsu.edu/hbasees/Biology/imgbio/synapse.png

La actividad neuronal en regiones específicas del sistema nervioso da una idea de cómo se distribuyen las cargas de procesamiento de estímulos y tareas dentro del cerebro. Las neuronas se activan con diferentes intensidades dependiendo del nivel de actividad, lo que puede ser medido mediante diferentes técnicas:

- Potenciales Evocados (electroencefalograma).

- Imágenes de Resonancia Magnética Funcional (fMRI).

Vistas ambas técnicas en capítulos anteriores.

\subsection{Capacidad de clasificación.}

Clasificar es una de las funciones elementales del cerebro en los seres vivos. Parte del entrenamiento básico del individuo en maduración consiste en adquirir (aprender) a establecer patrones de similitud y adquirir la habilidad de diferenciar objetos (estímulos). 
El aprendizaje crea físicamente conexiones dendríticas entre diferentes regiones del cerebro estableciendo redes neuronales que permiten realizar diferentes tareas de procesamiento no programadas genéticamente.

\subsection{Redes Neuronales Artificiales (RNA)}

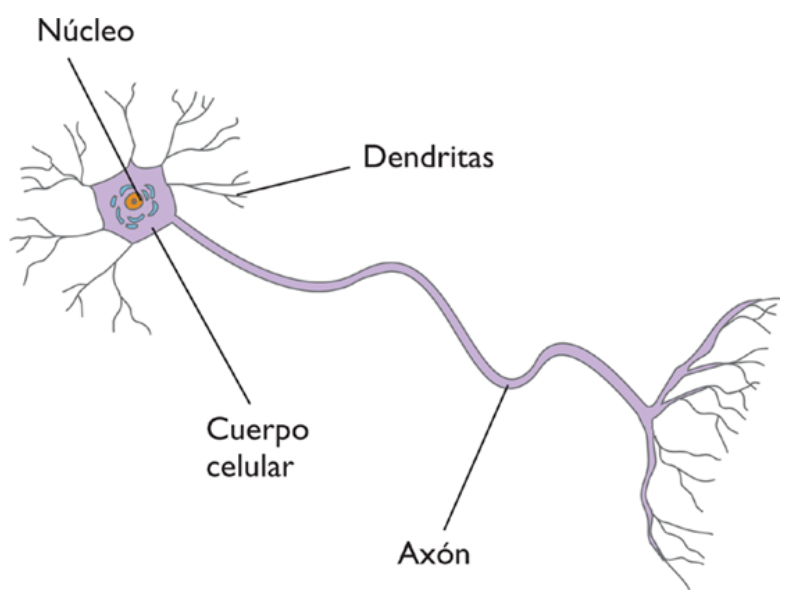

Figura 6.3.1: Neurona biológica.

Fuente: http://2.bp.blogspot.com/

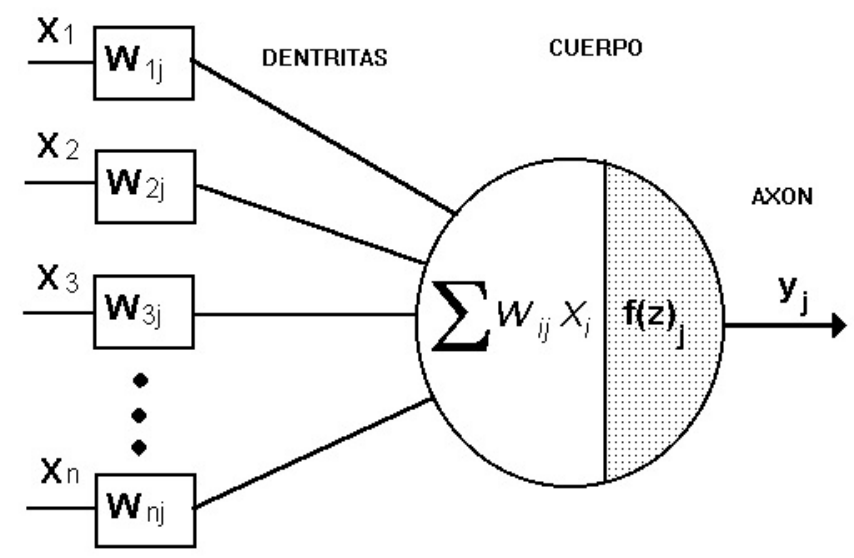

Figura 6.3.2: Neurona artificial.

Fuente: http://electronica.com.mx/neural/informacion/ 
Una RNA es un modelo de caja negra: el funcionamiento interno del modelo no tiene una analogía explícita con los sistemas observados, analizados o controlados.

La respuesta del sistema depende de los datos de entrada y de cómo éstos generan una salida al ser presentados a cada neurona según los pesos asociados a cada enlace y la función de activación asociada a la neurona:

- Los pesos asociados a los enlaces, determinantes de la funcionalidad de cada red neuronal, se establecen en el proceso de aprendizaje (entrenamiento).

- El aprendizaje puede ser supervisado o no supervisado.

- El aprendizaje supervisado presenta patrones de entrada asociados a salidas conocidas. El error en la salida respecto a la salida esperada ser realimentado al sistema en un proceso de corrección, usualmente iterativa (algoritmos de aprendizaje).

\subsection{Funciones de Activación de la Neurona.}

Las funciones de activación de las neuronas pueden ser:

- Binarias

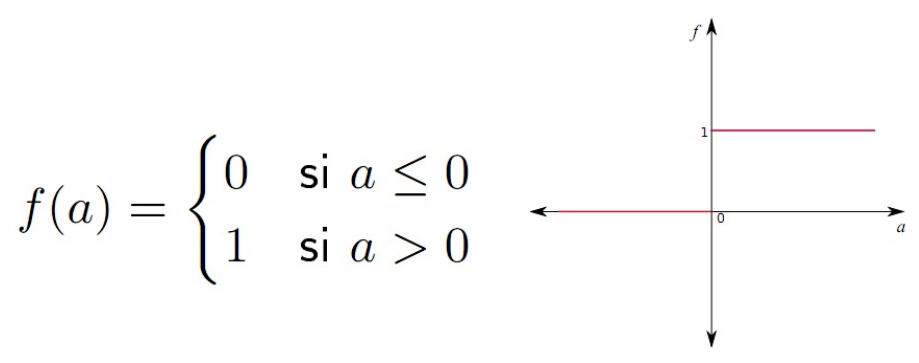

Figura 6.4.1: Activación Binaria.

- Lineales 


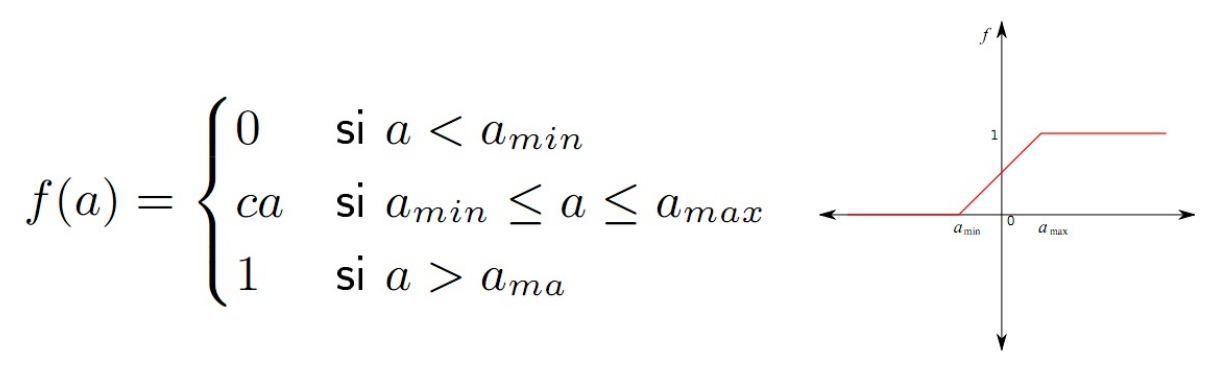

Figura 6.4.2: Activación Lineal.

- Sigmoidales

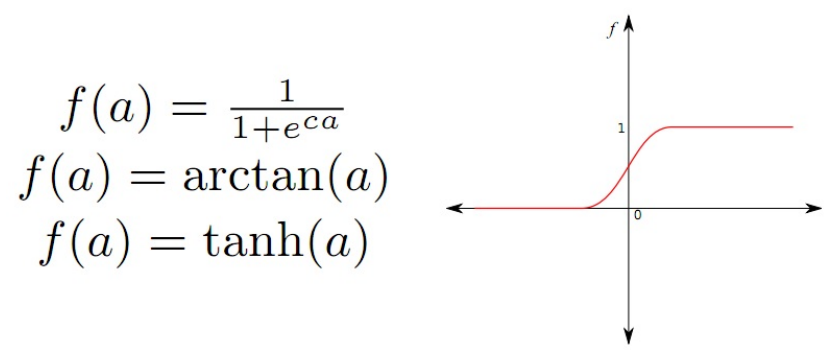

Figura 6.4.3: Activación Sigmoidal.

Un modelo de neurona artificial individual puede identificarse en la siguiente figura:

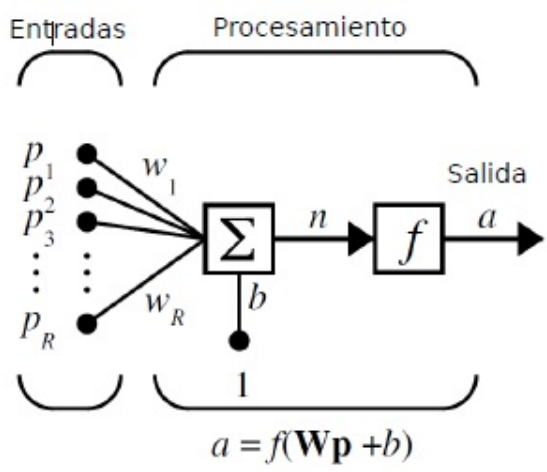

Figura 6.4.4: Modelo de neurona artificial individual.

Fuente: Adaptado de http://www.redes-neuronales.com.es/

La capa de neuronas, puede modelarse como sigue a continuación: 


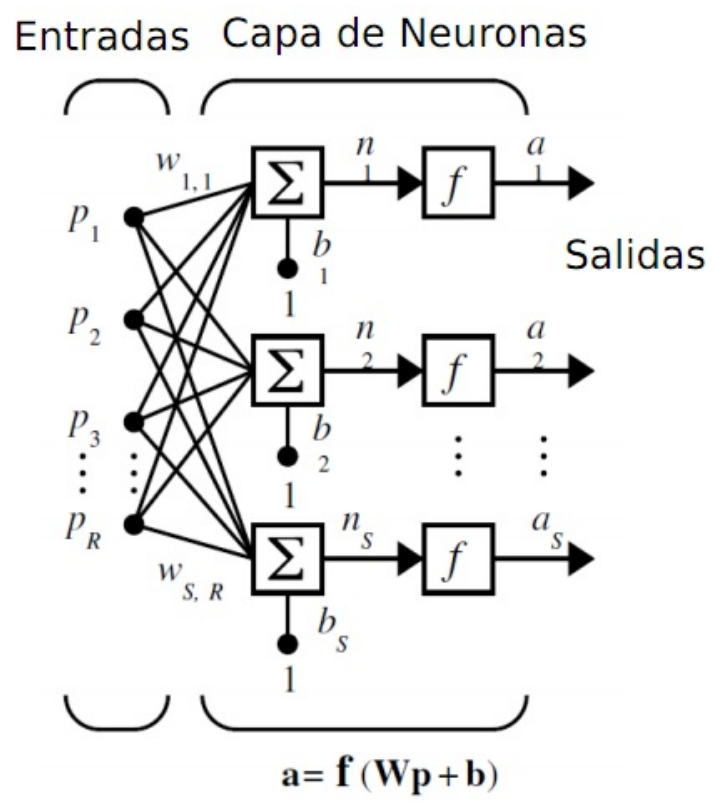

Figura 6.4.5: Capa de Neuronas.

Fuente: Adaptado de http://www.redes-neuronales.com.es/

Donde se observan las entradas a la capa de neuronas y sus salidas correspondientes.

\subsubsection{Modelos básicos de clasificación no formal}

Para ello se establecen los siguientes modelos:

- Modelos mononeuronales: Perceptrón y ADALINE.

- Modelos monocapa: Recurrentes Monocapa (Hopfield).

- Modelos multicapa: FeedForward, MADALINE, recurrentes multicapa, redes neuronales dinámicas y redes de Elman.

\section{El Perceptrón.}

Fue la primera aproximación a los modelos de redes neuronales artificiales (McCulloc, Pitts 1949).

Tenía por objeto el modelado del comportamiento fisiológico del sistema nervioso humano y por su funcionamiento se convirtió en un modelo de clasificación (o separación) de regiones donde 
se suele tener una función de transferencia de paso unitario (binaria).

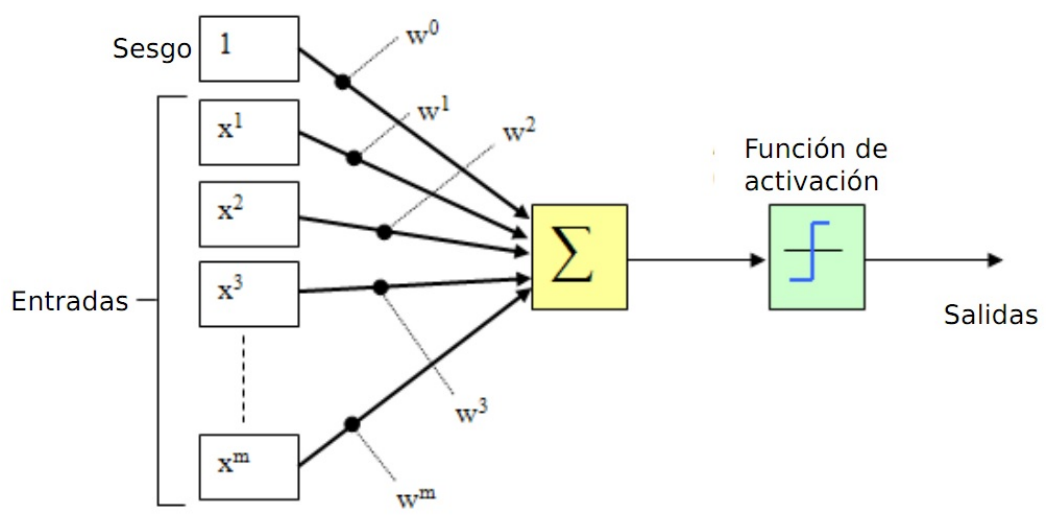

Figura 6.4.6: Modelo de perceptrón.

Fuente: Adaptado de https://www.researchgate.net/figure/Estructura-de-un-Perceptron-multicapa.html

Se describen brevemente a continuación dos de los tipos de modelo de perceptrón: Adaline y Madaline.

\section{ADALINE.}

Extensión del modelo de perceptrón donde la neurona no devuelve un parámetro de decisión binario sino un valor acorde a una función de activación arbitraria, usualmente lineal. Aquí se produce una especialización aplicada al procesamiento de señales cuando se implementa con una función de salida de tipo lineal y su comportamiento se hace análogo al de la aproximación por mínimos cuadrados.

\section{Red Feedforward, MADALINE.}

Cuando se organiza un conjunto de neuronas organizadas por capas, siendo las entradas de una capa dada las salidas de las neuronas de la capa anterior, se tiene una red neuronal multicapa. Si las neuronas son modelos ADALINE, se tiene una red MADALINE En el caso de las redes multicapa genéricas, se suelen usar aproximaciones continuas a funciones de clasificación (sigmoides). 


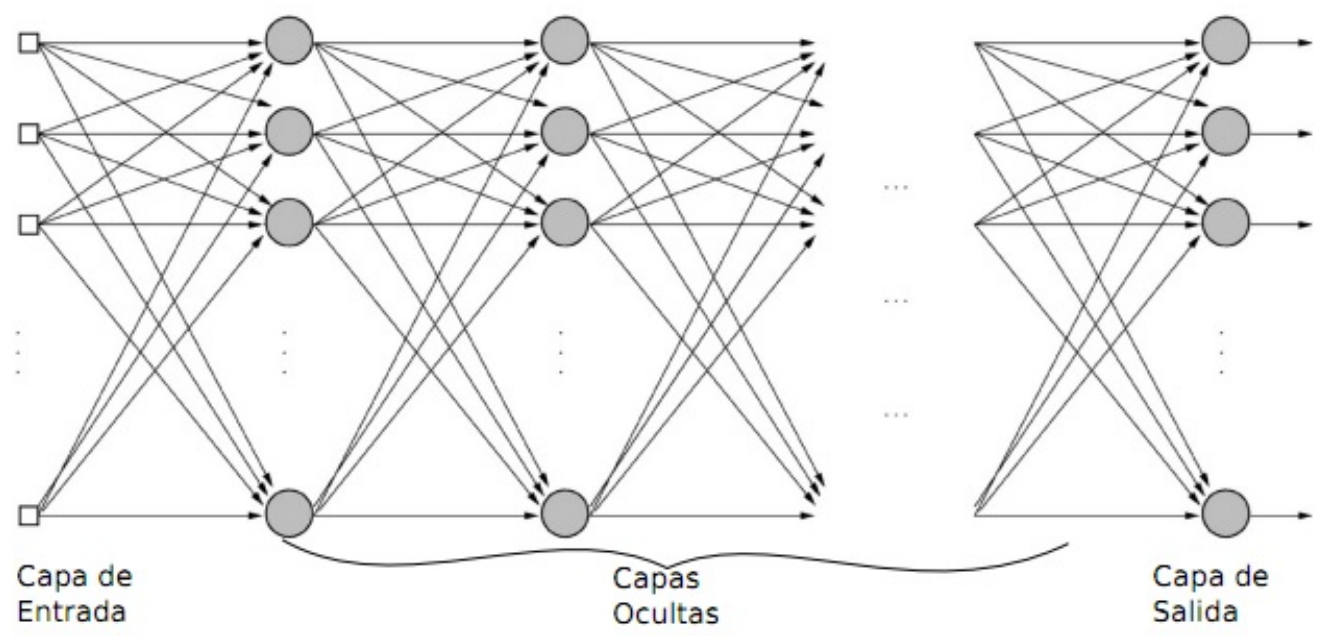

Figura 6.4.7: Modelo Red Feedforward, MADALINE

Fuente: Adaptado de https://www.researchgate.net/

\subsection{ELM (Extreme Learning Machine).}

Esta Tesis introduce la utilización del ELM para clasificación en BCI. Esto presenta una novedad importante ya que hasta ahora los métodos utilizados para clasificación de señales BCI, en los últimos dos años, son métodos clásicos [185, 186, 187, 188, 189]. ELM es un algoritmo para entrenar una SLFN (“Single hidden Layer Feedforward neural Network”). Está basado en el concepto de que si los pesos de entrada y los sesgos de la capa oculta de una SLFN, son asignados al azar, la SLFN puede ser considerada como un sistema lineal y los pesos de salida se pueden determinar analíticamente mediante la inversa generalizada. Esta idea ya fue estudiada en [143, 144] y en [161], hay un estudio profundo acerca de las diferencias entre el ELM y estos trabajos previos. Sin embargo, Huang demostró la capacidad que tiene el ELM para ser un aproximador universal donde los nodos elegidos al azar pueden ser generados de acuerdo con cualquier distribución de probabilidad continua, sin ningún conocimiento previo [161, 145].

Esta asignación aleatoria se puede hacer si las funciones de activación en la capa oculta son infinitamente diferenciables [159]. Así, para $\mathrm{N}$ distintas muestras aleatorias $\left(x_{j}, t_{j}\right)$, donde:

$$
x_{j}=\left[x_{j 1}, x_{j 2}, \ldots, x_{j n}\right] \tau \in \mathbb{R}_{n} ; t_{j}=\left[t_{j 1}, t_{j 2}, \ldots t_{j n}\right] \tau \in \mathbb{R}_{m},(6,1)
$$

y las SLFNs con M neuronas ocultas y función de activación $\mathrm{f}(\cdot)$ son resueltas matemáticamente mediante: 
$o_{j}=X_{M j=1}, f\left(w_{i} \cdot x_{j}+b_{i}\right), j=1, \ldots . N ;,(6,2)$

donde, $w_{i}=\left[w_{i 1}, w_{i 2}, \ldots, w_{i n}\right] \tau,(6,3)$

es el vector de pesos que conecta la i-ésima neurona oculta y las características de entrada;

$i=\left[\beta_{i 1}, \beta_{i 2}, \ldots, \beta_{i m}\right] \tau,(6,4)$, es el vector de pesos que conecta la i-ésima neurona oculta $\mathrm{y}$ las unidades de salida, y $b i$ es el sesgo (bias) de la i-ésima neurona oculta. Además, $w_{i} \cdot x_{j}$ es el producto escalar de $w_{i} y x_{j}$. Obsérvese que las unidades de salida de la red son lineales.

La función de activación más popular para las unidades de la capa oculta es la sigmoide y, en este caso, la SLFN se conoce como MLP ("Multi-Layer Perceptron”).

También se pueden utilizar otras funciones de activación, como por ejemplo las de base radial $[159,160]$ y, en este caso, la SLFN se conoce como RBF ("Radial Basis Function"). En general, las SLFNs estándar con M neuronas en la capa oculta y función de activación f, pueden aproximar estas $\mathrm{N}$ muestras con error cero. A continuación, se explica el algoritmo ELM de una forma más formal.

\subsubsection{Algoritmo ELM.}

Dado un conjunto de entrenamiento $D=\left\{\left(x_{j}, t_{j}\right) \mid x_{j} \in \mathbb{R}^{n}, t_{j} \in \mathbb{R}^{m}, j=1, \ldots, N\right\},(6,5)$, una función de activación f y un número de neuronas en la capa oculta $\mathrm{M}$,

1: Se asignan aleatoriamente los pesos de la capa de entrada $w_{i}$ y sesgos $b_{i} i=1, \ldots, M$.

2: Se calcula la matriz de la capa de salida oculta $H$.

3: Se calcula la matriz de pesos de la capa de salida: $\mathrm{B}=H^{\dagger} T$, siendo $H^{\dagger}$ la matriz inversa generalizada de Moore-Penrose de $H$.

\subsubsection{Métodos de poda para ELM.}

Una de las principales dificultades que presentan las redes neuronales, es encontrar la arquitectura óptima. Esto supone pruebas de ensayo y error que suponen un alto coste computacional. ELM dispone de varios métodos de poda que permiten encontrar de una forma eficiente la arquitectura óptima [178, 179, 180, 181]. Por ejemplo, algunos de estos métodos eliminan individualmente un peso cada vez, lo cual puede resultar sub-óptimo. Otros métodos eliminan uno o varios pesos en un sólo paso y, por lo tanto se reducen significativamente el tamaño de la red reduciendo la comple- 
jidad. En particular, en esta Tesis se utiliza una poda bastante eficiente realizada sobre los nodos ocultos de una SLFN entrenada con el algoritmo ELM. Como ya hemos mencionado, en el algoritmo ELM estándar, los pesos de la capa de salida (B) se calculan teniendo en cuenta los pesos de entrada prefijados aleatoriamente. Una vez calculados, la información de sus valores se emplea para descubrir nodos ocultos poco relevantes para la tarea a resolver $[151,150]$.

Con el fin de mejorar el esquema ELM, se han propuesto esquemas de podas automáticas [160, $162,163,164,166]$. Por lo general, estos métodos se aplican sobre redes ELM en un gran número de nodos de la capa oculta cuyos pesos se inicializan aleatoriamente. Posteriormente, se estudia la relevancia de dichos nodos para proceder a la poda. Se calcula la relevancia de cada nodo de la capa oculta en relación a la salida deseada $\left(\left\{t_{j}\right\}_{j=1}^{N}\right)$. De acuerdo a esa medida de relevancia, se podan o se mantienen los nodos ocultos. Así, los nodos de la capa oculta con baja relevancia se eliminan para obtener una red más compacta que aumenta la capacidad de generalización. El concepto de relevancia se define mediante una medida estadística que es diferente en cada algoritmo de poda $[160,162,163,164]$. Principalmente hay propuestos dos enfoques distintos: P-ELM (Poda ELM "Pruned-ELM") [162] y OP-ELM (Poda Óptima ELM “Optimally Pruned-ELM") [165]. A continuación, se analiza el segundo de estos dos métodos, que es el utilizado en esta Tesis.

\subsubsection{Poda Óptima ELM: OP-ELM.}

Puede ser aplicada tanto a la clasificación como a tareas de regresión. Además, en lugar de utilizar un subconjunto de validación, este procedimiento utiliza el método LOO ("Leave-One-Out") como criterio para la selección de las unidades ocultas. Por otra parte, el OP-ELM utiliza el algoritmo MRSR ("MultiResponse Sparse Regression") para la medición de la relevancia de las unidades ocultas [149]. La principal ventaja del MRSR es que realiza una valoración de las neuronas en la capa oculta. Como se muestra en [163], el OP-ELM ofrece un modelo extremadamente rápido y logra en la mayoría de los casos el mismo nivel de precisión que otros métodos de aprendizaje bien conocidos, como por ejemplo, las SVM ("Support Vector Machine"), GP ("Gaussian Processes") o MLP. A continuación, se detallan las tres etapas principales del método OP-ELM que, a modo de resumen, se muestran en la figura 6.5.1. 


\section{Muestras de entrada}

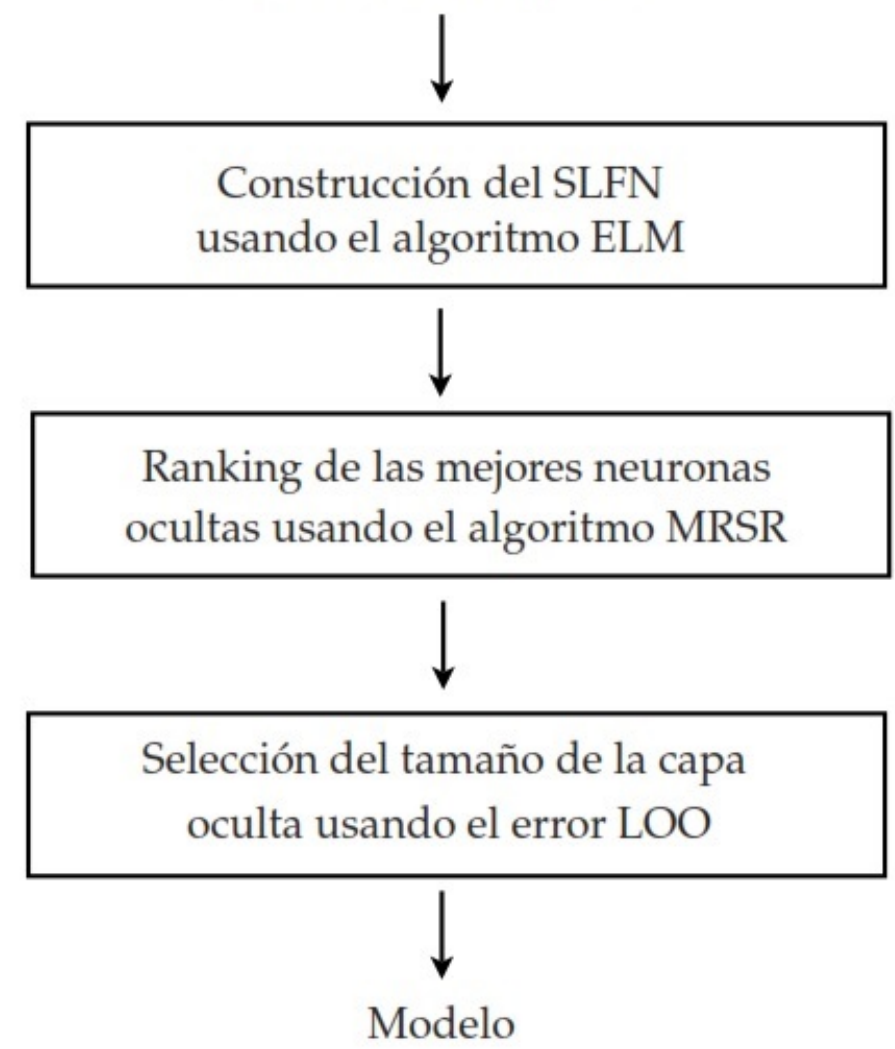

Figura 6.5.1: Etapas del algoritmo OP-ELM.

\subsubsection{Fase 1. Inicialización aleatoria.}

Este primer paso se realiza utilizando el algoritmo ELM estándar para un número de neuronas M. Desde el punto de vista práctico, se aconseja que $\mathrm{M}$ esté por encima del número de características de entrada: $M>>n$. Aunque la metodología ELM utiliza un solo tipo de función de activación o núcleo (por ejemplo, funciones sigmoidales), en OP-ELM se utilizan tres tipos de funciones (gaussiana, sigmoide y lineal) que pueden usarse en combinación para una mejor robustez y generalidad. Así, mientras que las funciones sigmoidales, los pesos son elegidos aleatoriamente según una distribución uniforme en un intervalo de los datos de entrada previamente normalizados (media cero y varianza uno), para los núcleos gaussianos, sus centros y anchuras son elegidos al azar entre los percentiles 20 y 80 de la distribución de las distancias de los datos de entrada [162].

\subsubsection{Fase 2. Ranking de unidades ocultas: Algoritmo MRSR.}

Como segunda etapa, el algoritmo MRSR se utiliza para hacer una clasificación de las neuronas ocultas en función de su relevancia [149]. MRSR es una extensión del conocido algoritmo LARS 
("Least Angle Regression") y, por lo tanto, es una técnica mediante ranking [181]. Los fundamentos del algoritmo MRSR en un modelo ELM son los siguientes, para la matriz de salida $H_{N * M}$ de los nodos ocultos, cada columna $h_{i}$ (vector de las $N$ salidas que produce la neurona i-ésima para las $N$ entradas) se añade una a una al modelo en sucesivos pasos del algoritmo. De esta manera, para el paso $k(k=1, \ldots, M)$, el modelo se define como:

$$
\tilde{O}_{N x m}^{k}=H_{N x M} B_{M x m}^{k},(6,6)
$$

donde $\tilde{O}^{k}$ y $B^{k}$ son, respectivamente, la matriz de salida del modelo y la matriz de pesos de salida para el paso k-ésimo. $B^{k}$ tiene k filas distintas de cero en el paso k-ésimo del algoritmo MRSR. Con cada nuevo paso y nueva fila distinta de cero en $B^{k}$, se introduce la nueva columna $\left(h_{k}\right)$ al modelo. En [149], Similä y otros definen un criterio que mide la suma de las correlaciones entre los residuos del modelo y el regresor considerado (k-ésimo nodo oculto del vector de salida) a través de todas las variables objetivo. MRSR selecciona regresores en una forma gradual en cada iteración. Los detalles sobre la definición de una correlación acumulativa se pueden encontrar en el artículo original sobre el MRSR [149]. Es importante tener en cuenta que el MRSR obtiene una clasificación exacta para problemas separables linealmente. Puesto que la salida de un esquema ELM es lineal con respecto a las unidades ocultas inicializadas de forma aleatoria, la clasificación obtenida de las neuronas por MRSR es exacta.

\subsubsection{Fase 3. Selección de las unidades ocultas.}

Una vez que las neuronas estén ordenadas por su relevancia, se seleccionan las mejores unidades ocultas para el modelo ELM ( $M^{*}$ nodos ocultos). Para ello, se divide al azar el conjunto de datos en aprendizaje y validación, por cada una de esas divisiones, el modelo se ajusta a los datos de aprendizaje y la precisión se evalúa a través de los datos de validación [183]. En este caso, los resultados varían si el análisis se repite con otro conjunto diferente generado de forma aleatoria. Una solución mejor es utilizar LOO (“Leave-One-Out"), utiliza una única muestra del conjunto de aprendizaje original como validación. Esto se repite de tal manera que cada observación en el conjunto de muestras se usa una vez como dato de validación, y por lo tanto, todas las muestras se utilizan para el aprendizaje y la validación. El principal inconveniente con el método LOO es que puede ser extremadamente costoso computacionalmente cuando el conjunto de datos tiene un gran número de muestras [183].

Sin embargo, el error LOO puede calcularse para modelos lineales mediante el uso del estadístico PRESS (PREdiction Sum of Squares) [182]. Considerando que $\hat{B}$ es la solución mediante el error por mínimos cuadrados cuando la j-ésima muestra (j-ésima fila de $\mathrm{H}$ ) es omitida, es decir: 


$$
\hat{B}_{(j)}=H_{(j)}^{\dagger} \cdot T_{(j)},(6,7)
$$

donde $H_{(j)}$ y $T_{(j)}$ son, respectivamente, $\mathrm{H}$ y T sin su j-ésima fila. Entonces el error LOO es dado por:

$$
\epsilon_{P R E S S}=\frac{1}{N} \cdot \sum_{j=1}^{N}\left\|h_{j} \hat{B}_{(j)}-T_{(j)}\right\|^{2},(6,8)
$$

donde $h_{j}$ es la j-ésima fila de H. Para seleccionar un modelo usando el criterio del error mediante LOO, se computa el $\epsilon_{P R E S S}$ para cada modelo y se elige el modelo con un mínimo $\epsilon_{P R E S S}$. Usando directamente la fórmula anterior, la computación de $\epsilon_{P R E S S}$ sería extremadamente ineficaz y computacionalmente prohibitivo ya que el modelo se ha calculado tantas veces como el número de muestras existente. Sin embargo, hay una fórmula bien conocida para realizar el estadístico PRESS de forma no iterativa y precisa:

$$
\epsilon_{P R E S S}=\frac{1}{N}\left\|\Gamma(I-P)^{-1}(P-I)\right\|_{F}^{2},(6,9)
$$

con $P=H \cdot H^{\dagger}$, $I$ es la matriz identidad y $\Gamma(A)$ mantiene sólo las entradas diagonales de la matriz cuadrada A. Siendo $\|A\|_{F}$ la norma de Frobenius de la matriz A.

Para redes OP-ELM, el estadístico PRESS se computa de forma iterativa añadiendo un nodo oculto al modelo. El modelo con $M^{*}$ neuronas ocultas obtiene el valor más bajo del estadístico PRESS, considerándose este modelo como óptimo, es decir,

$$
\epsilon_{P R E S S}^{M^{*}}<\epsilon_{P R E S S}^{k}, \forall k(1,2, \ldots, M),(6,10)
$$

Nótese que este procedimiento es bastante mejor que el OP-ELM, el cual requiere seleccionar un umbral. De acuerdo a [165, 162], la etapa de selección de los nodos tiene dos efectos importantes: se consigue una convergencia más rápida y los modelos ELM son más pequeños $(M<M)$. A continuación, en esta sección se incluye un resumen del algoritmo OP-ELM.

\subsubsection{Algoritmo de Poda Óptima ELM (OP-ELM)}

Dado un conjunto de entrenamiento $D=\left\{\left(x_{j}, t_{j}\right) \mid x_{j} \in \mathbb{R}^{m}, j=1, \ldots, N\right\},(6,11)$ ,varias funciones de activación (sigmoides, gaussianas y lineales), y un gran número de neuronas M, 1: Asignar al azar los pesos de entrada $\left\{w_{i}, b_{i}\right\}_{i=1}^{M},(6,12)$.

2: Calcular la matriz de la capa de salida de los nodos ocultos $H$ con $X$ y los pesos de la capa de entrada.

3: Clasificar las salidas ocultas usando el algoritmo MRSR, es decir, clasificar $H$, donde el conjunto 
$H^{0}$ representa una matriz vacía.

4: for $\mathrm{k}=1$ to $\mathrm{N}$ do

5: Añadir el nodo k-ésimo al modelo $\rightarrow H^{k}=\left[H^{k-1}, h_{k}\right],(6,13)$ siendo $h$ la k-ésima columna de $H$.

6: Calcular el error mediante $L O O\left(\epsilon_{P R E S S}^{k}\right) \operatorname{con} H^{k},(6,14)$.

7: end for

8: Seleccionar el tamaño de la red según $M^{*}=\operatorname{argmin}_{k}\left(\epsilon_{P R E S S}^{k}\right),(6,15)$

9: Calcular la matriz de los pesos de la capa de salida:

$B^{*}=\left(H^{*}\right)^{\dagger} T,(6,16)$.

Con el fin de evitar la inversión de la matriz y los costosos productos matriciales, hay trabajos que utilizan diferentes criterios de selección de variables, tales como el Criterio de Información de Hannan-Quinn [165] o el Test de Delta [164]. Estos trabajos proporcionan procedimientos más fáciles para la selección de modelos que el método original de LOO.

\subsubsection{Optimización para clasificación}

Cuando se trabaja en problemas de clasificación, los sesgos $b_{j}$ no son necesarios ya que el hiperplano de separación del espacio del ELM pasa a través del origen [159]. A diferencia de los trabajos anteriores sobre ELM para SVM [184], los cuales se basan en aplicar kernels ELM en SVM, Huang [183] estudia la optimización del ELM para clasificación demostrando que el ELM puede ser linealmente extendido a SVMs (pero con menos limitaciones de optimización) en lugar de sólo reemplazar kernels SVM con kernels ELM y por lo tanto el aprendizaje y la implementación de las SVMs se puede hacer mucho más simple y eficiente, ya que de acuerdo a las teorías del ELM $[159,160,162,163]$ todas las muestras de entrenamiento son linealmente separables por un hiperplano que pasa a través del origen con probabilidad uno en el espacio de características del ELM, por lo que ELM para la clasificación tiende a lograr una mejor generalización que las SVMs. 


\section{Capítulo 7}

\section{Experimentos y Resultados.}

En este capítulo se describen los experimentos realizados en esta Tesis para poder cumplir con los objetivos principales expuestos en la Introducción, que son: El primero y principal, es probar métodos lineales de extracción de características ampliamente conocidos en BCI tales como PSD, Hjörth y AAR en combinación con ELM como clasificador en sistemas BCI basados en MI. Y el segundo es probar el ELM con señales de EEG obtenidas de usuarios novatos durante la realización de experimentos BCI con paradigmas de MI, para ver si es un clasificador adecuado.

\subsection{Experimento 1: Clasificación de señales BCI de usuarios novatos con Máquina de Aprendizaje Extremo (ELM).}

El Experimento 1 viene a dar respuesta a parte de los objetivos descritos al inicio de esta Tesis Doctoral. A continuación se realiza una introducción, se describen las señales empleadas, las simulaciones realizadas y se presentan los resultados y las conclusiones obtenidas.

\subsubsection{Introducción. Experimento 1.}

Tal y como se ha explicado en los capítulos anteriores, los sistemas BCI, permiten controlar dispositivos externos solo con la actividad eléctrica cerebral. Para mejorar el sistema, se han propuesto diferentes enfoques de trabajo y de procesado de señal, probando distintas técnicas de extracción o selección de características, así como múltiples algoritmos de clasificación. Es habitual probar nuevos algoritmos con señales BCI que proceden de usuarios expertos, por lo que se obtienen resultados mejorados con respecto a sujetos inexpertos. También, debido a su calidad y disponibilidad gratuita en la red, es habitual, emplear señales de repositorios disponibles en Internet, en particular, de los "BCI Competitions", que también proceden de usuarios experimentados [86]. 
Estas señales se han convertido en bases de datos de referencia para la prueba de nuevas técnicas con el objetivo de obtener incrementos del rendimiento en clasificación. Es importante destacar, que para poder manejar un sistema BCI con éxito, no solo es necesario adaptar el sistema al usuario, sino que debe haber una adaptación del usuario al propio sistema, por lo que es necesario entrenarlo para obtener buenos resultados [126]. En un experimento de MI en BCI se espera una precisión entre $80 \%$ y $90 \%$ después de realizar de 6 a 9 sesiones de entrenamiento de 20 minutos. Sin embargo, y de acuerdo con el estado del arte, ciertos sujetos pueden tener dificultades para usar sistemas BCI basados en MI y, en estos casos, los rendimientos de clasificación son bajos incluso tras múltiples sesiones de capacitación. Por ello, para obtener resultados altos, en muchos experimentos se realiza una selección previa de sujetos con buenos rendimientos en clasificación. Sin embargo, los usuarios de estos sistemas, no siempre son expertos, sino que en muchas ocasiones son noveles. En ese caso, en media, se espera que estos usuarios inexpertos, obtengan resultados inferiores a los que se esperarían, extrapolando los obtenidos en algunos experimentos publicados.

Por otra parte, el ELM proporciona un rápido y eficiente entrenamiento de perceptrón multicapa (MLP) [192]. Aunque Huang formalizó la idea del algoritmo ELM [161, 183], este se analizó previamente en otros trabajos $[159,145]$ donde Huang demostró que el ELM es un aproximador universal para una amplia gama de nodos computacionales aleatorios. El ELM se ha empleado en sistemas BCI, usándolo en su forma clásica, basada en modelo ponderado probabilístico con ELM adaptativo y otras variantes $[150,172]$. Sin embargo, tal y como se ha expuesto previamente en la introducción de esta Tesis, no se ha probado en usuarios noveles, de ahí que la principal contribución de este trabajo se basa en probar la idoneidad del ELM para clasificar las señales EEG de dichos usuarios inexpertos en sistemas BCI.

Para ello, en este experimento, se han recopilado las señales de 5 sujetos noveles realizando sesiones de BCI basadas en imaginación del movimiento de mano derecha e izquierda. Se han extraído características lineales y se han aplicado to técnicas de clasificación ampliamente utilizadas en BCI, como el ELM, para establecer una comparación clara que nos dé una idea de la conveniencia de emplear ELM en este tipo de entornos.

En particular, se ha probado PSD como un método de extracción de características combinado con tres clasificadores: Máquina de Aprendizaje Extremo (ELM); Análisis Linear Discriminante (LDA) y Máquina de Soporte Vectorial (SVM), para saber cuál de ellos consigue alcanzar la máxima precisión en clasificación. 


\subsubsection{Generación y adquisición de señales EEG.}

Para este trabajo se ha utilizado un conjunto de datos generado en el Centro Universitario de Defensa de la Academia General del Aire de San Javier. El conjunto de datos se compone de señales EEG de 5 voluntarios varones diestros (21, 30, 30, 33, 33 años respectivamente) con visión normal, implementando una tarea de imaginación de movimiento (MI).

Los usuarios imaginaron los movimientos de ambas manos de acuerdo con un paradigma predefinido. Es importante remarcar que ninguno de estos voluntarios había utilizado un sistema BCI antes del experimento actual. Esto implica que no hubo una selección previa de los usuarios para evitar sujetos con poca habilidad en el control de este tipo de sistemas.

La señal EEG se ha capturado con un equipo G-USBamp (g.tec Medical Engineering GmbH, Austria). Se han implementado dos canales bipolares $\mathrm{C} 3$ y $\mathrm{C} 4$, mediante la ubicación de electrodos pasivos de $\mathrm{Ag} / \mathrm{AgCl}$ en las posiciones $\mathrm{FC} 3, \mathrm{CP} 3, \mathrm{FC} 4$ y CP4 tal y como muestra la figura 7.1.1.

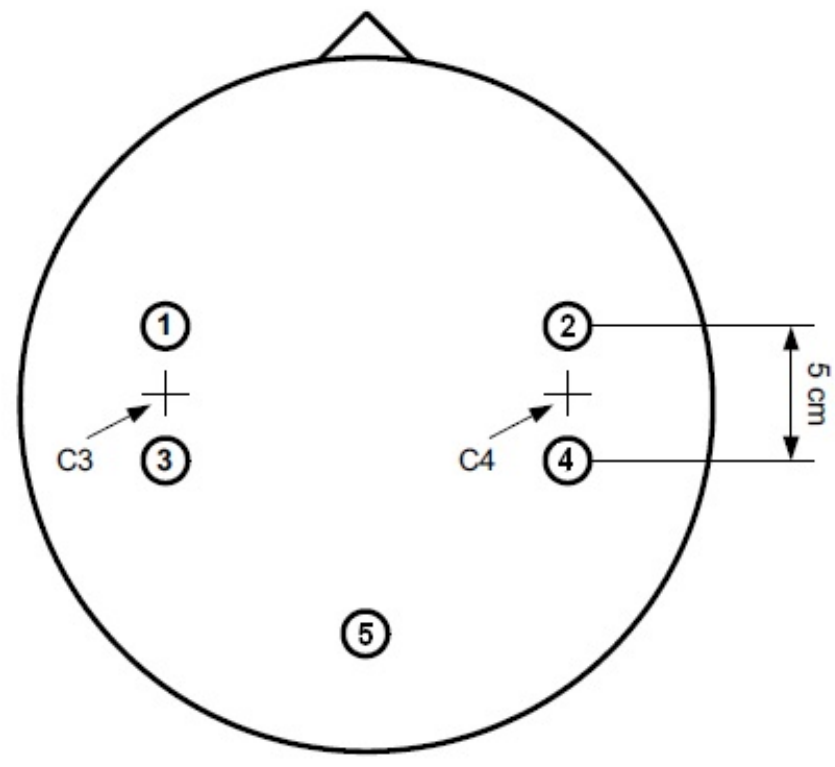

Figura 7.1.1: Disposición de los electrodos para la adquisición de las bioseñales.

La imagen 7.1.2 muestra cinco segundos de señal EEG capturada en un experimento de imaginación de movimiento en el canal C3. El amplificador fue configurado para adquirir los datos a una frecuencia de $256 \mathrm{~Hz}$ con 8 bits de resolución. También se aplicaron dos filtros, uno paso bajo a $50 \mathrm{~Hz}$ para eliminar el ruido de la red eléctrica y un filtro paso de banda entre $0,5 \mathrm{~Hz}$ y $30 \mathrm{~Hz}$ para eliminar posibles artefactos fisiológicos (ruidos propios del cuerpo humano). 


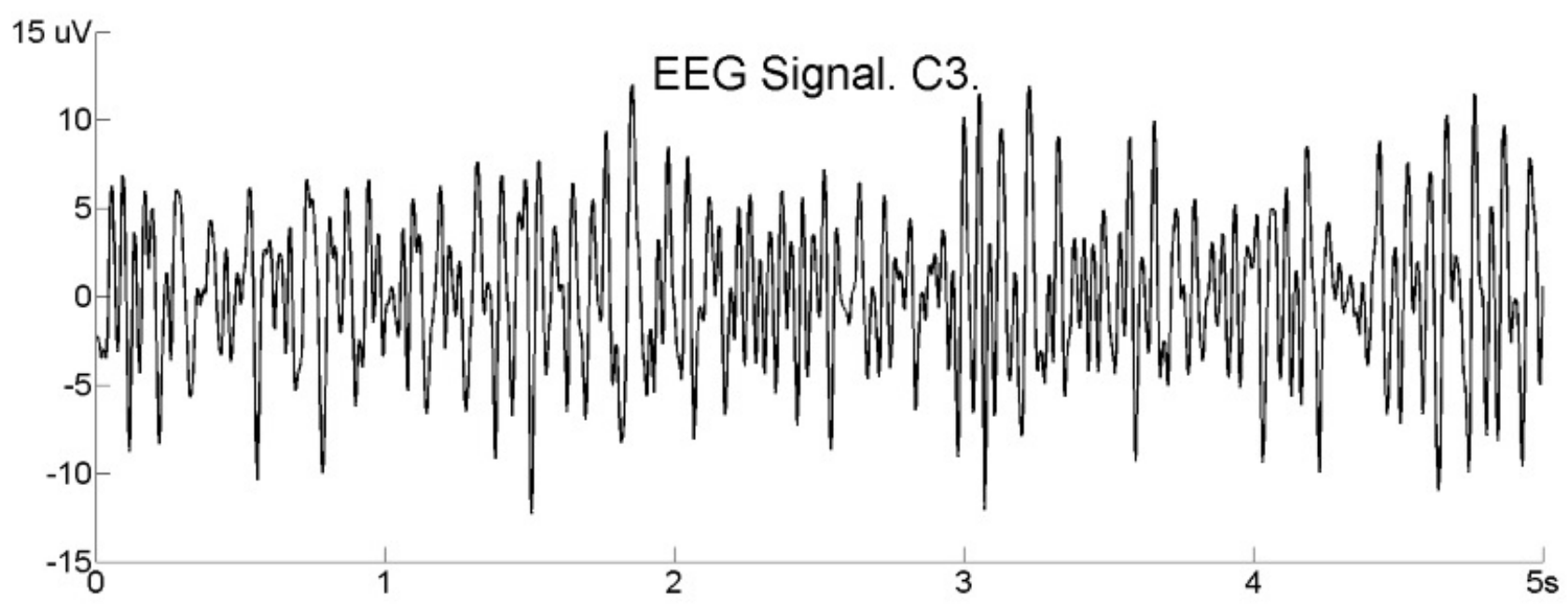

Figura 7.1.2: Cinco segundos de señal EEG capturada en un experimento de imaginación de movimiento en el canal C3.

Para realizar los experimentos, los usuarios estaban cómodamente sentados frente a un monitor de TV. El usuario debía estar relajado e imaginar el movimiento de la mano derecha o izquierda mirando la pantalla cuando el sistema BCI requería su atención. Cada experimento se compone de 40 ensayos (20 de la mano izquierda y 20 de la mano derecha).

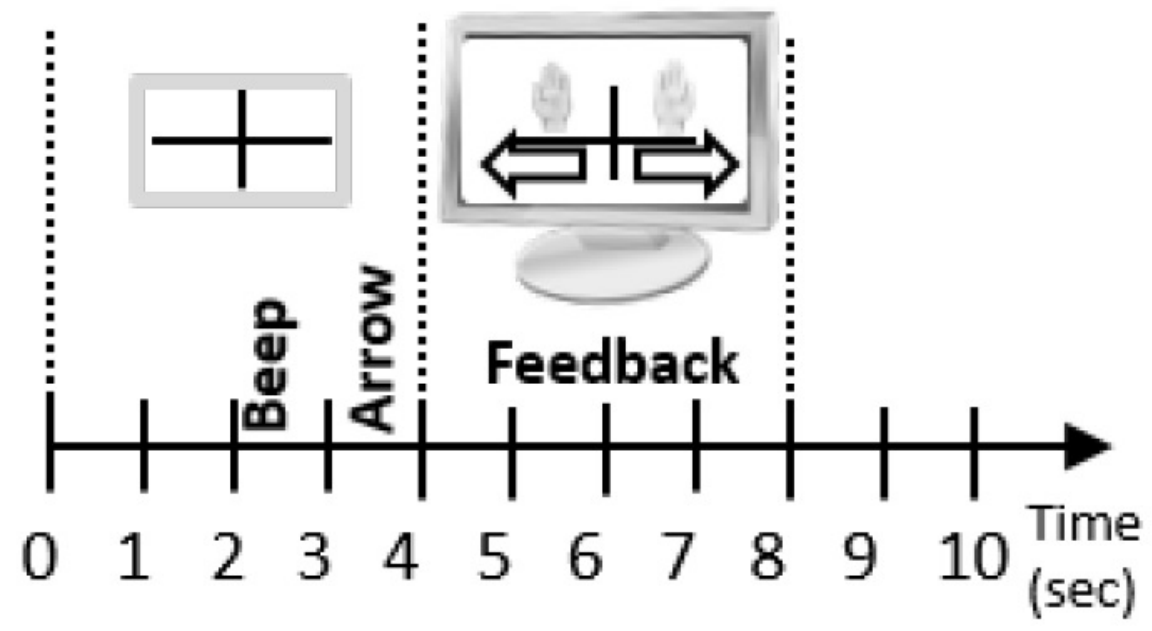

Figura 7.1.3: Esquema temporal experimento 1.

Al inicio de cada ensayo (véase la figura 7.1.3), la pantalla está en negro, luego aparece una cruz y en el segundo 2 se oye un 'Beep', una señal acústica para atraer la atención del usuario. En el tercer segundo del ensayo, el sistema presenta una flecha hacia la izquierda o hacia la derecha 
durante 1,25 seg. y en este momento el usuario imagina el movimiento de la mano según indique la flecha. En este período, la imaginación de movimiento se realiza durante 4 seg., por lo que cada ensayo necesita $8 \mathrm{seg}$. Por último, es importante observar que hay un tiempo aleatorio entre los ensayos que va de $0,5 \mathrm{seg}$. a 2,5 seg. para evitar la adaptación y la sincronización de la actividad cerebral al paradigma. Por otra parte, destacar que en este experimento el sistema no ofrece realimentación en tiempo real a los usuarios.

\subsubsection{Simulaciones.}

El objetivo de los experimentos fue probar ELM como algoritmo para clasificar las características extraídas con un método lineal (PSD) de sujetos novatos. En este estudio, se han empleado las señales de EEG que se han capturado como se describe en la sección anterior.

Para obtener las características, se han calculado en 2 ventanas de $1 \mathrm{seg}$. ubicadas en el centro del periodo de imaginación de movimiento en cada prueba (5-6seg. y 6-7seg.), ver figura 7.1.3. Posteriormente, cada conjunto de dos características obtenidas en cada ventana y cada canal son promediadas en único vector de características, por lo que hay dos características $(\alpha y \beta)$ de cada canal en cada prueba que van al clasificador.

Es importante destacar que se ha realizado una evaluación previa de algunas de las técnicas de extracción de características lineales más utilizadas en BCI, como PSD, Hjörth y AAR [155]. Sin embargo, los resultados preliminares muestran que Hjörth y AAR presentan un rendimiento muy bajo con todos los clasificadores probados en este trabajo, mientras que PSD obtiene resultados aceptables para estas señales. Por lo tanto, se han descartado otros métodos y se ha elegido PSD como el método más adecuado para explorar el ELM en sistemas BCI con usuarios novatos.

Para obtener una referencia, las actuaciones de ELM se han comparado con técnicas estándar de clasificación, LDA y SVM. Estos métodos son muy utilizados por los investigadores en entornos BCI debido a los buenos resultados obtenidos [184]. Para SVM, se ha utilizado un kernel lineal, ya que un SVM estándar con kernel lineal es el método más utilizado para BCI [86]. Para el ELM, se ha usado un kernel gaussiano, ya que proporciona mayor rendimiento en clasificación y un resultado no lineal.

Con el fin de hacer una evaluación precisa y justa del rendimiento de los diferentes métodos de clasificación, este estudio utiliza un procedimiento Leave-One-Out Cross-Validation (LOO-CV), el cual evita cambios indeseables de la selección aleatoria de los conjuntos de entrenamiento y prueba. El LOO-CV trabaja de la siguiente forma: Para el número total de $\mathrm{N}$ muestras involucradas en el estudio, una se retiene para la prueba, y las N-1 restantes se usan para entrenar el clasificador 
usando la aproximación de ELM.

Este proceso se repite $\mathrm{N}$ veces (es decir, una iteración por cada vector de entrada). Se debe tener en cuenta que todos los casos se utilizan para entrenamiento y prueba durante las $\mathrm{N}$ iteraciones del procedimiento LOO-CV y, que la evaluación del rendimiento se obtendrá al final, promediando los resultados de este procedimiento iterativo.

\subsubsection{Resultados y discusión.}

La Tabla 7.1.1 muestra los resultados de precisión obtenidos bajo LOO-CV (en \% ) usando PSD como método de extracción de características y ELM, LDA y SVM como clasificadores. Como es de esperar, los valores no son especialmente altos. Esto se considera dentro de la normalidad debido a la inexperiencia de los usuarios y la ausencia de realimentación en el sistema. Por la diferente naturaleza de los clasificadores, los resultados del LDA y del SVM, son persistentes al ser evaluados mediante LOO-CV, sin embargo, el ELM tiene una inicialización aleatoria de los pesos, por lo que se hicieron 30 inicializaciones, y los resultados se muestran en la tabla 7.1.1 con la media y la desviación estándar obtenidas.

De acuerdo con los resultados obtenidos, ELM mejora a LDA y SVM para el Usuario 2 con $71.36 \% \pm 04.02 \%$ frente al $66.67 \%$ de LDA, y el 51.287 \% del SVM. También mejora los resultados del Usuario 3 con $69.79 \% \pm 02.40 \%$ frente a $56.41 \%$ de LDA y SVM, y obtiene también los mejores resultados para el Usuario 4 con $58.54 \% \pm 04.70 \%$ frente a $41.03 \%$ de LDA y a $53.81 \%$ de SVM. Sin embargo, para el Usuario 1, SVM mostró el mejor resultado con $71.79 \%$ y, para el Usuario 5 LDA consiguió el resultado más alto con un $71.79 \%$. Es interesante observar que ELM obtiene resultados entre $65.67 \% \pm 3.21 \%$ y $71.36 \% \pm 4.02 \%$ en contraste con LDA que mostró un valor llamativamente bajo para el Usuario 4 (41.03\%) y SVM que presenta el $51.28 \%$ para el Usuario 2. Por lo tanto, en este estudio, ELM logró resultados aceptables para todos los sujetos.

Como se muestra en la 7.1.4, a partir de los datos promedio de los tres métodos, se puede afirmar que ELM mejora significativamente el rendimiento promedio de clasificación de los clasificadores LDA y SVM: $66.51 \%$ frente $60.51 \%$ y $59.47 \%$ respectivamente. Para validar esta afirmación, se ha realizado una prueba estadística no paramétrica. En particular, el Wilcoxon Signed Ranks Test [146]. Se ha realizado una comparación por pares. Comparando ELM con LDA, el p-valor obtenido es 0.04, lo que indica que difiere al $96 \%$, siendo el mejor el ELM. Igualmente, al aplicar la prueba entre ELM y SVM, el p-valor = 0.01 indica que hay diferencias significativas al 99\%, siendo ELM mejor que SVM. Por último la comparación entre LDA y SVM no presenta diferencias significativas, ya que el p-valor $=0.477$. 
Tabla 7.1.1: Resultados de precisión obtenida bajo LOO-CV (en \%) usando PSD como método de extracción de características y ELM, LDA y SVM como clasificadores.

\begin{tabular}{lll}
\hline Usuario Novel & Método & Precisión ( \%) \\
\hline Usuario $_{1}$ & LDA & 66.67 \\
& SVM & 71.79 \\
& ELM & $67.23 \pm 02.84$ \\
\hline Usuario $_{2}$ & LDA & 66.67 \\
& SVM & 51.28 \\
& ELM & $71.36 \pm 04.02$ \\
\hline Usuario $_{3}$ & LDA & 56.41 \\
& SVM & 56.41 \\
& ELM & $69.79 \pm 02.40$ \\
\hline Usuario $_{4}$ & LDA & 41.03 \\
& SVM & 53.81 \\
& ELM & $58.54 \pm 04.70$ \\
\hline Usuario $_{5}$ & LDA & 71.79 \\
& SVM & 64.10 \\
& ELM & $65.67 \pm 03.21$
\end{tabular}




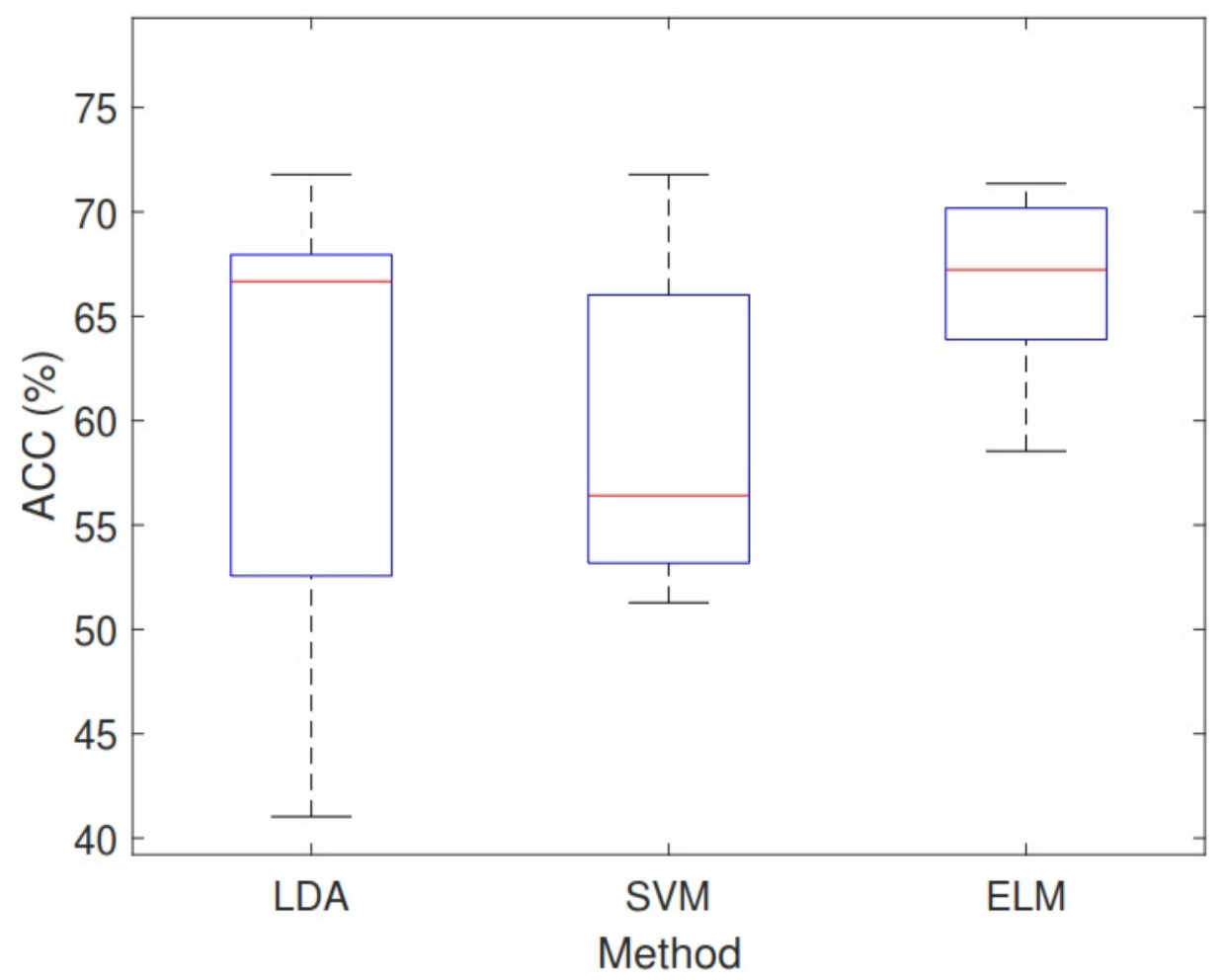

Figura 7.1.4: La comparación de la media de los tres métodos.

Es general, se asume que para el rendimiento del mismo experimento con el mismo sistema podría ser diferente entre los usuarios e incluso para el mismo usuario en diferentes ensayos o sesiones. La figura 7.1.5 muestra la precisión media valores de todos los usuarios teniendo en cuenta la media de los datos de los tres clasificadores aplicados para cada usuario.

Por lo tanto, los usuarios 1, 2 y 5 mejoraron el valor medio del grupo en contraste con los usuarios 2 y 3 . Probablemente los usuarios 1 y 2 tienen buenas habilidades para controlar los sistemas de $\mathrm{BCI}$ bajo paradigmas de imaginación de movimiento. Por lo tanto, podrían ser candidatos adecuados para ser entrenados y controlar con éxito los sistemas BCI.

\subsubsection{Conclusiones y trabajo futuro de este primer trabajo experimental.}

En este experimento se ha probado un ELM con señales EEG de 5 usuarios principiantes que usan un sistema BCI basado en MI. Se calcularon como características valores de PSD y se promediaron a partir de 2 ventanas centrales con 1 segundo cada una. Para comparar la precisión de los resultados de clasificación obtenidos por ELM, se han implementado dos clasificadores estándar en BCI, el LDA y el SVM. 


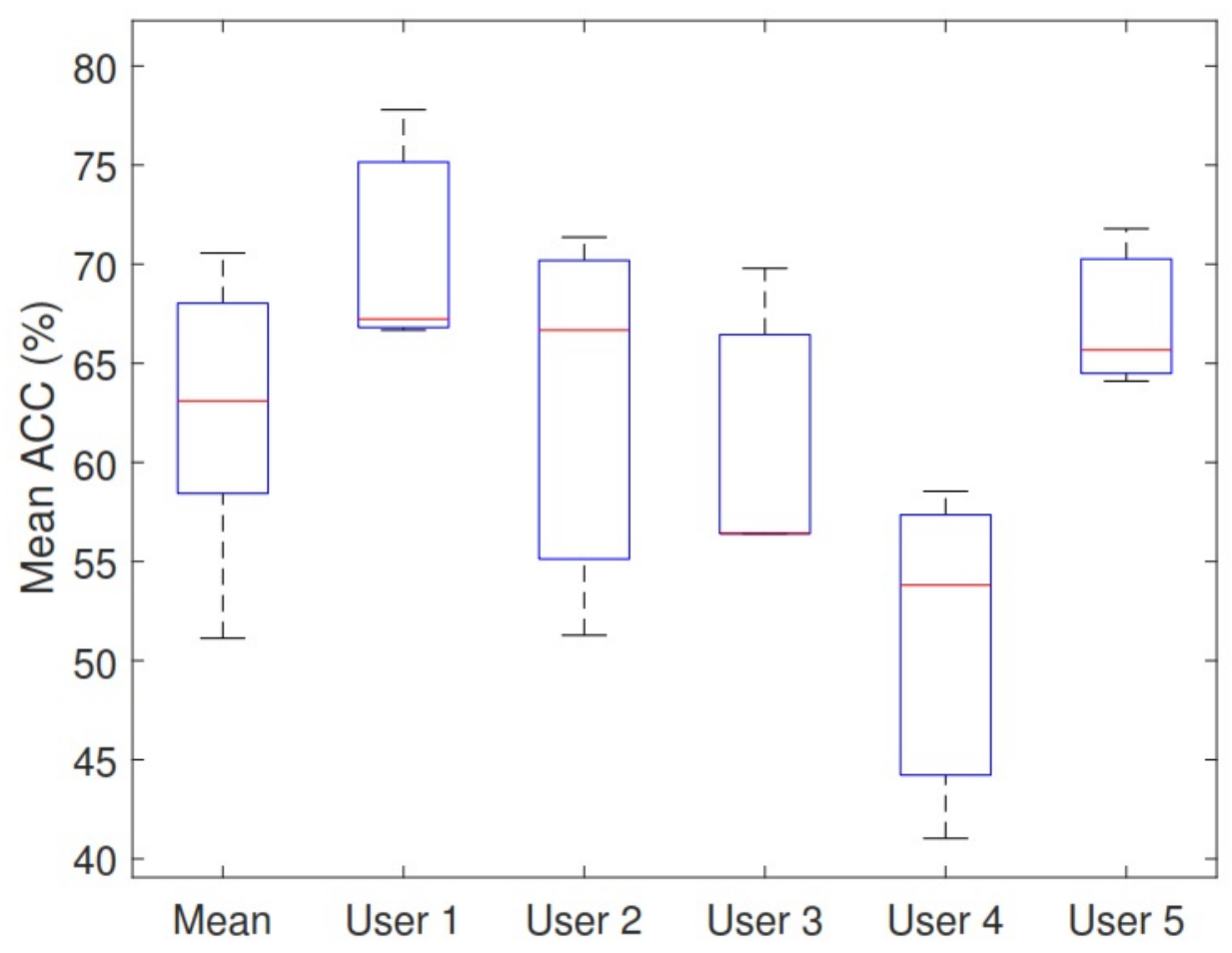

Figura 7.1.5: La comparación de la media de los 5 usuarios.

Los resultados se han evaluado bajo LOO-CV y han mostrado que, a diferencia de LDA y SVM, ELM alcanzó el nivel apropiado de resultados en todos los usuarios, y además de eso, superó en 3 de 5 usuarios a los métodos estándar. Por lo tanto, la metodología probada mostró un rendimiento adecuado para su aplicación en sistemas MI BCI con usuarios novatos.

La investigación futura sobre este tema debe enfocarse en probar ELM con conjuntos de datos más amplios, así como con señales de usuarios expertos en BCI o de señales de referencia como por ejemplo las generadas en competiciones BCI. Además, en un futuro se podrían realizar estudios para calcular y combinar características en tres o cuatro ventanas temporales con objeto de tener en cuenta la evolución a lo largo del periodo de imaginación de movimiento de la señal EEG.

Otras posibilidades para ELM son las diferentes variantes de poda y selección de la arquitectura. Finalmente, podría ser interesante implementar más técnicas de extracción de características y otros clasificadores para las señales EEG tratadas. 


\subsection{Experimento 2: Prueba de la Máquina de Aprendizaje Ex- tremo en sistemas de Interfaz Cerebro Ordenador bajo pa- radigmas de Imaginación de Movimiento.}

El Experimento 2 viene a complementar los resultados del Experimento 1 y cubre el resto de objetivos descritos en la introducción de la Tesis. A continuación se realiza una introducción al Experimento 2, se describen las señales empleadas, las simulaciones realizadas y se presentan los resultados y las conclusiones obtenidas de este experimento.

\subsubsection{Introducción. Experimento 2.}

En los sistemas BCI se han aplicado muchos enfoques en las etapas de extracción y clasificación de características. En la etapa de "Técnicas de extracción de características"se han intentado un amplio número de métodos para diseñar sistemas BCI, tales como CSP, Hjörth, AAR, PSD, Transformadas Wavelet etc... Sin embargo, no todas las características extraídas tienen información relevante, pues en ocasiones la información puede ser redundante, lo que provoca una bajada en el rendimiento del clasificador y un incremento innecesario de la complejidad y de la carga computacional del mismo. Por ello, es habitual reducir el vector de características obtenido de forma previa a su clasificación.

Para ello se usan métodos de reducción de la dimensionalidad con técnicas como el Análisis de Componentes Principales (PCA) o de Análisis de Componentes Independientes (ICA) [190]. Otro enfoque utilizado es seleccionar características con algoritmos genéticos u otras estrategias como la selección secuencial hacia atrás o selección secuencial hacia adelante.

Con respeto a la etapa de clasificación de patrones se han aplicado una gran variedad de clasificadores lineales y no lineales como por ejemplo: modelos de mezclas gaussianas [39]; LDA [196]; SVM [168]; clasificador de k vecinos más cercanos o ANN. Es importante destacar que en los últimos años, las metodologías de clasificación lineal de señales EEG para BCI propuestas son cada vez más rápidas, además de automáticas y adaptativas, además tienen pocos requisitos computacionales $[154,173]$.

Por otra parte, como es aceptado en [154] se considera la señal de EEG un sistema dinámico caótico. Además, una señal EEG es caótica en otro sentido, porque su amplitud cambia aleatoriamente con respecto al tiempo. Esto tiene una implicación clara en los sistemas BCI, pues los usuarios no generan la misma señal en cada sesión, ni en cada iteración de control en la misma sesión y ni siquiera la señal es la misma a lo largo del periodo de imaginación de movimiento. 
Este experimento tiene por objetivo probar el ELM con señales de referencia en BCI para compararlo con técnicas de clasificación estándar. Se pretende tener en cuenta el curso temporal de las señales. Para ello se han empleado tres métodos de extracción de características ampliamente conocidos: PSD; Hjörth y AAR. Estos datos se han combinado mediante tres técnicas diferentes para tener en cuenta la variación temporal de las señales: Ventana central; Promediado y Concatenación. Los resultados muestran que estos nuevos descriptores mejoran el rendimiento del ELM con respecto a las técnicas clásicas.

\subsubsection{Señales empleadas en el Experimento 2.}

Para este trabajo se ha utilizado el conjunto de datos II.B de la BCI Competitions IV [191]. El conjunto se compone de señales EEG de 9 sujetos diestros que tenían una visión normal o corregida a normal. Las pruebas las realizaron sentados en un sillón mirando un monitor situado a un metro de distancia y cada usuario realizó cinco sesiones, de las cuales dos eran sin realimentación y tres con realimentación.

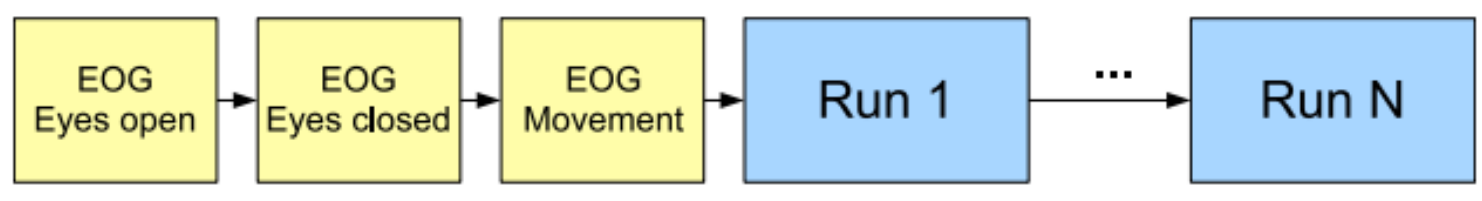

Figura 7.2.1: Etapas realizadas en cada sesión.

Fuente: Extraída de la documentación de http://www.bbci.de/competition/

La Figura 7.2.1 muestra las diferentes etapas que se siguieron para cada sesión de toma de datos. Primero se graban cinco minutos de señal EEG para estimar la influencia del EOG con los electrodos situados tal y como muestra la figura 7.2.2. Para ello, se realizan consecutivamente las siguientes tres etapas: (a) dos minutos con los ojos abiertos (mirando una cruz en la pantalla); (b) un minuto con los ojos cerrados y; (c) un minuto con movimientos de ojos.

Fuente: Extraída de la documentación de http://www.bbci.de/competition/

Al finalizar cada una de las tareas, después de quince segundos se dejaban cinco segundos de descanso y, durante las pruebas, un texto aparecía en pantalla indicando los movimientos de ojos que debían realizar los participantes (parpadeo, rodar, movimientos horizontales y verticales). Para 


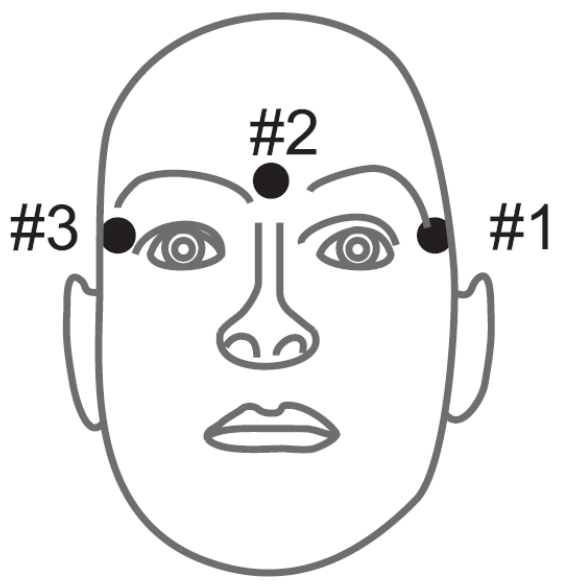

Figura 7.2.2: Posición de los electrodos para caracterizar el EOG.

indicar el inicio y el fin de cada tarea se empleaba un tono agudo y otro grave de advertencia.

La señal EEG fue adquirida en las posiciones C3, Cz y C4 (según el sistema 10/20), utilizando canales bipolares. La frecuencia de muestreo era de $250 \mathrm{~Hz}$ y tenían un rango dinámico de $\pm 100 \mu \mathrm{V}$. El preprocesado consiste en un filtro entre $0.5 \mathrm{~Hz}$ y $100 \mathrm{~Hz}$, y un filtro paso bajo a $50 \mathrm{~Hz}$ para eliminar el ruido de red.

Fuente: Extraída de la documentación de http://www.bbci.de/competition/

La Figura 7.2.3 (a) muestra la secuencia temporal seguida en cada ensayo. Cuando aparece una cruz en la pantalla, la prueba comienza. En el segundo 2 el sistema produce una señal acústica y 1 seg. más tarde, una flecha indica las tareas mentales que se implementarán (por ejemplo movimiento de la mano izquierda o movimiento de la mano derecha) durante 4 segundos. Finalmente, tras cada prueba había un breve descanso de al menos 1,5 seg. y adicionalmente, se agregó un tiempo aleatorio adicional de hasta $1 \mathrm{seg}$. al final del descanso para evitar la adaptación del usuario. La Figura 7.2.3 (b) refleja el paradigma seguido a partir de la tercera sesión, donde esta implementada la realimentación para que el usuario pueda modular su EEG en función del resultado que ve en la pantalla para tratar de incrementar el éxito del sistema. Para el Experimento 2, se han tomado 200 ensayos de la clase izquierda (MI de la izquierda) y 200 ensayos de la clase derecha (MI de la derecha) que aparecen etiquetados en la página de descarga principal.

\subsubsection{Simulaciones.}

Se han extraído características mediante tres técnicas ampliamente conocidas para aplicaciones BCI: PSD (en las bandas $\alpha(8-13 \mathrm{~Hz})$ y $\beta(13-30 \mathrm{~Hz})$ [16]), parámetros de Hjörth (actividad, 
(a) Screening
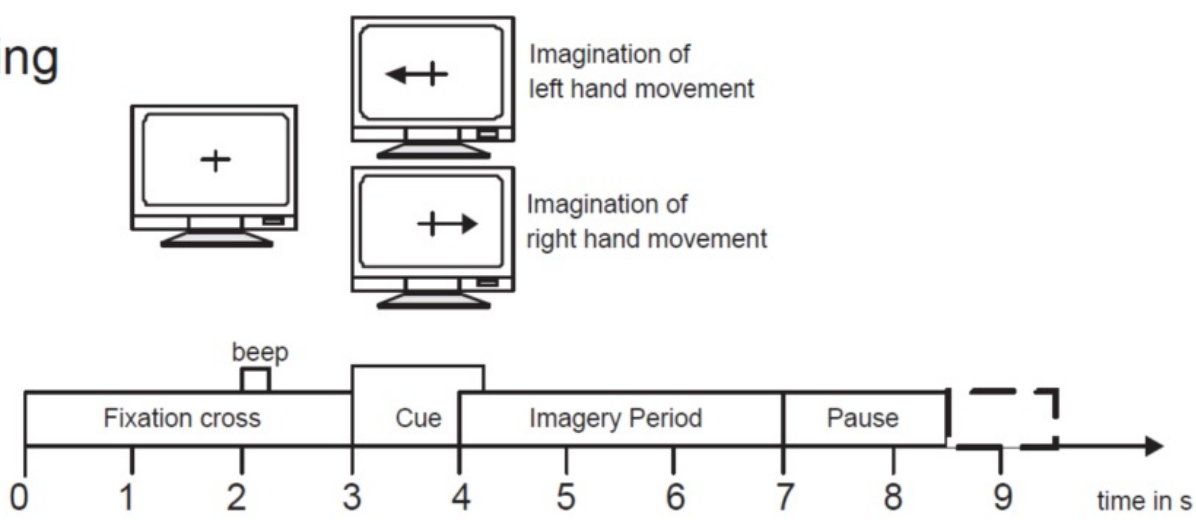

(b) Smiley Feedback

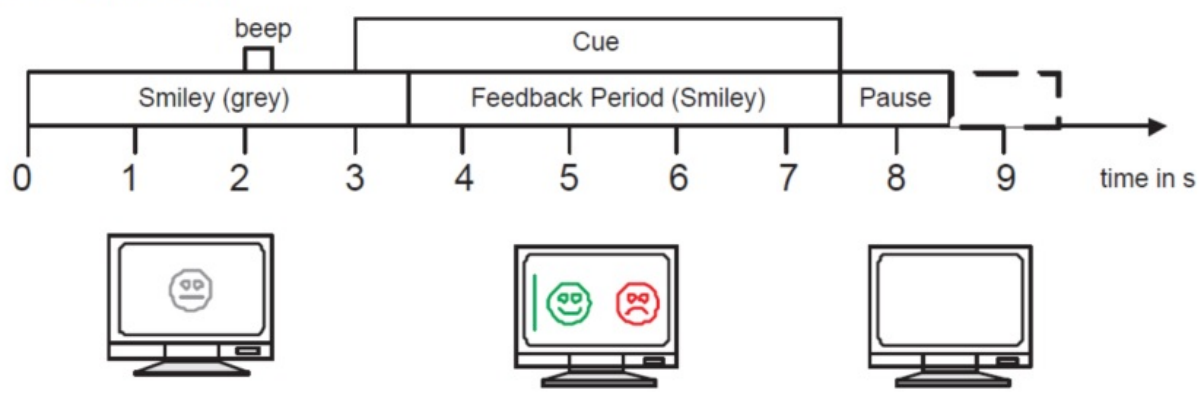

Figura 7.2.3: Esquema temporal de las pruebas. Pruebas con realimentación (a) y sin realimentación (b).

movilidad y complejidad) y AAR (orden 6 de acuerdo con otros trabajos previos [167, 154, 173].

Estos métodos son algunos de los métodos lineales más comunes de extracción de características [155]. Sin embargo, es habitual probar sólo uno o dos al mismo tiempo en sistemas BCI y no tres. El hecho de implementar tres métodos, es debido a que en este trabajo, se intenta comprobar si el ELM es capaz de explotar la información complementaria que pueden aportar diferentes técnicas de extracción de características.

Tal y como se muestra en la Figura 7.2.3, los paradigmas de MI por lo general necesitan varios segundos en los que el usuario debe imaginar el movimiento a realizar, sin embargo, las señales EEG cambian a lo largo de ese periodo porque son no estacionarias. Para tener en cuenta esta información temporal, es habitual dividir el período MI en segmentos. Seguidamente, se calculan las características en cada uno de ellos y, finalmente se fusionan en un vector único. Es importante observar que dentro de cada segmento, las señales se consideran estadísticamente estacionarias. Para este trabajo se han desarrollado tres enfoques diferentes para fusionar las características obtenidas en un vector único: 
- Ventana central: las características se han calculado desde una ventana de 2 segundos ubicada en el centro del período MI;

- Promediado: el período MI se ha dividido en cuatro ventanas de 1 segundo y las características obtenidas en cada ventana se han promediado en cada prueba;

- Concatenación: el período MI ha sido dividido en cuatro ventanas de 1 segundo y las características obtenidas en cada ventana se concatenan en solo vector en cada prueba;

Las características obtenidas en todos los casos componen un vector (D). Teniendo en cuenta que PSD proporciona 2 características, Hjörth proporciona 3 características, AAR proporciona 6 características por cada ventana, y que hay 3 canales de EEG, el tamaño de D cambiará en función de la estrategia elegida para obtener el vector final. En particular: D = 33 para la ventana central, D = 33 para el promediado de características y D = 132 para la concatenación de características.

En este experimento se prueba el ELM con cuatro kernels diferentes para todos los sujetos, estos son: lineal (1), sigmoide (s), gaussiana (g) y una combinación para cada capa de lineal-sigmoidegaussiana (lsg). Al igual que en el experimento anterior, para hacer una evaluación de forma precisa y justa de los diferentes enfoques de clasificación, este trabajo usa un procedimiento de LOO-CV. Tal y como se comentó anteriormente, es importante destacar que la evaluación mediante LOO-CV evita cambios no deseados de la selección aleatoria del conjunto de entrenamiento y del conjunto de prueba.

\subsubsection{Resultados y discusiones.}

La Tabla 7.2.1 muestra los resultados obtenidos de precisión de clasificación de LOO y su desviación correspondiente para diferentes métodos de extracción de características (PSD, H y AAR), utilizando Concatenación y cuatro núcleos diferentes ( $l, s, g$ y $l s g$ ) para el ELM.

La Tabla 7.2.2 los resultados obtenidos y su desviación correspondiente utilizando los mismos métodos de extracción de características, los mismos kernels para el ELM, pero bajo el enfoque de Ventana central.

Laa Tabla 7.2.3 muestra los resultados de clasificación LOO obtenidos y su desviación correspondiente para los mismos métodos de extracción de características, los mismos núcleos para el ELM, pero bajo un enfoque de Promediado de características.

Finalmente La Tabla 7.2.4 presenta los resultados obtenidos de precisión de clasificación de LOO y su desviación correspondiente para todas las características calculadas y usadas a la vez, 
combinadas mediante Concatenación, Ventana Central y Promediado y cuatro núcleos ( $l, s, g$ y $l s g$ ) para todos los sujetos.

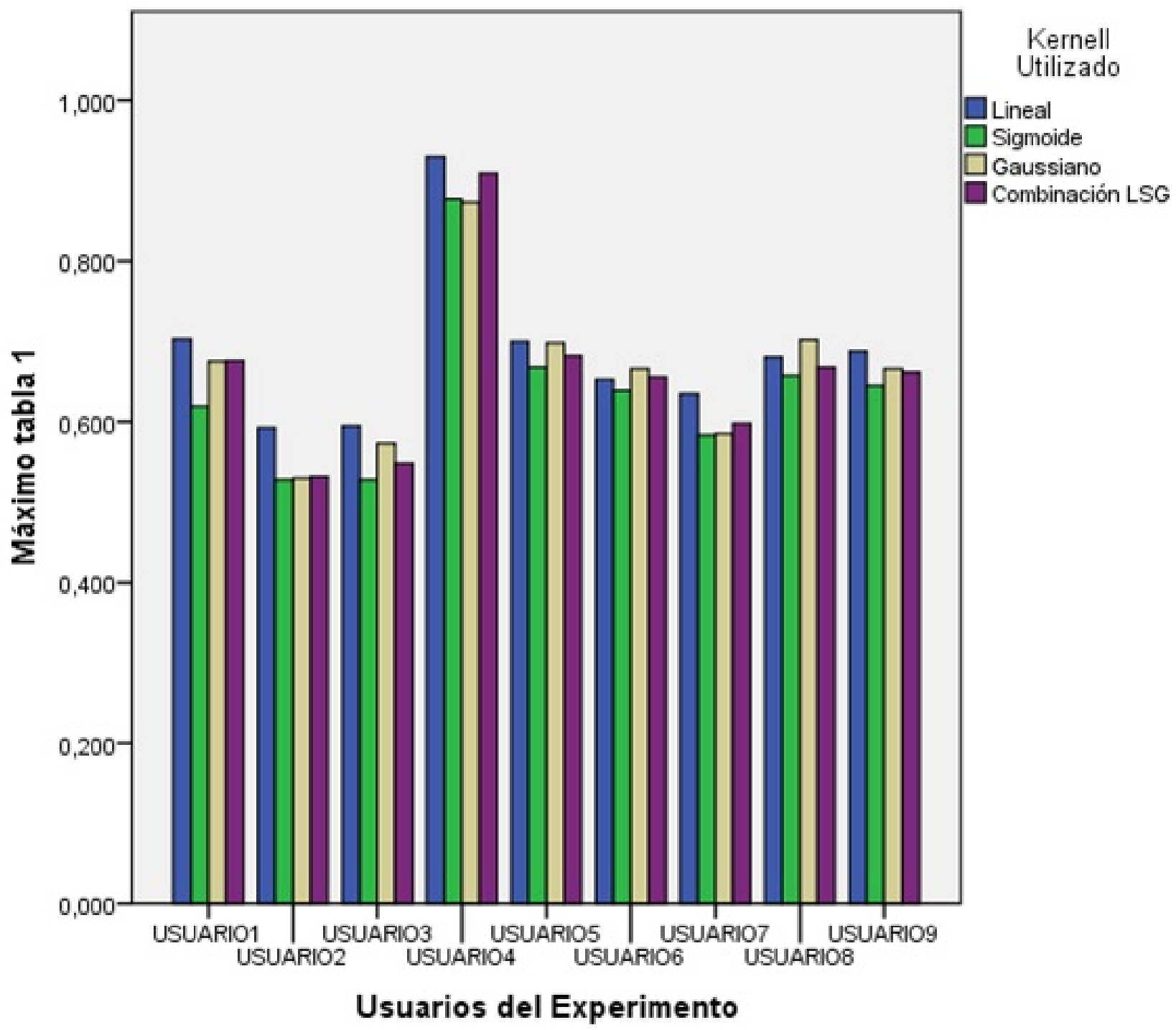

Figura 7.2.4: Diagrama de barras de los valores máximos de la Tabla 7.2.1, obtenidos con núcleos lineal, sigmoide, gaussiano y lsg. 
Tabla 7.2.1: Resultados de precisión de clasificación mediante LOO, utilizando PSD, H y AAR como métodos de extracción de características, concatenándolas y aplicando cuatro núcleos diferentes (l, s, g y lsg) para el ELM.

\begin{tabular}{|c|c|c|c|c|}
\hline \multicolumn{5}{|c|}{ Todas las características } \\
\hline Prueba & Kernel & PSD & HJÖRTH & AAR \\
\hline \multirow[t]{4}{*}{1} & 1 & $0.703 \pm 0.000$ & $0.64 \pm 0.000$ & $0.698 \pm 0.000$ \\
\hline & $\mathrm{s}$ & $0.614 \pm 0.024$ & $0.588 \pm 0.019$ & $0.619 \pm 0.016$ \\
\hline & $\mathrm{g}$ & $0.675 \pm 0.017$ & $0.612 \pm 0.020$ & $0.670 \pm 0.019$ \\
\hline & $\operatorname{lsg}$ & $0.650 \pm 0.013$ & $0.593 \pm 0.017$ & $0.676 \pm 0.016$ \\
\hline \multirow[t]{4}{*}{2} & 1 & $0.475 \pm 0.000$ & $0.515 \pm 0.000$ & $0.593 \pm 0.000$ \\
\hline & $\mathrm{s}$ & $0.528 \pm 0.013$ & $0.517 \pm 0.020$ & $0.522 \pm 0.017$ \\
\hline & $\mathrm{g}$ & $0.507 \pm 0.018$ & $0.517 \pm 0.018$ & $0.530 \pm 0.014$ \\
\hline & lsg & $0.518 \pm 0.028$ & $0.509 \pm 0.031$ & $0.532 \pm 0.016$ \\
\hline \multirow[t]{4}{*}{3} & 1 & $0.595 \pm 0.000$ & $0.525 \pm 0.000$ & $0.495 \pm 0.000$ \\
\hline & $\mathrm{s}$ & $0.528 \pm 0.027$ & $0.521 \pm 0.033$ & $0.488 \pm 0.022$ \\
\hline & $\mathrm{g}$ & $0.573 \pm 0.017$ & $0.493 \pm 0.013$ & $0.490 \pm 0.006$ \\
\hline & $\operatorname{lsg}$ & $0.548 \pm 0.026$ & $0.523 \pm 0.026$ & $0.485 \pm 0.010$ \\
\hline \multirow[t]{4}{*}{4} & 1 & $0.930 \pm 0.000$ & $0.843 \pm 0.000$ & $0.753 \pm 0.000$ \\
\hline & $\mathrm{s}$ & $0.877 \pm 0.009$ & $0.801 \pm 0.017$ & $0.700 \pm 0.014$ \\
\hline & $\mathrm{g}$ & $0.873 \pm 0.004$ & $0.851 \pm 0.012$ & $0.780 \pm 0.019$ \\
\hline & lsg & $0.909 \pm 0.010$ & $0.841 \pm 0.010$ & $0.773 \pm 0.008$ \\
\hline \multirow[t]{4}{*}{5} & 1 & $0.700 \pm 0.000$ & $0.620 \pm 0.000$ & $0.620 \pm 0.000$ \\
\hline & s & $0.668 \pm 0.026$ & $0.591 \pm 0.005$ & $0.567 \pm 0.011$ \\
\hline & $\mathrm{g}$ & $0.698 \pm 0.015$ & $0.617 \pm 0.005$ & $0.656 \pm 0.006$ \\
\hline & lsg & $0.682 \pm 0.020$ & $0.616 \pm 0.022$ & $0.625 \pm 0.021$ \\
\hline \multirow[t]{4}{*}{6} & 1 & $0.653 \pm 0.000$ & $0.618 \pm 0.000$ & $0.563 \pm 0.000$ \\
\hline & $\mathrm{s}$ & $0.639 \pm 0.022$ & $0.576 \pm 0.027$ & $0.537 \pm 0.013$ \\
\hline & $\mathrm{g}$ & $0.666 \pm 0.015$ & $0.593 \pm 0.014$ & $0.554 \pm 0.017$ \\
\hline & lsg & $0.656 \pm 0.022$ & $0.590 \pm 0.017$ & $0.564 \pm 0.026$ \\
\hline \multirow[t]{4}{*}{7} & 1 & $0.635 \pm 0.000$ & $0.570 \pm 0.000$ & $0.578 \pm 0.000$ \\
\hline & $\mathrm{s}$ & $0.583 \pm 0.042$ & $0.527 \pm 0.019$ & $0.550 \pm 0.011$ \\
\hline & $\mathrm{g}$ & $0.585 \pm 0.013$ & $0.517 \pm 0.023$ & $0.565 \pm 0.016$ \\
\hline & lsg & $0.598 \pm 0.007$ & $0.529 \pm 0.010$ & $0.584 \pm 0.015$ \\
\hline \multirow[t]{4}{*}{8} & 1 & $0.680 \pm 0.000$ & $0.67 \pm 0.000$ & $0.675 \pm 0.000$ \\
\hline & $\mathrm{s}$ & $0.639 \pm 0.017$ & $0.658 \pm 0.014$ & $0.572 \pm 0.019$ \\
\hline & $\mathrm{g}$ & $0.637 \pm 0.010$ & $0.702 \pm 0.018$ & $0.651 \pm 0.018$ \\
\hline & lsg & $0.664 \pm 0.017$ & $0.668 \pm 0.017$ & $0.663 \pm 0.023$ \\
\hline \multirow[t]{4}{*}{9} & 1 & $0.688 \pm 0.000$ & $0.688 \pm 0.000$ & $0.618 \pm 0.000$ \\
\hline & $\mathrm{s}$ & $0.645 \pm 0.009$ & $0.612 \pm 0.025$ & $0.571 \pm 0.021$ \\
\hline & $\mathrm{g}$ & $0.666 \pm 0.011$ & $0.653 \pm 0.019$ & $0.623 \pm 0.015$ \\
\hline & lsg & $0.662 \pm 0.010$ & $0.653 \pm 0.011$ & $0.614 \pm 0.014$ \\
\hline
\end{tabular}


Tabla 7.2.2: Resultados de precisión de clasificación mediante LOO, utilizando PSD, H y AAR como métodos de extracción de características, utilizando una ventana central y, aplicando cuatro núcleos diferentes (l, s, g y lsg) para el ELM.

\begin{tabular}{|c|c|c|c|c|}
\hline \multicolumn{5}{|c|}{ Ventana Central } \\
\hline Prueba & Kernel & PSD & HJÖRTH & AAR \\
\hline \multirow[t]{4}{*}{1} & 1 & $0.605 \pm 0.000$ & $0.478 \pm 0.000$ & $0.503 \pm 0.000$ \\
\hline & $\mathrm{s}$ & $0.569 \pm 0.026$ & $0.516 \pm 0.019$ & $0.525 \pm 0.021$ \\
\hline & g & $0.595 \pm 0.020$ & $0.509 \pm 0.015$ & $0.523 \pm 0.017$ \\
\hline & $\operatorname{lsg}$ & $0.597 \pm 0.016$ & $0.512 \pm 0.016$ & $0.517 \pm 0.025$ \\
\hline \multirow[t]{4}{*}{2} & 1 & $0.523 \pm 0.000$ & $0.550 \pm 0.000$ & $0.525 \pm 0.000$ \\
\hline & $\mathrm{s}$ & $0.501 \pm 0.026$ & $0.499 \pm 0.018$ & $0.526 \pm 0.009$ \\
\hline & $\mathrm{g}$ & $0.508 \pm 0.025$ & $0.494 \pm 0.015$ & $0.531 \pm 0.005$ \\
\hline & $\operatorname{lsg}$ & $0.500 \pm 0.017$ & $0.507 \pm 0.026$ & $0.524 \pm 0.021$ \\
\hline \multirow[t]{4}{*}{3} & 1 & $0.520 \pm 0.000$ & $0.528 \pm 0.000$ & $0.450 \pm 0.000$ \\
\hline & $\mathrm{s}$ & $0.505 \pm 0.006$ & $0.479 \pm 0.036$ & $0.477 \pm 0.024$ \\
\hline & $\mathrm{g}$ & $0.520 \pm 0.014$ & $0.506 \pm 0.014$ & $0.503 \pm 0.016$ \\
\hline & lsg & $0.509 \pm 0.024$ & $0.484 \pm 0.031$ & $0.499 \pm 0.012$ \\
\hline \multirow[t]{4}{*}{4} & 1 & $0.848 \pm 0.000$ & $0.543 \pm 0.000$ & $0.550 \pm 0.000$ \\
\hline & $\mathrm{s}$ & $0.813 \pm 0.003$ & $0.543 \pm 0.022$ & $0.563 \pm 0.016$ \\
\hline & $\mathrm{g}$ & $0.850 \pm 0.010$ & $0.527 \pm 0.008$ & $0.541 \pm 0.022$ \\
\hline & $\operatorname{lsg}$ & $0.829 \pm 0.018$ & $0.531 \pm 0.009$ & $0.557 \pm 0.010$ \\
\hline \multirow[t]{4}{*}{5} & 1 & $0.533 \pm 0.000$ & $0.578 \pm 0.000$ & $0.500 \pm 0.000$ \\
\hline & $\mathrm{s}$ & $0.518 \pm 0.009$ & $0.540 \pm 0.018$ & $0.509 \pm 0.016$ \\
\hline & $\mathrm{g}$ & $0.510 \pm 0.014$ & $0.579 \pm 0.014$ & $0.476 \pm 0.016$ \\
\hline & lsg & $0.511 \pm 0.021$ & $0.535 \pm 0.016$ & $0.492 \pm 0.011$ \\
\hline \multirow[t]{4}{*}{6} & 1 & $0.588 \pm 0.000$ & $0.450 \pm 0.000$ & $0.500 \pm 0.000$ \\
\hline & $\mathrm{s}$ & $0.535 \pm 0.023$ & $0.518 \pm 0.019$ & $0.497 \pm 0.012$ \\
\hline & g & $0.545 \pm 0.011$ & $0.519 \pm 0.012$ & $0.516 \pm 0.011$ \\
\hline & $\operatorname{lsg}$ & $0.534 \pm 0.023$ & $0.519 \pm 0.018$ & $0.488 \pm 0.020$ \\
\hline \multirow[t]{4}{*}{7} & 1 & $0.540 \pm 0.000$ & $0.500 \pm 0.000$ & $0.550 \pm 0.000$ \\
\hline & $\mathrm{s}$ & $0.539 \pm 0.016$ & $0.498 \pm 0.031$ & $0.554 \pm 0.012$ \\
\hline & $\mathrm{g}$ & $0.534 \pm 0.017$ & $0.500 \pm 0.011$ & $0.551 \pm 0.016$ \\
\hline & lsg & $0.553 \pm 0.007$ & $0.481 \pm 0.015$ & $0.577 \pm 0.027$ \\
\hline \multirow[t]{4}{*}{8} & 1 & $0.675 \pm 0.000$ & $0.583 \pm 0.000$ & $0.525 \pm 0.000$ \\
\hline & $\mathrm{s}$ & $0.635 \pm 0.020$ & $0.576 \pm 0.028$ & $0.533 \pm 0.021$ \\
\hline & $\mathrm{g}$ & $0.657 \pm 0.012$ & $0.579 \pm 0.010$ & $0.563 \pm 0.006$ \\
\hline & lsg & $0.651 \pm 0.023$ & $0.591 \pm 0.015$ & $0.551 \pm 0.012$ \\
\hline \multirow[t]{4}{*}{9} & 1 & $0.613 \pm 0.000$ & $0.550 \pm 0.000$ & $0.615 \pm 0.000$ \\
\hline & $\mathrm{s}$ & $0.552 \pm 0.011$ & $0.548 \pm 0.009$ & $0.576 \pm 0.011$ \\
\hline & $\mathrm{g}$ & $0.582 \pm 0.013$ & $0.546 \pm 0.011$ & $0.585 \pm 0.014$ \\
\hline & $1 \mathrm{sg}$ & $0.561 \pm 0.016$ & $0.516 \pm 0.017$ & $0.582 \pm 0.012$ \\
\hline
\end{tabular}




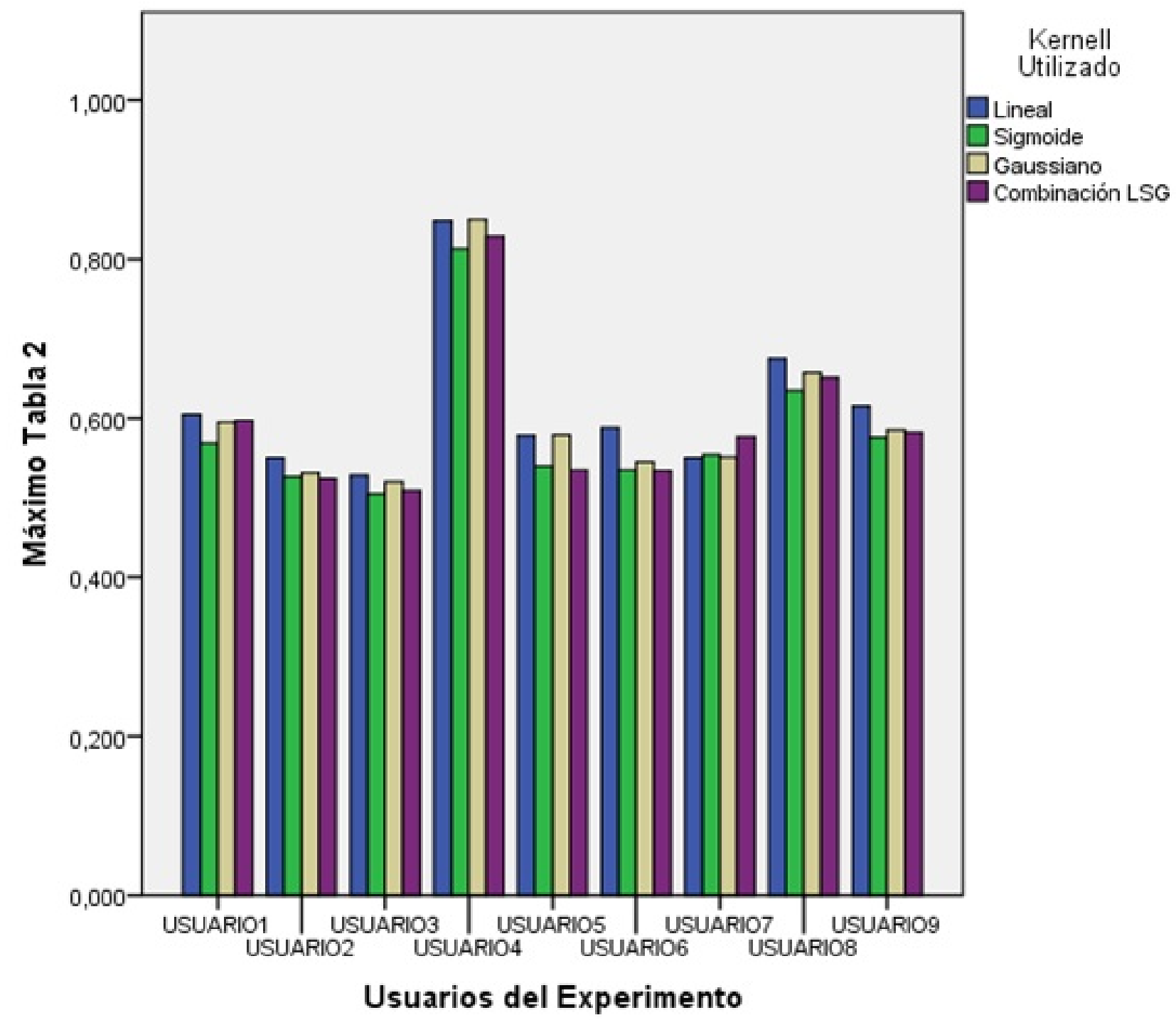

Figura 7.2.5: Diagrama de barras de los valores máximos de la Tabla 7.2.2 para cada sujeto, obtenidos con núcleos lineal, sigmoide, gaussiano y lsg. 
Tabla 7.2.3: Resultados de precisión de clasificación mediante LOO, utilizando PSD, H y AAR como métodos de extracción de características, promediándolas, y aplicando cuatro núcleos diferentes (l, s, g y lsg) para el ELM.

\begin{tabular}{|c|c|c|c|c|}
\hline \multicolumn{5}{|c|}{ Promedio de Características } \\
\hline Prueba & Kernel & PSD & HJÖRTH & AAR \\
\hline \multirow[t]{4}{*}{1} & 1 & $0.625 \pm 0.000$ & $0.638 \pm 0.000$ & $0.658 \pm 0.000$ \\
\hline & $\mathrm{s}$ & $0.575 \pm 0.024$ & $0.620 \pm 0.027$ & $0.615 \pm 0.033$ \\
\hline & $\mathrm{g}$ & $0.634 \pm 0.019$ & $0.646 \pm 0.011$ & $0.611 \pm 0.024$ \\
\hline & lsg & $0.574 \pm 0.019$ & $0.661 \pm 0.012$ & $0.664 \pm 0.020$ \\
\hline \multirow[t]{4}{*}{2} & 1 & $0.523 \pm 0.000$ & $0.573 \pm 0.000$ & $0.513 \pm 0.000$ \\
\hline & s & $0.529 \pm 0.010$ & $0.530 \pm 0.031$ & $0.540 \pm 0.024$ \\
\hline & $\mathrm{g}$ & $0.502 \pm 0.022$ & $0.521 \pm 0.018$ & $0.484 \pm 0.020$ \\
\hline & lsg & $0.472 \pm 0.026$ & $0.533 \pm 0.008$ & $0.521 \pm 0.007$ \\
\hline \multirow[t]{4}{*}{3} & l & $0.505 \pm 0.000$ & $0.513 \pm 0.000$ & $0.495 \pm 0.000$ \\
\hline & s & $0.500 \pm 0.023$ & $0.496 \pm 0.028$ & $0.466 \pm 0.018$ \\
\hline & $\mathrm{g}$ & $0.492 \pm 0.018$ & $0.490 \pm 0.021$ & $0.454 \pm 0.024$ \\
\hline & $\operatorname{lsg}$ & $0.504 \pm 0.012$ & $0.506 \pm 0.007$ & $0.473 \pm 0.036$ \\
\hline \multirow[t]{4}{*}{4} & 1 & $0.875 \pm 0.000$ & $0.745 \pm 0.000$ & $0.728 \pm 0.000$ \\
\hline & s & $0.810 \pm 0.016$ & $0.727 \pm 0.012$ & $0.686 \pm 0.015$ \\
\hline & $\mathrm{g}$ & $0.876 \pm 0.005$ & $0.749 \pm 0.008$ & $0.705 \pm 0.016$ \\
\hline & lsg & $0.851 \pm 0.007$ & $0.748 \pm 0.012$ & $0.728 \pm 0.017$ \\
\hline \multirow[t]{4}{*}{5} & 1 & $0.645 \pm 0.000$ & $0.655 \pm 0.000$ & $0.490 \pm 0.000$ \\
\hline & $\mathrm{s}$ & $0.620 \pm 0.010$ & $0.601 \pm 0.020$ & $0.520 \pm 0.018$ \\
\hline & $\mathrm{g}$ & $0.666 \pm 0.006$ & $0.631 \pm 0.019$ & $0.567 \pm 0.008$ \\
\hline & lsg & $0.643 \pm 0.018$ & $0.627 \pm 0.018$ & $0.527 \pm 0.036$ \\
\hline \multirow[t]{4}{*}{6} & 1 & $0.595 \pm 0.000$ & $0.578 \pm 0.000$ & $0.575 \pm 0.000$ \\
\hline & $\mathrm{s}$ & $0.546 \pm 0.016$ & $0.562 \pm 0.018$ & $0.504 \pm 0.027$ \\
\hline & $\mathrm{g}$ & $0.588 \pm 0.019$ & $0.589 \pm 0.019$ & $0.525 \pm 0.017$ \\
\hline & lsg & $0.540 \pm 0.010$ & $0.578 \pm 0.018$ & $0.537 \pm 0.005$ \\
\hline \multirow[t]{4}{*}{7} & 1 & $0.538 \pm 0.000$ & $0.523 \pm 0.000$ & $0.615 \pm 0.000$ \\
\hline & $\mathrm{s}$ & $0.527 \pm 0.024$ & $0.480 \pm 0.025$ & $0.538 \pm 0.020$ \\
\hline & $\mathrm{g}$ & $0.524 \pm 0.008$ & $0.481 \pm 0.022$ & $0.576 \pm 0.008$ \\
\hline & lsg & $0.544 \pm 0.031$ & $0.488 \pm 0.011$ & $0.566 \pm 0.016$ \\
\hline \multirow[t]{4}{*}{8} & 1 & $0.695 \pm 0.000$ & $0.660 \pm 0.000$ & $0.605 \pm 0.000$ \\
\hline & $\mathrm{s}$ & $0.642 \pm 0.024$ & $0.641 \pm 0.025$ & $0.562 \pm 0.019$ \\
\hline & $\mathrm{g}$ & $0.664 \pm 0.008$ & $0.679 \pm 0.010$ & $0.558 \pm 0.017$ \\
\hline & lsg & $0.667 \pm 0.012$ & $0.663 \pm 0.011$ & $0.570 \pm 0.022$ \\
\hline \multirow[t]{4}{*}{9} & 1 & $0.725 \pm 0.000$ & $0.628 \pm 0.000$ & $0.533 \pm 0.000$ \\
\hline & $\mathrm{s}$ & $0.654 \pm 0.011$ & $0.594 \pm 0.020$ & $0.537 \pm 0.023$ \\
\hline & $\mathrm{g}$ & $0.704 \pm 0.020$ & $0.605 \pm 0.008$ & $0.569 \pm 0.030$ \\
\hline & lsg & $0.686 \pm 0.009$ & $0.591 \pm 0.021$ & $0.545 \pm 0.014$ \\
\hline
\end{tabular}




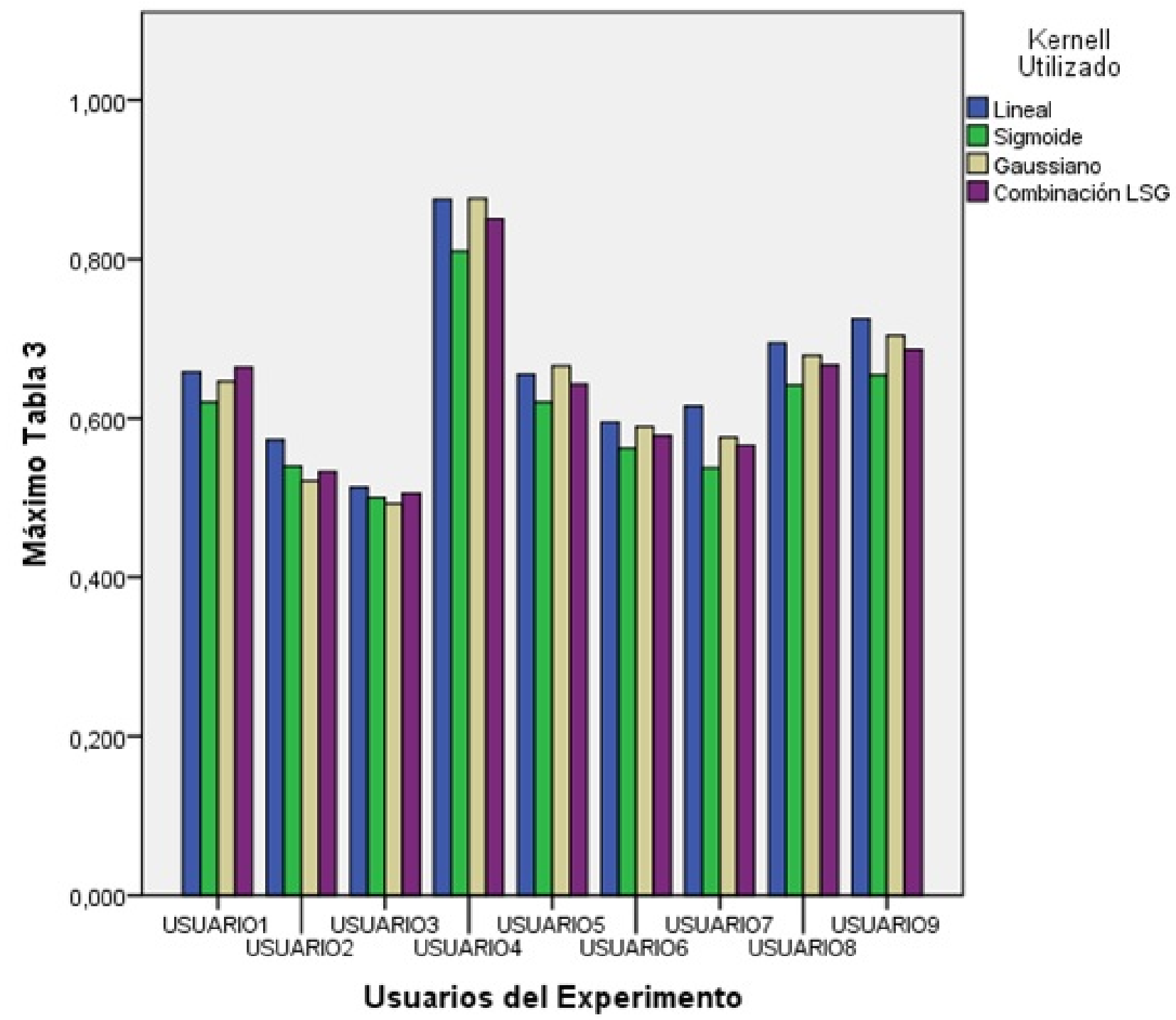

Figura 7.2.6: Diagrama de barras de los valores máximos de la Tabla 7.2.3 para cada sujeto, obtenidos con núcleos lineal, sigmoide, gaussiano y lsg. 
Tabla 7.2.4: Resultados de precisión de clasificación mediante LOO, utilizando PSD, H y AAR como métodos de extracción de características de forma combinada, aplicando concatenación, ventana central y promedio sobre el conjunto de todas ellas y, aplicando cuatro núcleos diferentes $(1, \mathrm{~s}$, g y lsg) para el ELM.

\begin{tabular}{|c|c|c|c|c|}
\hline Prueba & Kernel & Concatenación & Ventana Central & Promedio \\
\hline \multirow[t]{4}{*}{1} & 1 & $0.758 \pm 0.000$ & $0.705 \pm 0.000$ & $0.588 \pm 0.000$ \\
\hline & $\mathrm{s}$ & $0.615 \pm 0.011$ & $0.610 \pm 0.021$ & $0.558 \pm 0.018$ \\
\hline & $\mathrm{g}$ & $0.730 \pm 0.007$ & $0.693 \pm 0.014$ & $0.603 \pm 0.007$ \\
\hline & lsg & $0.741 \pm 0.005$ & $0.659 \pm 0.019$ & $0.613 \pm 0.004$ \\
\hline \multirow[t]{4}{*}{2} & 1 & $0.463 \pm 0.000$ & $0.573 \pm 0.000$ & $0.553 \pm 0.000$ \\
\hline & s & $0.553 \pm 0.004$ & $0.526 \pm 0.016$ & $0.521 \pm 0.019$ \\
\hline & $\mathrm{g}$ & $0.508 \pm 0.014$ & $0.547 \pm 0.020$ & $0.514 \pm 0.009$ \\
\hline & lsg & $0.519 \pm 0.014$ & $0.529 \pm 0.019$ & $0.518 \pm 0.053$ \\
\hline \multirow[t]{4}{*}{3} & 1 & $0.473 \pm 0.000$ & $0.523 \pm 0.000$ & $0.503 \pm 0.000$ \\
\hline & $\mathrm{s}$ & $0.501 \pm 0.016$ & $0.483 \pm 0.002$ & $0.485 \pm 0.004$ \\
\hline & $\mathrm{g}$ & $0.539 \pm 0.015$ & $0.487 \pm 0.017$ & $0.494 \pm 0.016$ \\
\hline & lsg & $0.528 \pm 0.008$ & $0.489 \pm 0.019$ & $0.509 \pm 0.009$ \\
\hline \multirow[t]{4}{*}{4} & 1 & $0.930 \pm 0.000$ & $0.888 \pm 0.000$ & $0.845 \pm 0.000$ \\
\hline & $\mathrm{s}$ & $0.810 \pm 0.011$ & $0.813 \pm 0.004$ & $0.775 \pm 0.007$ \\
\hline & $\mathrm{g}$ & $0.908 \pm 0.010$ & $0.888 \pm 0.010$ & $0.831 \pm 0.005$ \\
\hline & Isg & $0.927 \pm 0.006$ & $0.888 \pm 0.003$ & $0.825 \pm 0.011$ \\
\hline \multirow[t]{4}{*}{5} & 1 & $0.698 \pm 0.000$ & $0.698 \pm 0.000$ & $0.588 \pm 0.000$ \\
\hline & s & $0.665 \pm 0.004$ & $0.621 \pm 0.009$ & $0.530 \pm 0.007$ \\
\hline & $\mathrm{g}$ & $0.738 \pm 0,009$ & $0.680 \pm 0.009$ & $0.581 \pm 0.012$ \\
\hline & $\operatorname{lsg}$ & $0.722 \pm 0.025$ & $0.648 \pm 0.014$ & $0.554 \pm 0.019$ \\
\hline \multirow[t]{4}{*}{6} & 1 & $0.663 \pm 0.000$ & $0.560 \pm 0.000$ & $0.548 \pm 0.000$ \\
\hline & $\mathrm{s}$ & $0.594 \pm 0.005$ & $0.550 \pm 0.007$ & $0.506 \pm 0.030$ \\
\hline & $\mathrm{g}$ & $0.666 \pm 0.009$ & $0.595 \pm 0.034$ & $0.558 \pm 0.014$ \\
\hline & lsg & $0.669 \pm 0.006$ & $0.561 \pm 0.005$ & $0.563 \pm 0.013$ \\
\hline \multirow[t]{4}{*}{7} & 1 & $0.618 \pm 0.000$ & $0.593 \pm 0.000$ & $0.578 \pm 0.000$ \\
\hline & $\mathrm{s}$ & $0.571 \pm 0.009$ & $0.531 \pm 0.023$ & $0.568 \pm 0.003$ \\
\hline & $\mathrm{g}$ & $0.614 \pm 0.022$ & $0.590 \pm 0.013$ & $0.549 \pm 0.012$ \\
\hline & lsg & $0.637 \pm 0.015$ & $0.569 \pm 0.002$ & $0.559 \pm 0.009$ \\
\hline \multirow[t]{4}{*}{8} & 1 & $0.718 \pm 0.000$ & $0.723 \pm 0.000$ & $0.655 \pm 0.000$ \\
\hline & $\mathrm{s}$ & $0.649 \pm 0.048$ & $0.633 \pm 0.018$ & $0.625 \pm 0.014$ \\
\hline & $\mathrm{g}$ & $0.716 \pm 0.004$ & $0.729 \pm 0.007$ & $0.666 \pm 0.009$ \\
\hline & lsg & $0.728 \pm 0.020$ & $0.703 \pm 0.028$ & $0.667 \pm 0.006$ \\
\hline \multirow[t]{4}{*}{9} & 1 & $0.688 \pm 0.000$ & $0.700 \pm 0.000$ & $0.668 \pm 0.000$ \\
\hline & $\mathrm{s}$ & $0.645 \pm 0.035$ & $0.629 \pm 0.005$ & $0.588 \pm 0.014$ \\
\hline & $\mathrm{g}$ & $0.689 \pm 0.012$ & $0.665 \pm 0.013$ & $0.626 \pm 0.005$ \\
\hline & Isg & $0.672 \pm 0.021$ & $0.656 \pm 0.016$ & $0.605 \pm 0.011$ \\
\hline
\end{tabular}




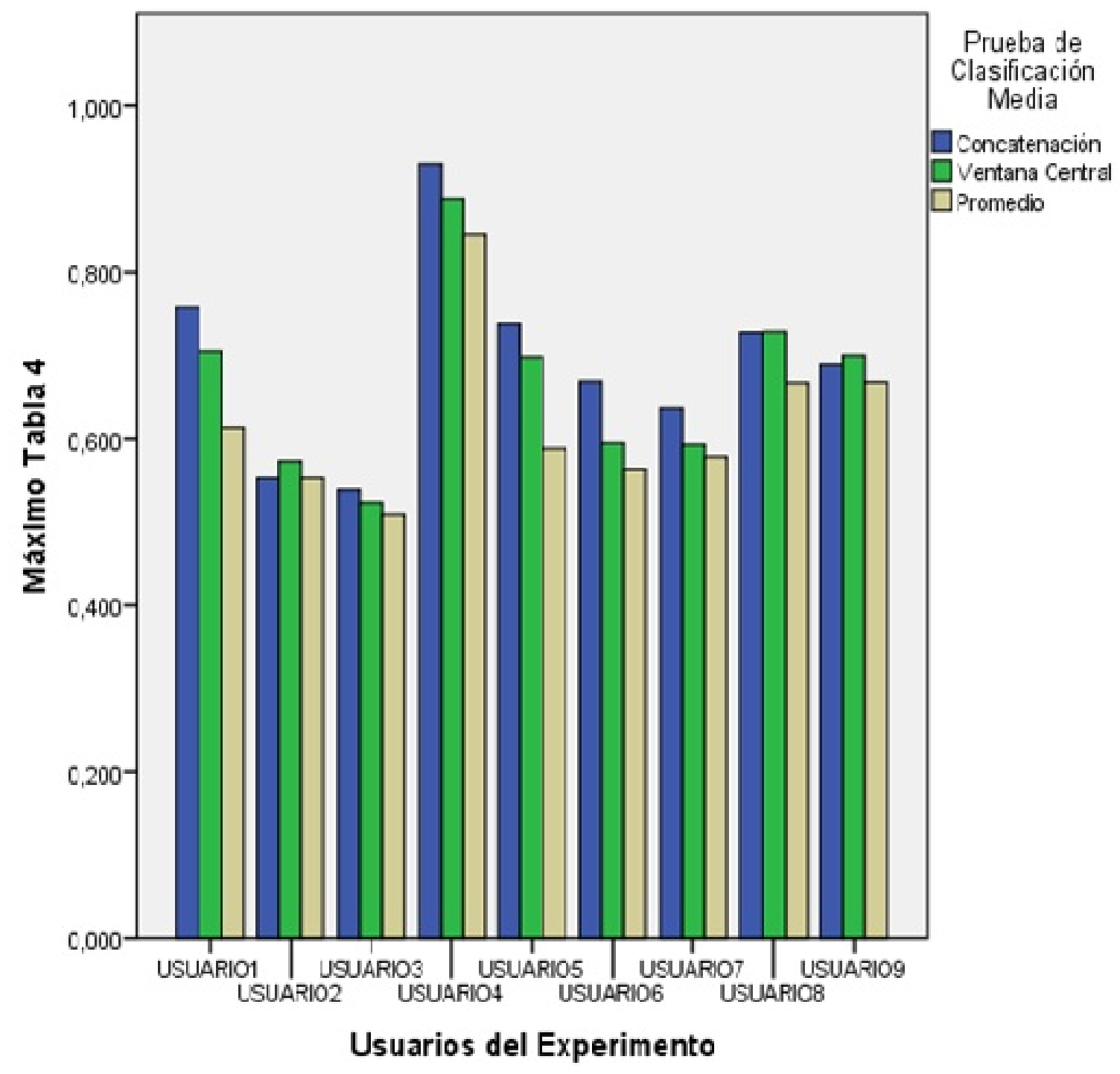

Figura 7.2.7: Diagrama de barras de los valores máximos de la Tabla 7.2.3 para cada sujeto, obtenidos con núcleos lineal, sigmoide, gaussiano y lsg.

Tal y como se muestra en las Tablas 7.2.1, 7.2.2, 7.2.3, 7.2.4 y en las Figuras 7.2.4, 7.2.5, 7.2.6 y 7.2.7 los resultados no son altos. Sería deseable obtener resultados que estuvieran en todo caso por encima del 0.70 , pero vemos que en numerosas ocasiones están por debajo, como sucede con los Sujetos 2, 3, 4 y 6. Analizando que combinación de métodos nos ofrece mejores resultados, se observa que en la Tabla 7.2.1, en la primera fila, se presentan los resultados obtenidos con los cuatro kernels empleados y con PSD como método de extracción de características y podemos comprobar que obtiene los mejores resultados para tres sujetos ( 4 y 7) con $0.595 \pm 0.0000,0.93 \pm 0.0000 \mathrm{y}$ $0.635 \pm 0.0000$ respectivamente, ver Figura 7.2.4. 
Es importante destacar que todos ellos han sido obtenidos usando un kernel lineal, ver 7.2.4. En la misma Tabla se muestra el mejor resultado para el Sujeto 2 con $0.595 \pm 0.0000$ empleando también un kernel lineal, pero AAR como forma de obtener las características. En la Tabla 7.2.3 los resultados de PSD, presentan el mejor resultado para el Sujeto 9 (0,7255 \pm 0,0000), obtenido usando un kernel lineal, ver 7.2.6. Sin embargo, es en la última Tabla, la 7.2.4, donde se presentan los mejores resultados para cinco de los nueve Sujetos $(1,4,5,6$ y 8) con $0.758 \pm 0.0000,0.930 \pm$ $0.0000,0.738 \pm 0.009,0.669 \pm 0.006$ y $0.728 \pm 0.020$. Cabe tener en cuenta que el Sujeto 4 obtiene en esta tabla los mismos resultados que en la Tabla 7.2.1. Con respecto a los núcleos empleados, el rendimiento más alto se ha obtenido con $l$, ver 7.2.7, puesto que en 6 de las nueve ocasiones ha sido el más eficaz. En dos ocasiones ha sido el $l s g$ y en una el $g$. Finalmente, es interesante destacar que, en cuanto a los métodos de combinación de características, claramente la concatenación es el más adecuado, puesto que para los sujetos $1,2,3,4,5,6,7$ y 8 ha sido el que ha proporcionado los valores más altos en clasificación, siendo únicamente el sujeto 9 el que los ha obtenido mediante Promediado de características (PSD).

\subsubsection{Conclusiones.}

En este Experimento 2, se han extraído características mediante el uso de tres técnicas diferentes (PSD, H y AAR), se han combinado bajo tres diferentes enfoques (Ventana Central, Promediado y Concatenación de características). Estas han sido clasificadas utilizando ELM con cuatro núcleos diferentes (1, s, g y lsg).

Los resultados muestran que ELM ofrece resultados bajos usando solo un método de extracción de características, independientemente de las estrategias de extracción de características empleadas y el kernel implementado por el ELM. Sin embargo, se produce una mejora de los resultados de clasificación mediante la extracción y combinación de todas las características a la vez para su clasificación. Por lo tanto, es capaz de explotar la información complementaria de los tres métodos de extracción de características implementados. El ELM selecciona las características más relevantes,

ajustando los pesos artificiales de la red neuronal, por lo tanto, se convierte en un método adecuado para ser aplicado en sistemas BCI basados en MI. En particular, como se muestra en la Tabla 7.2.4, los mejores resultados se obtienen concatenando las características obtenidas bajo PSD, Hjörth y AAR. Es importante destacar también que con respecto a el kernel, en general, el $l$ obtiene los mejores resultados de clasificación. 
Capítulo 7. Experimentos y Resultados. 


\section{Capítulo 8}

\section{Conclusiones y Trabajos Futuros.}

Tal y como se dice en el Capítulo 1 de esta Tesis, los sistemas BCI permiten la identificación de patrones de activación generados por el cerebro de los usuarios. En general, los BCI tienen diferentes pasos: la adquisición de señales de EEG multicanal; la detección de artefactos y el preprocesamiento de señales; la extracción de características y la clasificación de los vectores de características utilizando técnicas estadísticas de aprendizaje automático. Muchos esfuerzos de investigación se han centrado en las dos últimas etapas: extracción de características y clasificación.

Inicialmente, muchas características se extraen de diferentes métodos y de canales que cubren todas las áreas cerebrales potencialmente útiles. Aunque se han empleado grandes esfuerzos en buscar los métodos de selección de características y el clasificador más adecuado, el ELM no se ha probado en profundidad y además, muchos de estos esfuerzos se han desarrollado con bases de datos estándar que contienen EEG de usuarios ya experimentados.

Por eso, en este trabajo se ha probado ELM con diferentes métodos de extracción de características y también con usuarios que nunca antes había usado un sistema BCI para ver cuál es su rendimiento en clasificación.

\subsection{Conclusiones}

Esta Tesis ha testeado ELM como clasificador para sistemas BCI basados en Imaginación de Movimiento. Para ello se han desarrollado dos experimentos:

El primero explora el rendimiento del clasificador con señales de usuarios que nunca antes se habían enfrentado a un sistema BCI. Para ello debido a que no hay disponibilidad en la red de este tipo de señales, se realizaron experimentos de imaginación de movimiento, de las manos derecha e izquierda con 5 usuarios. Se emplearon electrodos pasivos conformando dos canales bipolares en 
C3 y C4. Como método de extracción de características, se empleó PSD (alpha y beta) en dos ventanas de 1 segundo. Posteriormente, se promediaron las características para generar el vector final de características y se clasificaron con tres clasificadores distintos: LDA; SVM; y ELM. Téngase en cuenta que los dos primeros han sido ampliamente utilizados en BCI y sus resultados sirven como referencia para poder compararlos con los obtenidos por el ELM. En este experimento se empleó un kernel no lineal (gaussiano) para el ELM. Los resultados muestran que el ELM superaba a los otros clasificadores en 3 de los 5 sujetos, por lo que podría ser un clasificador aplicable para este tipo de sistemas.

El segundo experimento explora cual de las configuraciones del ELM y sería conveniente para este tipo de problemas. En este caso, emplearon señales estándar extraídas del conjunto de datos IIb del BCI Competitions IV. Se implementaron tres métodos de extracción de características muy usados en BCI como son: PSD; AAR y Hjörth. Seguidamente, tras establecer dos ventanas de 1 segundo para la extracción de las características, se definieron tres estrategias de combinación de las mismas: Ventana central; Promediado y Concatenación. La clasificación se realizó primero, utilizando las características de cada uno de estos métodos combinadas según las estrategias de combinación enumeradas y probando 4 núcleos diferentes para el ELM, l, s, g y lsg. Y segundo, utilizando las características de todos los métodos extraídas a la vez y combinadas según las estrategias de combinación vistas. Nuevamente se probaron otra vez los 4 kernels para el ELM. Los resultados muestran que el ELM ofrece bajos resultados utilizando solo un método de extracción de características, independientemente de las estrategias de combinaciones empleadas y del núcleo implementado. Sin embargo, se observa una mejora de los resultados de precisión en clasificación mediante el uso de todas las características extraídas en el al mismo tiempo, al combinarlas y clasificarlas. Por lo tanto, el ELM es capaz de explotar la información complementaria que aportan los tres métodos de extracción de características implementados. Además, el ELM selecciona las características más relevantes ajustando los pesos de la red neuronal artificial. Esto explica que los mejores resultados se hayan obtenido mediante la concatenación de todas las características calculadas. De esta forma, el ELM se convierte en un método adecuado para ser aplicado en sistemas BCI basados en Imaginación de Movimiento. Por último, atendiendo a los resultados obtenidos, cabe destacar que es el kernel lineal el que obtiene mejores resultados

\subsection{Trabajos Futuros}

El campo que abre la investigación en BCI es tremendamente amplio y se podrían emprender muchísimas iniciativas en cada una de las etapas del BCI. Sin embargo, se han plasmado aquí las principales líneas de trabajo futuro que se han planteado: 
Se propone como trabajo futuro probar con más bases de datos la metodología empleada e incluir nuevos métodos de extracción de características para ver si siguen incrementando el rendimiento en clasificación aprovechando la información complementaria que pueden aportar a ELM.

También se propone, visto que es un método aplicable a usuarios noveles, realizar el entrenamiento completo de varios usuarios teniendo como clasificador de referencia ELM e incluso implementar un sistema BCI con realimentación con un ELM como clasificador.

Finalmente, se propone implementar algoritmos también basados en redes neuronales como el "Deep Learning", para evaluar su rendimiento, tanto con usuarios noveles como experimentados.

\subsection{Trabajos Publicados}

Los resultados de esta tesis se pueden resumir (en términos de publicaciones) en 2 artículos de revista (ISI-JCR) y un artículo en una revista nacional. Aunque se incluyen más adelante una un anexo los artículos ISI-JCR, se realiza aquí un listado.

Artículos Publicados en Revistas ISI-JCR:

- F. J. Martínez-Albaladejo; A. Bueno-Crespo; G. Rodríguez-Bermúdez. Testing Extreme Learning Machine in Motor Imagery Brain Computer Interface, Journal of Intelligent \& Fuzzy Systems. 2017, 3, 3103-3111. ISI-JCR 2016: 1.261 (Q3 Computer Science, Artificial Intelligence).

- G. Rodríguez-Bermúdez; A. Bueno-Crespo; F. J. Martínez-Albaladejo. Classifying BCI signals from novice users with Extreme Learning Machine, Open Physics. 2017, 1, 494-500. ISI-JCR 2016: 0.745 (Q3 Physics, Multidisciplinary).

- Estos dos artículos forman parte del plan nacional con referencia MTM2014-51891P.

Artículos Publicados en Revistas no ISI-JCR:

- F. J. Martínez-Albaladejo; G. Rodríguez-Bermúdez; P.J. García-Laencina. Estado del arte en plataformas software para el diseño de sistemas Brain Computer Interface. Revista VI Jornadas de introducción a la investigación de la UPCT. 2014, 7, 1888-8356. 


\section{Bibliografía}

[1] Khalid, M.B.; Rao, N.I.; Rizwan-i-Haque, I.; Munir, S.; Tahir, F. Towards a Brain Computer Interface Using Wavelet Transform with Averaged and Time Segmented Adapted Wavelets. In Proceedings of the 2nd International Conference on Computer, Control and Communication (IC4’09) Karachi, Sindh, Pakistan, February 2009; pp. 1-4. 3, 27

[2] Wolpaw, J.R.; Birbaumer, N.; McFarland, D.J.; Pfurtscheller, G.; Vaughan, T.M. Braincomputer interfaces for communication and control. Clin. Neurophysiol. 2002, 113, 767-791. 3, 26, 36

[3] Wolpaw, J.R. Brain-computer interfaces as new brain output pathways. J. Physiol. 2007, 579, 613-619. 3

[4] Wolpaw, J.R.; Birbaumer, N.; Heetderks, W.J.; McFarland, D.J.; Peckham, P.H.; Schalk, G.; Donchin, E.; Quatrano, L.A.; Robinson, C.J.; Vaughan, T.M. Brain-computer interface technology: A review of the first international meeting. IEEE Trans. Rehabil. Eng. 2000, 8, 164-173. 26,35

[5] Sellers, E.W.; Vaughan, T.M.; Wolpaw, J.R. A brain-computer interface for long-term independent home use. Amyotroph. Lateral Scler. 2010, 11, 449-455. 18, 21, 40, 49

[6] Cincotti, F.; Mattia, D.; Aloise, F.; Bufalari, S.; Schalk, G.; Oriolo, G.; Cherubini, A.; Marciani, M.G.; Babiloni, F. Non-invasive brain-computer interface system: Towards its application as assistive technology. Brain Res. Bull. 2008, 75, 796-803. 44

[7] Lebedev, M.A.; Nicolelis, M.A.L. Brain-machine interfaces: Past, present and future. Trends Neurosci. 2006, 29, 536-546. 40

[8] Usakli, A.B. Improvement of EEG signal acquisition: An electrical aspect for state of the art of front end. Comput. Intell. Neurosci. 2010, 2010, 630649. 18

[9] Fonseca, C.; Cunha, J.P.S.; Martins, R.E.; Ferreira, V.M.; de Sa, J.P.M.; Barbosa, M.A.; da Silva, A.M. A Novel Dry Active Electrode for EEG Recording. IEEE Trans. Biomed. Eng. 2007, 54, 162-165. 18 
[10] Leach, W.M., Jr. Fundamentals of low-noise analog circuit design. Proc. IEEE 1994, 82, 1515-1538. 19, 59

[11] Kubler, A.; Kotchoubey, B.; Kaiser, J.; Wolpaw, J.R.; Birbaumer, N. Brain-Computer Communication: Unlocking the Locked in; American Psychological Association: Washington, DC, USA, 2001. 19, 59

[12] Klimesch, W.; Doppelmayr, M.; Yonelinas, A.; Kroll, N.E.A.; Lazzara, M.; Röhm, D.; Gruber, W. Theta synchronization during episodic retrieval: Neural correlates of conscious awareness. Cogn. Brain. Res. 2001, 12, 33-38. 19

[13] Black, A.H. The Operant Conditioning of Central Nervous System Electrical Activity. In Psychology of Learning and Motivation, Gordon, H.B., Ed.; Academic Press: New York, NY, USA, 1972; Volume 6, pp. 47-95. 19

[14] Klimesch, W. EEG-alpha rhythms and memory processes. Int. J. Psychophysiol. 1997, 26, 319-340. 19, 20

[15] Venables, L.; Fairclough, S. The influence of performance feedback on goal-setting and mental effort regulation. Motiv. Emotion 2009, 33, 63-74. 19

[16] Pfurtscheller, G.; Brunner, C.; Schlögl, A.; Lopes da Silva, F.H. Mu rhythm (de) synchronization and EEG single-trial classification of different motor imagery tasks. Neuroimage 2006, 31, 153-159. 19, 96

[17] Pfurtscheller, G.; Neuper, C. Motor imagery and direct brain-computer communication. Proc. IEEE 2001, 89, 1123-1134. 20

[18] Lee, K.-H.; Williams, L.M.; Breakspear, M.; Gordon, E. Synchronous Gamma activity: A review and contribution to an integrative neuroscience model of schizophrenia. Brain Res. Rev. 2003, 41, 57-78. 20

[19] Brown, P.; Salenius, S.; Rothwell, J.C.; Hari, R. Cortical correlate of the piper rhythm in humans. J. Neurophysiol. 1998, 80, 2911-2917. 34

[20] Jasper, H.H. The ten-twenty electrode system of the International Federation. Electroencephalogr. Clin. Neurophysiol. 1958, 10, 371-375. 20

[21] Babiloni, C.; Pizzella, V.; Gratta, C.D.; Ferretti, A.; Romani, G.L.; Fundamentals of Electroencefalography, Magnetoencefalography, and Functional Magnetic Resonance Imaging. In Brain Machine Interfaces for Space Applications; Luca, R., Dario, I., Leopold, S., Eds.; Academic Press: New York, NY, USA, 2009; Volume 86, pp. 67-80. 21, 22 
[22] Mellinger, J.; Schalk, G.; Braun, C.; Preissl, H.; Rosenstiel, W.; Birbaumer, N.; Kübler, A. An MEG-based brain-computer interface (BCI). NeuroImage 2007, 36, 581-593. 21

[23] Wang, W.; Sudre, G.P.; Xu, Y.; Kass, R.E.; Collinger, J.L.; Degenhart, A.D.; Bagic, A.I.; Weber, D.J. Decoding and cortical source localization for intended movement direction with MEG. J. Neurophysiol. 2010, 104, 2451-2461. 21

[24] Kauhanen, L.; Nykopp, T.; Lehtonen, J.; Jylanki, P.; Heikkonen, J.; Rantanen, P.; Alaranta, H.; Sams, M. EEG and MEG brain-computer interface for tetraplegic patients. IEEE Trans. Neural Syst. Rehabil. Eng. 2006, 14, 190-193. 21

[25] Georgopoulos, A.; Langheim, F.; Leuthold, A.; Merkle, A. Magnetoencephalographic signals predict movement trajectory in space. Exp. Brain Res. 2005, 167, 132-135. 21

[26] Jinyin, Z.; Sudre, G.; Xin, L.; Wei, W.; Weber, D.J.; Bagic, A. Clustering linear discriminant analysis for MEG-Based brain computer interfaces. IEEE Trans. Neural Syst. Rehabil. Eng. 2011, 19, 221-231. 21

[27] Sabra, N.I.; Wahed, M.A. The Use of MEG-Based Brain Computer Interface for Classification of Wrist Movements in Four Different Directions. In Proceedings of the 28th National Radio Science Conference (NRSC' 11), Cairo, Egypt, April 2011; pp. 1-7. 21

[28] Ball, T.; Kern, M.; Mutschler, I.; Aertsen, A.; Schulze-Bonhage, A. Signal quality of simultaneously recorded invasive and non-invasive EEG. Neuroimage 2009, 46, 708-716. 21

[29] Loeb, G.E.; Walker, A.E.; Uematsu, S.; Konigsmark, B.W. Histological reaction to various conductive and dielectric films chronically implanted in the subdural space. J. Biomed. Mater. Res. 1977, 11, 195-210. 21

[30] Bullara, L.A.; Agnew, W.F.; Yuen, T.G.H.; Jacques, S.; Pudenz, R.H. Evaluation of electrode array material for neural prostheses. Neurosurgery 1979, 5, 681-686. 21

[31] Yuen, T.G.H.; Agnew, W.F.; Bullara, L.A. Tissue response to potential neuroprosthetic materials implanted subdurally. Biomaterials 1987, 8, 138-141. 21

[32] Margalit, E.; Weiland, J.D.; Clatterbuck, R.E.; Fujii, G.Y.; Maia, M.; Tameesh, M.; Torres, G.; D’Anna, S.A.; Desai, S.; Piyathaisere, D.V.; et al. Visual and electrical evoked response recorded from subdural electrodes implanted above the visual cortex in normal dogs under two methods of anesthesia. J. Neurosci. Methods 2003, 123, 129-137. 21

[33] Chao, Z.C.; Nagasaka, Y.; Fujii, N. Long-term asynchronous decoding of arm motion using electrocorticographic signals in monkeys. Front. Neuroeng. 2010, 3, doi: 10.3389/fneng.2010.00003. 21 
[34] Matsuo, T.; Kawasaki, K.; Osada, T.; Sawahata, H.; Suzuki, T.; Shibata, M.; Miyakawa, N.; Nakahara, K.; Iijima, A.; Sato, N.; et al. Intrasulcal electrocorticography in macaque monkeys with minimally invasive neurosurgical protocols. Front. Syst. Neurosci. 2011, doi: 10.3389/fnsys.2011.00034. 21

[35] Crone, N.E.; Miglioretti, D.L.; Gordon, B.; Lesser, R.P. Functional mapping of human sensorimotor cortex with electrocorticographic spectral analysis. II. Event-related synchronization in the gamma band. Brain 1998, 121, 2301-2315. 22

[36] Miller, K.J.; denNijs, M.; Shenoy, P.; Miller, J.W.; Rao, R.P.N.; Ojemann, J.G. Real-time functional brain mapping using electrocorticography. NeuroImage 2007, 37, 504-507. 22

[37] Levine, S.P.; Huggins, J.E.; BeMent, S.L.; Kushwaha, R.K.; Schuh, L.A.; Passaro, E.A.; Rohde, M.M.; Ross, D.A. Identification of electrocorticogram patterns as the basis for a direct brain interface. J. Clin. Neurophysiol. 1999, 16, 439-447. 22

[38] Leuthardt, E.C.; Schalk, G.; Wolpaw, J.R.; Ojemann, J.G; Moran, D.W. A braincomputer interface using electrocorticographic signals in humans. J. Neural Eng. 2004, doi: $10.1088 / 17412560 / 1 / 2 / 001.22$

[39] Nicolas-Alonso L., Gomez-Gil J., Brain computer interfaces, a review, Sensors, 2012, 1211-1279. 94

[40] Schalk, G.; Schalk, G.; Kubanek, J.; Miller, K.J.; Anderson, N.R.; Leuthardt, E.C.; Ojemann, J.G.; Limbrick, D.; Moran, D.; Gerhardt, L.A.; et al. Decoding two-dimensional movement trajectories using electrocorticographic signals in humans. J. Neural Eng. 2007, doi: 10.1088/17412560/4/3/012. 22

[41] Polikov, V.S.; Tresco, P.A.; Reichert, W.M. Response of brain tissue to chronically implanted neural electrodes. J. Neurosci. Methods 2005, 148, 1-18. 22, 23

[42] Maynard, E.M.; Nordhausen, C.T.; Normann, R.A. The Utah Intracortical Electrode Array: A recording structure for potential brain-computer interfaces. Electroencephalogr. Clin. Neurophysiol. 1997, 102, 228-239. 22, 23

[43] Lauer, R.T.; Peckham, P.H.; Kilgore, K.L.; Heetderks, W.J. Applications of cortical signals to neuroprosthetic control: A critical review. IEEE Trans. Rehabil. Eng. 2000, 8, 205-208. 23

[44] Georgopoulos, A.; Schwartz, A.; Kettner, R. Neuronal population coding of movement direction. Science 1986, 233, 1416-1419. 23

[45] Schwartz, A.B. Motor cortical activity during drawing movements: population representation during sinusoid tracing. J. Neurophysiol. 1993, 70, 28-36. 23 
[46] Taylor, D.M.; Tillery, S.I.H.; Schwartz, A.B. Direct cortical control of 3D neuroprosthetic devices. Science 2002, 296, 1829-1832. 23

[47] Vargas-Irwin, C.E.; Shakhnarovich, G.; Yadollahpour, P.; Mislow, J.M.K.; Black, M.J.; Donoghue, J.P. Decoding complete reach and grasp actions from local primary motor cortex populations. J. Neurosci. 2010, 30, 9659-9669. 23

[48] Carpaneto, J.; Umiltà, M.A.; Fogassi, L.; Murata, A.; Gallese, V.; Micera, S.; Raos, V. Decoding the activity of grasping neurons recorded from the ventral premotor area F5 of the macaque monkey. Neuroscience 2011, 188, 80-94. 23

[49] Kennedy, P.R.; Kirby, M.T.; Moore, M.M.; King, B.; Mallory, A. Computer control using human intracortical local field potentials. IEEE Trans. Neural Syst. Rehabil. Eng. 2004, 12, 339-344. 23

[50] deCharms, R.C.; Christoff, K.; Glover, G.H.; Pauly, J.M.; Whitfield, S.; Gabrieli, J.D.E. Learned regulation of spatially localized brain activation using real-time fMRI. Neuroimage 2004, 21, 436-443. 23

[51] Lee, J.; Ryu, J.; Jolesz, F.A.; Cho, Z.H.; Yoo, S.S. Brain-machine interface via real-time fMRI: Preliminary study on thought-controlled robotic arm. Neurosci. Lett. 2009, 450, 1-6. 23

[52] Logothetis, N.K.; Pauls, J.; Augath, M.; Trinath, T.; Oeltermann, A. Neurophysiological investigation of the basis of the fMRI signal. Nature 2001, 412, 150-157. 23

[53] Weiskopf, N.; Sitaram, R.; Josephs, O.; Veit, R.; Scharnowski, F.; Goebel, R.; Birbaumer, N.; Deichmann, R.; Mathiak, K. Real-time functional magnetic resonance imaging: Methods and applications. Magn. Reson. Imaging 2007, 25, 989-1003. 23

[54] Christopher deCharms, R. Applications of real-time fMRI. Nat. Rev. Neurosci. 2008, 9, $720-729.23$

[55] Taga, G.; Homae, F.; Watanabe, H. Effects of source-detector distance of near infrared spectroscopy on the measurement of the cortical hemodynamic response in infants. NeuroImage 2007, 38, 452-460. 24

[56] Kennan, R.P.; Horovitz, S.G.; Maki, A.; Yamashita, Y.; Koizumi, H.; Gore, J.C. Simultaneous recording of event-related auditory oddball response using transcranial near infrared optical topography and surface EEG. Neuroimage 2002, 16, 587-592. 24

[57] Izzetoglu, M.; Devaraj, A.; Bunce, S.; Onaral, B. Motion artifact cancellation in NIR spectroscopy using Wiener filtering. IEEE Trans. Biomed. Eng. 2005, 52, 934-938. 24 
[58] Strangman, G.; Boas, D.A.; Sutton, J.P. Non-invasive neuroimaging using near-infrared light. Biol. Psychiatry 2002, 52, 679-693. 24

[59] Cui, X.; Bray, S.; Reiss, A.L. Functional near infrared spectroscopy (NIRS) signal improvement based on negative correlation between oxygenated and deoxygenated hemoglobin dynamics. Neuroimage 2010, 49, 3039-3046. 24

[60] Shirley, C.; Ward, T.; Markham, C.; McDarby, G. On the suitability of near-infrared (NIR) systems for next-generation brain-computer interfaces. Physiol. Meas. 2004, 25, 815. 24

[61] Villringer, A.; Planck, J.; Hock, C.; Schleinkofer, L.; Dirnagl, U. Near infrared spectroscopy (NIRS): A new tool to study hemodynamic changes during activation of brain function in human adults. Neurosci. Lett. 1993, 154, 101-104. 24

[62] Jinghai , Y.; Derong, J.; Jianfeng, H. Design and Application of Brain-Computer Interface Web Browser Based on VEP. In Proceedings of the International Conference on Future BioMedical Information Engineering (FBIE'09), Sanya, China, 13-14 December 2009; pp. 77-80. 29, 43

[63] Odom, J.V.; Bach, M.; Barber, C.; Brigell, M.; Marmor, M.F.; Tormene, A.P.; Holder, G.E. Visual evoked potentials standard (2004). Doc. Ophthalmol. 2004, 108, 115-123. 29

[64] Zhu, D.; Bieger, J.; Garcia Molina, G.; Aarts, R.M. A survey of stimulation methods used in SSVEP-Based BCIs. Comput. Intell. Neurosci. 2010, doi: 10.1155/2010/702357. 29

[65] Galloway, N. Human brain electrophysiology: Evoked potentials and evoked magnetic fields in science and medicine. Br. J. Ophthalmol. 1990, 74, 255. 30

[66] Perlstein, W.M.; Cole, M.A.; Larson, M.; Kelly, K.; Seignourel, P.; Keil, A. Steady-state visual evoked potentials reveal frontally-mediated working memory activity in humans. Neurosci. Lett. 2003, 342, 191-195. 30

[67] Gray, M.; Kemp, A.H.; Silberstein, R.B.; Nathan, P.J. Cortical neurophysiology of anticipatory anxiety: An investigation utilizing steady state probe topography (SSPT). Neuroimage 2003, 20,975-986. 30

[68] Guangyu, B.; Xiaorong, G.; Yijun, W.; Bo, H.; Shangkai, G. VEP-based brain-computer interfaces: Time, frequency, and code modulations [Research Frontier]. IEEE Comput. Intell. Mag. 2009, 4, 22-26. 30

[69] Lee, P.; Hsieh, J.; Wu, C.; Shyu, K.; Wu, Y. Brain computer interface using flash onset and offset visual evoked potentials. Clin. Neurophysiol. 2008, 119, 605-616. 30, 31 
[70] Dan, Z.; Alexander, M.; Xiaorong, G.; Bo, H.; Andreas, K.E.; Shangkai, G. An independent brain-computer interface using covert non-spatial visual selective attention. J. Neural Eng. 2010, 7, 016010. 31

[71] Yijun, W.; Xiaorong, G.; Bo, H.; Chuan, J.; Shangkai, G. Brain-computer interfaces based on visual evoked potentials. IEEE Eng. Med. Biol. Mag. 2008, 27, 64-71. 31

[72] Wu, Z.; Lai, Y.; Xia, Y.; Wu, D.; Yao, D. Stimulator selection in SSVEP-based BCI. Med. Eng. Phys. 2008, 30, 1079-1088. 31

[73] Birbaumer, N.; Elbert, T.; Canavan, A.G.; Rockstroh, B. Slow potentials of the cerebral cortex and behavior. Physiol. Rev. 1990, 70, 1-41. 32

[74] Hinterberger, T.; Schmidt, S.; Neumann, N.; Mellinger, J.; Blankertz, B.; Curio, G.; Birbaumer, N. Brain-computer communication and slow cortical potentials. IEEE Trans. Biomed. Eng. 2004, 51, 1011-1018. 31

[75] Kaiser, J. Self-initiation of EEG-based communication in paralyzed patients. Clin. Neurophysiol. 2001, 112, 551-554. 32

[76] Neumann, N.; Birbaumer, N. Predictors of successful self control during brain-computer communication. J. Neurol. Neurosurg. Psychiatry 2003, 74, 1117-1121. 32, 36

[77] Kubler, A.; Kotchoubey, B.; Hinterberger, T.; Ghanayim, N.; Perelmouter, J.; Schauer, M.; Fritsch, C.; Taub, E.; Birbaumer, N. The thought translation device: A neurophysiological approach to communication in total motor paralysis. Exp. Brain Res. 1999, 124, 223-232. 32, 39, 40

[78] Birbaumer, N.; Hinterberger, T.; Kubler, A.; Neumann, N. The thought-translation device (TTD): Neurobehavioral mechanisms and clinical outcome. IEEE Trans. Neural Syst. Rehabil. Eng. 2003, 11, 120-123. 32, 39, 40

[79] Iversen, I.H.; Ghanayim, N.; Kübler, A.; Neumann, N.; Birbaumer, N.; Kaiser, J. A braincomputer interface tool to assess cognitive functions in completely paralyzed patients with amyotrophic lateral sclerosis. Clin. Neurophysiol. 2008, 119, 2214-2223. 32, 39

[80] Farwell, L.A.; Donchin, E. Talking off the top of your head: Toward a mental prosthesis utilizing event-related brain potentials. Electroencephalogr. Clin. Neurophysiol. 1988, 70, 510-523. 40,41

[81] Polich, J.; Ellerson, P.C.; Cohen, J. P300, stimulus intensity, modality, and probability. Int. J. Psychophysiol. 1996, 23, 55-62. 33, 41 
[82] Ravden, D.; Polich, J. On P300 measurement stability: Habituation, intra-trial block variation, and ultradian rhythms. Biol. Psychol. 1999, 51, 59-76. 33

[83] Mugler, E.M.; Ruf, C.A.; Halder, S.; Bensch, M.; Kubler, A. Design and implementation of a P300-based brain-computer interface for controlling an internet browser. IEEE Trans. Neural Syst. Rehabil. Eng. 2010, 18, 599-609. 33, 41, 43

[84] Furdea, A.; Halder, S.; Krusienski, D.J.; Bross, D.; Nijboer, F.; Birbaumer, N.; Kübler, A. An auditory oddball (P300) spelling system for brain-computer interfaces. Psychophysiology 2009, $46,617-625.33$

[85] Rivet, B.; Souloumiac, A.; Attina, V.; Gibert, G. xDAWN algorithm to enhance evoked potentials: Application to brain-computer interface. IEEE Trans. Biomed. Eng. 2009, 56, 2035-2043. 33

[86] Rakotomamonjy, A.; Guigue, V. BCI Competition III: Dataset II-Ensemble of SVMs for BCI P300 Speller. IEEE Trans. Biomed. Eng. 2008, 55, 1147-1154. 33, 85, 89

[87] Salvaris, M.; Sepulveda, F. Visual modifications on the P300 speller BCI paradigm. J. Neural Eng. 2009, 6, 046011. 33

[88] Ikegami, S.; Takano, K.; Saeki, N.; Kansaku, K. Operation of a P300-based brain-computer interface by individuals with cervical spinal cord injury. Clin. Neurophysiol. 2011, 122, 991-996. 34

[89] Hill, J.; Farquhar, J.; Martens, S.; Bießmann, F.; Schölkopf, B. Effects of stimulus type and of error-correcting code design on BCI speller performance. In Proceedings of the Twenty-Second Annual Conference on Neural Information Processing Systems (NIPS 2008), Vancouver, Canada, 8-11 December 2008. 33, 34

[90] Martens, S.M.M.; Hill, N.J.; Farquhar, J.; Schölkopf, B. Overlap and refractory effects in a brain-computer interface speller based on the visual P300 event-related potential. J. Neural Eng. 2009, 6, 026003. 34

[91] Townsend, G.; LaPallo, B.K.; Boulay, C.B.; Krusienski, D.J.; Frye, G.E.; Hauser, C.K.; Schwartz, N.E.; Vaughan, T.M.; Wolpaw, J.R.; Sellers, E.W. A novel P300-based brain-computer interface stimulus presentation paradigm: Moving beyond rows and columns. Clin. Neurophysiol. 2010, 121, 1109-1120. 34

[92] Brunner, P.; Joshi, S.; Briskin, S.; Wolpaw, J.R.; Bischof, H.; Schalk, G. Does the 'P300' speller depend on eye gaze? J. Neural Eng. 2010, 7, 056013. 34 
[93] Pfurtscheller, G.; Lopes da Silva, F.H. Event-related EEG/MEG synchronization and desynchronization: Basic principles. Clin. Neurophysiol. 1999, 110, 1842-1857. 34

[94] Jeannerod, M. Mental imagery in the motor context. Neuropsychologia 1995, 33, 1419-1432. 34

[95] Pfurtscheller, G.; Neuper, C.; Flotzinger, D.; Pregenzer, M. EEG-based discrimination between imagination of right and left hand movement. Electroencephalogr. Clin. Neurophysiol. 1997, 103, 642-651. 34

[96] Blankertz, B.; Sannelli, C.; Halder, S.; Hammer, E.M.; Kubler, A.; Müller, K.R.; Curio, G.; Dickhaus, T. Neurophysiological predictor of SMR-based BCI performance. Neuroimage 2010, 51, 1303-1309. 34

[97] Neuper, C.; Scherer, R.; Reiner, M.; Pfurtscheller, G. Imagery of motor actions: Differential effects of kinesthetic and visual-motor mode of imagery in single-trial EEG. Cogn. Brain. Res. 2005, 25, 668-677. 34, 35

[98] Nijboer, F.; Furdea, A.; Gunst, I.; Mellinger, J.; McFarland, D.J.; Birbaumer, N.; Kübler, A. An auditory brain-computer interface (BCI). J. Neurosci. Methods 2008, 167, 43-50. 34

[99] Hwang, H.; Kwon, K.; Im, C. Neurofeedback-based motor imagery training for braincomputer interface (BCI). J. Neurosci. Methods. 2009, 179, 150-156. 35

[100] Blankertz, B.; Losch, F.; Krauledat, M.; Dornhege, G.; Curio, G.; Muller, K.R. The berlin brain-computer interface: Accurate performance from first-session in BCI-Native subjects. IEEE Trans. Biomed. Eng. 2008, 55, 2452-2462. 35

[101] Pfurtscheller, G.; Neuper, C.; Muller, G.R.; Obermaier, B.; Krausz, G.; Schlogl, A.; Scherer, R.; Graimann, B.; Keinrath, C.; Skliris, D.; et al. Graz-BCI: State of the art and clinical applications. IEEE Trans. Neural Sys. Rehabil. Eng. 2003, 11, 1-4. 35, 37, 43

[102] Bai, O.; Rathi, V.; Lin, P.; Hwang, D.; Battapady, H.; Fei, D.; Schneider, L.; Houdayer, E.; Chen, X.; Hallett, M. Prediction of human voluntary movement before it occurs. Clin.Neurophysiol. 2011, 122, 364-372. 35

[103] Kubler, A.; Birbaumer, N. Brain-computer interfaces and communication in paralysis: Extinction of goal directed thinking in completely paralysed patients? Clin.Neurophysiol. 2008, 119, 2658-2666. 36, 38

[104] Betke, M.; Gips, J.; Fleming, P. The Camera Mouse: Visual tracking of body features to provide computer access for people with severe disabilities. IEEE Trans. Neural Sys. Rehabil. Eng. 2002, 10, 1-10. 36 
[105] Miller, L.A.; Stubblefield, K.A.; Lipschutz, R.D.; Lock, B.A.; Kuiken, T.A. Improved myoelectric prosthesis control using targeted reinnervation surgery: A case series. IEEE Trans. Neural Sys. Rehabil. Eng. 2008, 16, 46-50. 37

[106] Birbaumer, N.; Ghanayim, N.; Hinterberger, T.; Iversen, I.; Kotchoubey, B.; Kubler, A.; Perelmouter, J.; Taub, E.; Flor, H. A spelling device for the paralysed. Nature 1999, 398, 297-298. 39

[107] Chambayil, B.; Singla, R.; Jha, R. Virtual Keyboard BCI Using Eye Blinks in EEG. In Proceedings of the 6th IEEE International Conference on Wireless and Mobile computing, Networking and Communications (WiMob'10), Niagara Falls, ON, Canada, October 2010; pp. 466-470. 39

[108] Obermaier, B.; Muller, G.R.; Pfurtscheller, G. "Virtual keyboard" controlled by spontaneous EEG activity. IEEE Trans. Neural Sys. Rehabil. Eng. 2003, 11, 422-426. 39, 41

[109] Silvoni, S.; Volpato, C.; Cavinato, M.; Marchetti, M.; Priftis, K.; Merico, A.; Tonin, P.; Koutsikos, K.; Beverina, F.; Piccione, F. P300-based brain-computer interface communication: evaluation and follow-up in amyotrophic lateral sclerosis. Front. Neurosci. 2009, 3, 60. 39

[110] Karim, A.A.; Hinterberger, T.; Richter, J.; Mellinger, J.; Neumann, N.; Flor, H.; Kübler, A.; Birbaumer, N. Neural internet: Web surfing with brain potentials for the completely paralyzed. Neurorehabil. Neural Repair 2006, 20, 508-515. 42

[111] Bensch, M.; Karim, A.A.; Mellinger, J.; Hinterberger, T.; Tangermann, M.; Bogdan, M.; Rosenstiel, W.; Birbaumer, N. Nessi: An EEG-controlled web browser for severely paralyzed patients. Comput. Intell. Neurosci. 2007, 2007, 71863. 43

[112] Braz, G.P.; Russold, M.; Davis, G.M. Functional electrical stimulation control of standing and stepping after spinal cord injury: A review of technical characteristics. Neuromodulation: Technol. Neural Interface 2009, 12, 180-190. 43

[113] Lauer, R.T.; Peckham, P.H.; Kilgore, K.L. EEG based control of a hand grasp neuroprosthesis. NeuroReport 1999, 10, 1767-1771. 43

[114] Hu, X.L.; Tong, K.Y.; Li, R.; Chen, M.; Xue, J.J.; Ho, S.K.; Chen, P.N. Post-stroke wrist rehabilitation assisted with an intention-driven functional electrical stimulation (FES)robot system. In Proceedings of the IEEE International Conference on Rehabilitation Robotics (ICORR'11), Zurich, Switzerland, July 2011; pp. 1-6. 43

[115] Pfurtscheller, G.; Guger, C.; Müller, G.; Krausz, G.; Neuper, C. Brain oscillations control hand orthosis in a tetraplegic. Neurosci. Lett. 2000, 292, 211-214. 44 
[116] Broetz, D.; Braun, C.; Weber, C.; Soekadar, S.R.; Caria, A.; Birbaumer, N. Combination of brain-computer interface training and goal-directed physical therapy in chronic stroke: A case report. Neurorehabil. Neural Repair 2010, 24, 674-679. 44

[117] Caria, A.; Weber, C.; Brötz, D.; Ramos, A.; Ticini, L.F.; Gharabaghi, A.; Braun, C.; Birbaumer, N. Chronic stroke recovery after combined BCI training and physiotherapy: A case report. Psychophysiology 2011, 48, 578-582. 44

[118] Serruya, M.D.; Hatsopoulos, N.G.; Paninski, L.; Fellows, M.R.; Donoghue, J.P. Brainmachine interface: Instant neural control of a movement signal. Nature 2002, 416, 141-142. 45

[119] Millan, J.R.; Renkens, F.; Mourino, J.; Gerstner, W. Noninvasive brain-actuated control of a mobile robot by human EEG. IEEE Trans. Biomed. Eng. 2004, 51, 1026-1033. 44, 45

[120] Rebsamen, B.; Cuntai, G.; Haihong, Z.; Chuanchu, W.; Cheeleong, T.; Ang, M.H.; Burdet, E. A brain controlled wheelchair to navigate in familiar environments. IEEE Trans. Neural Syst. Rehabil. Eng. 2010, 18, 590-598. 45

[121] Philips, J.; del R. Millan, J.; Vanacker, G.; Lew, E.; Galan, F.; Ferrez, P.W.; Van Brussel, H.; Nuttin, M. Adaptive Shared Control of a Brain-Actuated Simulated Wheelchair. In Proceedings of the IEEE 10th International Conference on Rehabilitation Robotics (ICORR'07), Noordwijk, The Netherlands, June 2007; pp. 408-414. 45

[122] Angelakis, E.; Stathopoulou, S.; Frymiare, J.; Green, D.; Lubar, J.; Kounios, J. EEG neurofeedback: A brief overview and an example of peak alpha frequency training for cognitive enhancement in the elderly. Clin. Neuropsychol. 2007, 21, 110-129. 47

[123] Hanslmayr, S.; Sauseng, P.; Doppelmayr, M.; Schabus, M.; Klimesch, W. Increasing individual upper alpha power by neurofeedback improves cognitive performance in human subjects. Appl. Psychophysiol. Biofeedback 2005, 30, 1-10. 47

[124] Rota, G.; Sitaram, R.; Veit, R.; Erb, M.; Weiskopf, N.; Dogil, G.; Birbaumer, N. Selfregulation of regional cortical activity using real-time fMRI: The right inferior frontal gyrus and linguistic processing. Hum. Brain Mapp. 2009, 30, 1605-1614. 47

[125] Sitaram, R.; Lee, S.; Ruiz, S.; Rana, M.; Veit, R.; Birbaumer, N. Real-time support vector classification and feedback of multiple emotional brain states. Neuroimage 2011, 56, 753-765. 47

[126] Halder, S.; Rea, M.; Andreoni, R.; Nijboer, F.; Hammer, E.M.; Kleih, S.C.; Birbaumer, N.; Kübler, A. An auditory oddball brain-computer interface for binary choices. Clin. Neurophysiol. 2010, 121, 516-523. 86 
[127] Walker, J.E.; Kozlowski, G.P. Neurofeedback treatment of epilepsy. Child Adolesc. Psychiatr. Clin. N. Am. 2005, 14, 163-176. 47

[128] Sterman, M.; Egner, T. Foundation and practice of neurofeedback for the treatment of epilepsy. Appl. Psychophysiol. Biofeedback 2006, 31, 21-35. 47

[129] Strehl, U.; Leins, U.; Goth, G.; Klinger, C.; Hinterberger, T.; Birbaumer, N. Self-regulation of slow cortical potentials: A new treatment for children with attention deficit/hyperactivity disorder. Pediatrics 2006, 118, 1530-1540. 47

[130] Schneider, F.; Rockstroh, B.; Heimann, H.; Lutzenberger, W.; Mattes, R.; Elbert, T.; Birbaumer, N.; Bartels, M. Self-regulation of slow cortical potentials in psychiatric patients: Schizophrenia.Appl. Psychophysiol. Biofeedback 1992, 17, 277-292. 47

[131] Schneider, F.; Heimann, H.; Mattes, R.; Lutzenberger, W.; Birbaumer, N. Self-regulation of slow cortical potentials in psychiatric patients: Depression. Appl. Psychophysiol. Biofeedback 1992, 17, 203-214. 47

[132] Schneider, F.; Elbert, T.; Heimann, H.; Welker, A.; Stetter, F.; Mattes, R.; Birbaumer, N.; Mann, K. Self-regulation of slow cortical potentials in psychiatric patients: Alcohol dependency. Appl. Psychophysiol. Biofeedback 1993, 18, 23-32. 4, 47

[133] Renaud, P.; Joyal, C.; Stoleru, S.; Goyette, M.; Weiskopf, N.; Birbaumer, N. Real-Time Functional Magnetic Imaging - Brain-Computer Interface and Virtual Reality: Promising Tools for the Treatment of Pedophilia. In Progress in Brain Research; Green, A.M., Chapman, C.E., Kalaska, J.F., Lepore, F., Eds.; Elsevier: New York, NY, USA, 2011; Volume 192, pp. 263-272. 4, 47

[134] Georgopoulos A.P.; Karageorgiou, E.; Leuthold, A.C.; Lewis, S.M.; Lynch, J.K.; Alonso, A.A.; Aslam, Z.; Carpenter, A.F.; Georgopoulos, A.; Hemmy, L.S.; et al. Synchronous neural interactions assessed by magnetoencephalography: A functional biomarker for brain disorders. J. Neural Eng. 2007, doi: 10.1088/1741-2560/4/4/001. 47

[135] Vecchiato, G.; De Vico Fallani, F.; Astolfi, L.; Toppi, J.; Cincotti, F.; Mattia, D.; Salinari, S.; Babiloni, F. The issue of multiple univariate comparisons in the context of neuroelectric brain mapping: An application in a neuromarketing experiment. J. Neurosci. Methods 2010, 191, 283-289. 47

[136] Ambler, T.; Braeutigam, S.; Stins, J.; Rose, S.; Swithenby, S. Salience and choice: Neural correlates of shopping decisions. Psychol. Market 2004, 21, 247-261. 47 
[137] Ariely, D.; Berns, G.S. Neuromarketing: The hope and hype of neuroimaging in business. Nat. Rev. Neurosci. 2010, 11, 284-292. 47

[138] Fisher, C.E.; Chin, L.; Klitzman, R. Defining neuromarketing: Practices and professional challenges. Harv. Rev. Psychiatry 2010, 18, 230-237. 47, 48

[139] Neuromarketing, Neuroscientific Consumer Testing. NeuroFocus. Accesible online: http://www.neurofocus.com/. 48

[140] Neuroconsult. Accesible online: http://www.neuroconsult.at/. 48

[141] Neuro Insight. Accesible online: http://www.neuro-insight.com/. 48

[142] EmSense: Quantitative Biosensory Metrics. Accesible online: http://www.emsense.com/ 48

[143] Pao Y.-H., Park G.-H., Sobajic D. J., Learning and generalization characteristics of the random vector functional-link net Neurocomputing, Elsevier, 1994, 6, 163-180. 78

[144] Igelnik B., Pao Y.-H., Stochastic choice of basis functions in adaptive function approximation and the functional-link net Neural Networks, IEEE Transactions on, 1995, 6, 1320-1329. 78

[145] Huang G.-B., Chen L., Convex incremental extreme learning machine, Neurocomputing, 2007, 70 (16), 3056-3062. 78, 86

[146] Kruskal W. H. Historical notes on the wilcoxon unpaired two-sample test, Journal of the American Statistical Association, 1957, 52 (279), 356-360. 90

[147] Power, S.D.; Kushki, A.; Chau, T. Towards a system-paced near-infrared spectroscopy braincomputer interface: Differentiating prefrontal activity due to mental arithmetic and mental singing from the no-control state. J. Neural Eng. 2011, 8, 066004. 24

[148] Xiaorong, G.; Dingfeng, X.; Ming, C.; Shangkai, G. A BCI-based environmental controller for the motion-disabled. IEEE Trans. Neural Syst. Rehabil. Eng. 2003, 11, 137-140. 29

[149] Similä T., Tikka J., Multiresponse sparse regression with application to multidimensional scaling, In: Proceedings of the 15th International Conference on Artificial Neural Networks: Formal Models and Their Applications - ICANN 2005, LNCS, 2005, 3697, 97-102. 80, 81, 82

[150] Tan P., Tan G.-Z., Cai Z.-X., Sa W.-P., Zou Y.-Q., Using ELM-based weighted probabilistic model in the classification of synchronous EEG BCI, Medical \& biological engineering \& computing, 2017, 55 (1), 33-43. 80, 86 
[151] Tan P., Sa W., Yu L., Applying Extreme Learning Machine to classification of EEG BCI, Cyber Technology in Automation, Control, and Intelligent Systems (CYBER), 2016 IEEE International Conference on, 2016, 228-232. 80

[152] Neuro Insight. Accesible online: http://www.neuro-insight.com/. 48

[153] Tanaka, K.; Matsunaga, K.; Wang, H.O. Electroencephalogram-based control of an electric wheelchair. IEEE Trans. Robot. 2005, 21, 762-766. 33, 45

[154] Rodríguez-Bermúdez, G. \& García-Laencina, P. (2015). Analysis of eeg signals using nonlinear dynamics and chaos: A review. Applied Mathematics \& Information Sciences. 63, 94, 97

[155] Bashashati, A., Fatourechi, M., Ward, R. K. \& Birch, G. E., (2007). A survey of signal processing algorithms in brain-computer interfaces based on electrical brain signals. Journal of Neural Engineering 4 (2), R32-R57. 60, 89, 97

[156] Hjorth, B. (1970). EEG analysis based on time domain properties. Electroencephalography and Clinical Neurophysiology 29 (3), 306-310. 61

[157] Schlögl, A. (2000). The electroencephalogram and the adaptive autoregressive model: theory and applications. Shaker Verlag. 62, 63

[158] Allison, B.Z.; McFarland, D.J.; Schalk, G.; Zheng, S.D.; Jackson, M.M.; Wolpaw, J.R. Towards an independent brain-computer interface using steady state visual evoked potentials. Clin. Neurophysiol. 2008, 119, 399-408. 30

[159] Huang, G., Zhu, Q. \& Siew, C., (2006). Extreme learning machine: Theory and applications. Neurocomputing 70 (1-3), 489-501. 78, 79, 84, 86

[160] Rong, H.-J., Ong, Y.-S., Tan, A.-H. \& Zhu, Z. (2008). A fast pruned-extreme learning machine for classification problem. Neurocomputing 72 (1-3), 359-366 79, 80, 84

[161] Huang, G.-B., Wang, D. H. \& Lan, Y. (2011). Extreme learning machines: a survey. International Journal of Machine Learning and Cybernetics 2 (2), 107-122. 78, 86

[162] Miche, Y., Bas, P., Jutten, C., Simula, O. \& Lendasse, A. (2008). A methodology for building regression models using extreme learning machine: OP-ELM. In: Proceedings of the European Symposium on Artificial Neural Networks (ESANN). 247-252. 80, 81, 83, 84

[163] Miche, Y., Sorjamaa, A. \& Lendasse, A. (2008). OP-ELM: Theory, experiments and a toolbox. In: Proceedings of the International Conference on Artificial Neural Networks (ICANN). LNCS 5163. pp. 145-154. 80, 84 
[164] Mateo, F. \& Lendasse, A. (2008). A variable selection approach based on the delta test for extreme learning machine models. In: Proceedings of the European Symposium on Time Series Prediction (ESTP). pp. 57-66. 80, 84

[165] Miche, Y. \& Lendasse, A. (2009). A faster model selection criterion for OPELM and OPKNN: Hannan-quinn criterion. In: Proceeding of the European Symposium on Artificial Neural Networks (ESANN). 177-182. 80, 83, 84

[166] Miche, Y., Sorjamaa, A., Bas, P., Simula, O., Jutten, C. \& Lendasse, A. (2009). OP-ELM: Optimally Pruned Extreme Learning Machine. IEEE Transactions on Neural Networks 21 (1), 158-162. 80

[167] Rodríguez-Bermúdez, G. \& García-Laencina, P. J. (2012). Automatic and Adaptive Classification of Electroencephalographic Signals for Brain Computer Interfaces. Journal of Medical Systems (36), 51-63. 97

[168] Lima, C.A.M. Cohelo, A.L.V. Eisencraft, M. (2010). Tackling EEG signal classification with least squares support vector machines: A sensitivity analysis study. Computers in Biology and Medicine (40), 705-714. 94

[169] Taheri, B.A., Knight, R.T., Smith, R.L. (1994).Electroencephalogr. Clin. Neurophysiol. Meas. Sci. Rev (90), 376-383. 18

[170] Gargiulo, G., Calvo, R.A., Bifulco, P., Cesarelli, M., Jin, C., Mohamed, A., van Schaik, A. (2010).A new EEG recording system for passive dry electrodes. Clin. Neurophysiol (121), 686-693. 18, 19

[171] Aftanas, L.I., Golocheikine, S.A. (2001).Human anterior and frontal midline theta and lower alpha reflect emotionally positive state and internalized attention: High-resolution EEG investigation of meditation. Neurosci. Lett.(310), 57-60. 19

[172] Duan L. and Zhong H. and Miao J., Yang Z., Ma W., Zhang X., A voting optimized strategy based on ELM for improving classification of motor imagery BCI data, Cognitive Computation, 2014, 477-483. 86

[173] G. Rodríguez-Bermúdez, M.A. Sánchez-Granero, P.J. García-Laencina, M. FernándezMartínez, J. Serna, and J. Roca-Dorda, Testing the Self-Similarity Exponent to Feature Extraction in Motor Imagery Based Brain Computer Interface Systems, International Journal of Bifurcation and Chaos, 25 (14) (2015), 1540023 [9 pages]. 94, 97

[174] Microsoft Research-Computational User Experiences: Brain-Computer Interfaces. Available online: http://research.microsoft.com/en us/um/redmond/groups/cue/bci/. 47 
[175] Lalor, E.C.; Kelly, S.P.; Finucane, C. Steady-state VEP-based brain-computer interface control in an immersive 3D gaming environment. J. Appl. Signal Proc. 2005, 2005, 3156-3164. 46

[176] Vidal, J.J.: Toward direct brain-computer communication. Annual Review of Biophysics and Bioengineering 2, 157-180 (1973). 3, 49

[177] Schalk, G., McFarland, D.J., Hinterberger, T., Birbaumer, N., Wolpaw, J.R.: BCI2000: A General-Purpose Brain-Computer Interface (BCI) System. IEEE Transactions on Biomedical Engineering 51, 1034-1043 (2004). 51

[178] Reed, R.: Pruning algorithms, a review. IEEE Transactions on Neural Networks, 7:740-747, 1993. 79

[179] Sietsma, J.; Dow, R.: Creating artificial neural networks that generalize. Neural Networks, 4:67-79, 1991. 79

[180] Pelillo, M.; Fanelli, A.: A method of pruning layered feed-forward neural networks. New Trends in Neural Computation, volume 686 of Lecture Notes in Computer Science, pages 278-283. Springer Berlin, Heidelberg, 1993. 79

[181] Bishop, C.M.: Neural Networks for Pattern Recognition. Oxford University Press, Oxford, $\mathrm{UK}, 1995.79,82$

[182] Bartoli, A.: On computing the prediction sum of squares statistic in linear least squares problems with multiple parameter or measurement sets. International Journal on Computer Vision, 85:133-142, November 2009. 82

[183] Huang, G.B.; Ding, X.; Zhou, H.: Optimization method based extreme learning machine for classification. Neurocomputing, 74 (1-3):155-163, December 2010. 82, 84, 86

[184] Frénayand B., Verleysen M:. Using SVM with randomised feature spaces: an extreme learning approach. In Proceedings of The 18th European Symposium on Artificial Neural Networks (ESANN), pages 315-320, Bruges, Belgium, 28-30 April 2010. 84, 89

[185] Keerthika, P.; Sivachitra, M. and Bala, M. P. Eye state EEG signal classification using complex valued neural classifiers Proc. Embedded and Communication Systems (ICIIECS) 2017 Int. Conf. Innovations in Information, 2017, 1-4. 78

[186] Su, L.; Bi, L.; Fei, W. and Lian, J. Motion velocity estimation from electroencephalography signals with extreme learning machine Proc. Chinese Automation Congress (CAC), 2017, 49014905. 78 
[187] Qureshi, M. N. I.; Cho, D. and Lee, B. EEG classification for motor imagery BCI using phase-only features extracted by independent component analysis Proc. 39th Annual Int. Conf. of the IEEE Engineering in Medicine and Biology Society (EMBC), 2017, 2097-2100. 78

[188] Chatterjee, R.; Guha, D.; Sanyal, D. K. and Mohanty, S. N. Discernibility matrix based dimensionality reduction for EEG signal Proc. IEEE Region 10 Conf. (TENCON), 2016, 27032706. 78

[189] Tan, P.; Sa, W. and Yu, L. Applying Extreme Learning Machine to classification of EEG BCI Proc. and Intelligent Systems (CYBER) 2016 IEEE Int. Conf. Cyber Technology in Automation, Control, 2016, 228-232. 78

[190] Gupta, S. and Saini, H. EEG features extraction using PCA plus LDA approach based on L1-norm for motor imaginary classification Proc. IEEE Int. Conf. Computational Intelligence and Computing Research, 2014, 1-5. 94

[191] Wang, Y.; Zhang, Z.; Li, Y.; Gao, X.; Gao, S. and Yang, F. BCI competition 2003-data set IV:An algorithm based on CSSD and FDA for classifying single-trial EEG IEEE Transactions on Biomedical Engineering, 2004, 51, 1081-1086. 95

[192] Tang, J.; Deng, C. and Huang, G. B. Extreme Learning Machine for Multilayer Perceptron IEEE Transactions on Neural Networks and Learning Systems, 2016, 27, 809-821. 86

[193] Schack, B.; G. Witte, G.: Parametrische Methoden der dynamischen Spektralanalyse und ihre Anwendung in der Biosignalanalyse, Biomedizinische Technik, 1993, 38, 79-80. 61

[194] Schlögl, A.; Lee, F.; Bischof, H.; Pfurtscheller, G.: Characterization of four-class motor imagery EEG data, Journal of Neural Enginering, $n^{\circ}$ 2, pp. 14-22, 2005. 63

[195] Ince, N.; Arica, S.; Tewfik, A.: Classification of single trial motor imagery EEG recordings with subject adapted non-dyadic arbitrary timefrequency tilings, Journal of Neural Engineering, $\mathrm{n}^{\mathrm{o}} 3$, pp. 235-244, 2006. 63

[196] McFarland D., Wolpaw, J.: Sensorimotor rhythm-based braincomputer interface (BCI): Feature selection by regression improves performance, IEEE Transactions on Neural Systems and Rehabilitation Engineering, $\mathrm{n}^{\mathrm{0}}$ 13, pp. 372-379, 2005. 63, 94

[197] Haykin, S.: Adaptive Filter Theory, Englewood Cliffs, NJ. Prentice Hall, 1996. 63

[198] Patomaki, L.; Kaipio, J.; Karjalainen, P.; Juntunen, M.: King of non stationary EEG with the polynomial root perturbation, Proceedings of the 18th Annual International Conference of the IEEE Engineering in Medicine and Biology Society, New York, 1995. 63 
[199] Bianchi, A.; Mainardi, L.; Meloni, C.; Chierchia, S.; Cerutti, S.: Continuous monitoring of the Sympatho-Vagal Balance through spectral analysis, IEEE Engineering in Medicine and Biology, vol. 16, no 5, pp. 64-73, 1997. 63

[200] Jansen, B.; Bourne, J.; Ward, J.: Autoregressive estimation of short segment spectra for computerized EEG analysis, IEEE Transaction Biomedical Engineering, vol. 28, $\mathrm{n}^{\circ}$ 9, 1981. 63

[201] Isaksson, A.:A sparsely updated Kalman filter with application to EEG signals, Department of Telecommunication Theory, Royal Institute of Technology, Stockholm, 1975. 63

[202] Wang, Y.; Gao, S.; Gao, X.: Çommon Spatial Pattern Method for Channel Selelction in Motor Imagery Based Brain-computer Interface,'2005 IEEE Engineering in Medicine and Biology 27th Annual Conference, Shanghai, 2005, pp. 5392-5395. 66

[203] Blankertz, B., Lemm, S., Treder, M., Haufe, S., Müller, K. R. (2011). Single-trial analysis and classification of ERP components-a tutorial. NeuroImage, 56(2), 814-825. 67

[204] Kindermans, P. J., Verstraeten, D., Schrauwen, B. (2012). A bayesian model for exploiting application constraints to enable unsupervised training of a P300-based BCI. PloS one, 7(4), e33758. 68

[205] Burges, C.J.C. A Tutorial on Support Vector Machines for Pattern Recognition, 1998, 2, 121-167. 68

[206] Xiang, L., Dezhong, Y., Wu, D. y Chaoyi, L. , Combining Spatial Filters for the Classification of Single-Trial EEG in a Finger Movement Task, IEEE Trans. Biomed. Eng. 2007, 54, 821-831. 68

[207] Cover T.M. Geometrical and Statistical Properties of Systems of Linear Inequalities with Applications in Pattern Recognition, IEEE Trans. Electron. Comput. 1965, EC-14, 326- 334. 68

[208] Kayikcioglu, T.; Aydemir, O.: A polynomial fitting and k-NN based approach for improving classification of motor imagery BCI data, 2010, 31, 1207-1215. 69

[209] Blankertz, B.; Curio, G. y Müller, K. Classifying Single Trial EEG: Towards Brain Computer Interfacing, Advances in Neural Information Processing Systems (ANPS'02), Vancouver, BC, Canada, December 2002; pp. 157-164. 69

[210] Garcia, G.N.; Ebrahimi, T. y Vesin, J.M., Support vector EEG classification in the Fourier and time-frequency correlation domains, First International IEEE EMBS Conference on Neural Engineering (NER'03), Capri Island, Italy, March 2003; pp. 591-594. 69 
[211] Haihong, Z., Cuntai, G. y Chuanchu, W.: Asynchronous P300 Based Brain Computer Interfaces: A Computational Approach With Statistical Models, IEEE Trans. Biomed. Eng. 2008, 55, 1754-1763. 69

[212] Kaper, M., Meinicke, P., Grossekathoefer, U., Lingner, T., Ritter, H.: BCI competition 2003data set IIb: support vector machines for the P300 speller paradigm, IEEE Trans. Biomed. Eng. 2004, 51, 1073-1076. 69

[213] Gabi, M.; Neves, K.; Masseron, C.; Ribeiro, P. F. M.; Ventura-Antunes, L.; Torres, L.; Mota, B.; Kaas, J. H. and Herculano-Houzel, S. No relative expansion of the number of prefrontal neurons in primate and human evolution. Proceedings of the National Academy of Sciences of the United States of America, 2016, 113, 9617-9622. 11

[214] http://www.schalklab.org/research/bci2000.

[215] http://openvibe.inria.fr/.

[216] http://sccn.ucsd.edu/wiki/BCILAB. 51

[217] http://www.sensibilab.lecco.polimi.it/. 51

[218] http://www.tobi-project.org/. 51

52

[219] http://sourceforge.net/projects/xbci/. 52

[220] http://www.brainterface.com/.

[221] http://bbci.de/pyff/index.html/. 52

53

[222] https://www.emotiv.com/epoc/.

[223] http://www.asterics.eu/. 53 


\section{Apéndice A}

\section{Tabla de Acrónimos}

BCI: Brain Computer Interface

EEG: Electroencefalografía

MEG: Magnetoencefalografía

ECoG: Electrocorticografía

fMRI: Imágenes por resonancia magnética funcional

NIRS: Espectroscopia Infrarroja Cercana

VEP: Potencial visual evocado

SCP: Potencial cortical lento

PSD: Densidad Espectral de Potencia

AAR: Modelo adaptativo autorregresivo

CSP: Patrón Espacial Común

FLD: Discriminante lineal de Fisher

SVM: Máquina de soporte vectorial 
ANN: Redes Neuronales Artificiales

ELM: Extreme Learning Machine

OP-ELM: Poda Óptima 